Illinois State University

ISU ReD: Research and eData

Theses and Dissertations

4-13-2014

\title{
Surf's Up: Communicative Aspects of Online Trust-Building Via Reducing Uncertainty Online in Couchsurfing
}

Maura Rae Cherney

Illinois State University, mrchern@ilstu.edu

Follow this and additional works at: https://ir.library.illinoisstate.edu/etd

Part of the Communication Commons

\section{Recommended Citation}

Cherney, Maura Rae, "Surf's Up: Communicative Aspects of Online Trust-Building Via Reducing Uncertainty Online in Couchsurfing" (2014). Theses and Dissertations. 162.

https://ir.library.illinoisstate.edu/etd/162

This Thesis is brought to you for free and open access by ISU ReD: Research and eData. It has been accepted for inclusion in Theses and Dissertations by an authorized administrator of ISU ReD: Research and eData. For more information, please contact ISUReD@ilstu.edu. 


\title{
SURF'S UP: COMMUNICATIVE ASPECTS OF ONLINE TRUST-BUILDING VIA REDUCING UNCERTAINTY ONLINE IN COUCHSURFING
}

\author{
Maura Rae Cherney
}

151 Pages

May 2014

Couchsurfing is a website community allowing members to offer and receive travel accommodations, with members, typically connecting online before meeting offline. Risky behaviors associated with Couchsurfing require members to have great amounts of trust for the other parties involved. Because trust can be achieved through uncertainty reduction and considering the predicted outcome value, the present study seeks to determine how members seek information online in order to trust other members. An online questionnaire was circulated to Couchsurfing hosts to report about what website features provide the most essential information to trust other members and, within those features, what additionally members look for to build trust. Within each of the website features, essentiality was determined for specific communicative aspects of each feature. Findings indicated that the website features hosts rely on most when making decisions to accept or reject a request are the references and request message. Qualitative responses elaborated on and clarified quantitative findings. 
SURF'S UP: COMMUNICATIVE ASPECTS OF ONLINE TRUST-BUILDING

VIA REDUCING UNCERTAINTY ONLINE

IN COUCHSURFING

MAURA RAE CHERNEY

A Thesis Submitted in Partial Fulfillment of the Requirements for the Degree of

MASTER OF SCIENCE

School of Communication

ILLINOIS STATE UNIVERSITY 
Copyright 2014 Maura Rae Cherney 
SURF'S UP: COMMUNICATIVE ASPECTS OF ONLINE TRUST-BUILDING VIA REDUCING UNCERTAINTY ONLINE IN COUCHSURFING

MAURA RAE CHERNEY

COMMITTEE MEMBERS:

Daniel Cochece Davis, Co-Chair

Sandra M. Metts, Co-Chair 


\section{ACKNOWLEDGEMENTS}

My co-chairs have been much more than just academically supportive throughout the process of completing my thesis. I would first like to thank Dr. Daniel Cochece Davis for his willingness to listen and genuine interest in my project from the beginning. Throughout the last year I have been appreciative of Cochece's ability to help me realize that it is possible to study something I'm passionate about. Being able to study a community I enjoy so much myself helped motivate me to continue, even when the end seemed far away. His encouragement had no boundaries. He motivated me to create the first draft of my review of literature in only a few days to submit to the National Communication Association for the annual convention. Although, at the time, I thought he was crazy for even suggesting it, I was accepted and was able to complete my first conference presentation! I also enjoyed working with Cochece specifically because he encouraged me to work independently. Sometimes when I came to him with a question he would answer, "it will be interesting to see how you handle this." Answers like these encouraged me to critically think about each step, helping me grow as a scholar and a person. Sometimes being given the answer is much less of a learning experience than having to figure it out independently. Thank you, Cochece, for all your support, both academically and personally.

I am extremely thankful for having the support of Dr. Sandra Metts throughout my thesis. What I most appreciated about working with Dr. Metts was her willingness to listen and carefully consider multiple perspectives. Having such an experienced and well 
recognized mentor throughout this process had obvious benefits. Dr. Metts is an expert on what works and what does not work in a thesis. Beyond that, I really appreciated Dr. Metts' careful consideration of questions. She took time to think through and explain her reasoning for her suggestions throughout the process. Dr. Metts went above and beyond what I ever would have expected of a chair. She was willing to meet with me over the summer, provide quick feedback on drafts, and even contact me outside of campus to touch base. Dr. Metts turned into, not only a wonderful mentor, but also a friend. Thank you for everything, Dr. Metts. I could not have gotten through this process without you. Aside from my chairs, several other people supported me through the process of completing this thesis. Dr. Caleb Carr, thank you for the valuable suggestions you provided. I appreciated your support at NCA by attending my presentation, your expertise on the computer-mediated aspects of my paper, and your willingness to help me navigate Select Survey. My family has provided me with unconditional support, especially in times of frustration and personal hardship. Thank you, Mom, Dad, Grandma, and Mckenzie for always lending an ear. Thank you, Kayla, for your willingness to share about both of our thesis experiences, and Nico for your extra effort throughout the process to support my project. Finally, I would like to thank the faculty, staff, and graduate students in the School of Communication for the help and support throughout my two years at Illinois State University. I have such pride in our program!

M.R.C. 


\section{CONTENTS}

\section{Page}

ACKNOWLEDGEMENTS

CONTENTS $\quad$ iii

FIGURES

CHAPTER

I. REVIEW OF RELATED LITERATURE 1

Statement of the Problem 1

Review of Literature 2

Historical Hospitality

Theoretical Framework $\quad 7$

Couchsurfing $\quad 17$

Photos 31

User References $\quad 39$

Request Messages $\quad 47$

Textual Profile Information 55

$\begin{array}{lll}\text { II. } & \text { METHODS }\end{array}$

$\begin{array}{ll}\text { Sample } & 62\end{array}$

Procedures $\quad 64$

Measurements $\quad 65$

Analysis $\quad 69$

$\begin{array}{lll}\text { III. } & \text { RESULTS } & 71\end{array}$

$\begin{array}{ll}\text { Quantitative Results } & 71\end{array}$

Research Questions 1 and 2

Research Questions 3 and $4 \quad 74$

Research Questions 5 and $6 \quad 76$

Research Questions 7 and $8 \quad 79$

Research Questions 9 and $10 \quad 81$ 
Qualitative Results $\quad 82$

Research Questions 1 and 2

Research Questions 3 and $4 \quad 85$

Research Questions 5 and $6 \quad 86$

Research Questions 7 and $8 \quad 89$

Research Questions 9 and $10 \quad 90$

$\begin{array}{ll}\text { IV. DISCUSSION } & 92\end{array}$

$\begin{array}{ll}\text { Synthesis of Findings } & 92\end{array}$

Website Features $\quad 92$

Photos $\quad 94$

References $\quad 94$

Request Messages 95

Other Textual Profile Elements 96

$\begin{array}{lr}\text { Implications } & 97\end{array}$

$\begin{array}{ll}\text { Limitations } & 101\end{array}$

Small Sample Size 101

Focus of Population 105

Measurement 106

Directions for Future Research 108

$\begin{array}{ll}\text { Sample } & 109\end{array}$

Predictive 110

Demographic Differences $\quad 111$

$\begin{array}{ll}\text { Social Capital } & 112\end{array}$

$\begin{array}{ll}\text { Conclusion } & 113\end{array}$

$\begin{array}{ll}\text { REFERENCES } & 114\end{array}$

$\begin{array}{ll}\text { APPENDIX A: Tables } & 121\end{array}$

APPENDIX B: Online Questionnaire 139 


\section{FIGURES}

Figure

1. Online Questionnaire Participant Process
Page

68 


\section{CHAPTER I}

\section{REVIEW OF RELATED LITERATURE}

\section{Statement of the Problem}

Cognitive trust is the belief that another person will behave with intelligence, character, and goodwill (Yoo, 2005), which are the three sources of trust outlined by Aristotle (1932). In other words, trust is a psychological phenomenon; a sentiment within an individual that may have behavioral implications. In an interaction, participants can reduce uncertainty of another individual through gaining information about the person (Berger \& Calbrese, 1975). A reduction in uncertainty about another individual leads to trust (Yoo, 2005). Because of this, trust can be described as a psychological phenomenon that can be achieved through interaction. Communication with others can lead to the formation of trust.

Meeting others online, however, implicates several different variables to the ability to trust others through information-seeking behavior. With a lack of face-to-face interaction comes a loss in nonverbal communicative cues that would normally be present in an offline interaction. Researchers can look to the communicative aspects of online interaction to understand how trust is built when interactants cannot meet face-to-face.

Couchsurfing, an online community allowing members to meet other members online before meeting face-to-face, can be used as a communicative medium to build trust. Members create individual profiles with information they provide, along with 
references from other members. Offline, Couchsurfing introduces members into a challenging interaction in an intimate environment, where a host is sharing her or his living space with a stranger met online. Moving from meeting a member online to hosting her or him in one's home requires trust in the other individual. CouchSurfing offers several communicative features allowing members to gain more information about others to build trust before making a hosting decision. The present study seeks to understand how trust in others is attained through online communication, specifically the intimate interactions found on Couchsurfing.

Fortunately, several theories exist for looking further into this phenomenon. Uncertainty reduction and predicted outcome value theories can be applied to how trust may be formed through the communicative aspects of Couchsurfing. Before a theoretical framework for the present study is explained, the history of the host-guest relationship will be explored.

\section{Review of Literature}

From Ancient Greece and Rome to Biblical times to early England to modern times, the act of hospitality is nothing new. Welcoming strangers into one's home has been common since the beginning of recorded history and mythology, and hospitality is argued to be fundamental in human existence and vital in the success of societies (O’Gorman, 2007). The long prevalence of the host-guest relationship calls for an understanding of the transformation of hospitality through history and how developments in technology may affect this remarkable relationship. 


\section{Historical Hospitality}

Greece. Ancient Greek culture recognized polytheism, or the existence of many gods, with Zeus being the leader of the gods. In conjunction with serving as the god of all gods, Zeus was known as the patron god of hospitality (O'Gorman, 2007). It was believed that if one treated guests poorly, it was an act of also treating Zeus poorly. Because of the strong belief in many gods and the gods' unannounced visits to Earth, Ancient Greeks believed that gods sometimes traveled to Earth acting as guests in humans' homes. In these Greek societies, when a stranger requested accommodation, these potential hosts not only faced the risk of the traveler being dangerous, but also faced the risk of disappointing the gods (O'Gorman, 2007).

Plato, a Classical Greek philosopher and author of Laws, proposed several laws for Greek society and their roles within the population. Of mention in Plato's Laws, alongside laws having to do with education, religion and politics, appear indication of laws about hospitality: "A friendly reception must be provided for the man who visits from abroad" (Plato, 12:952d). Plato also mentions the role of Zeus in hospitality, reminding readers that if hosts follow the laws for hosting guests, they are acting in a way that honors Zeus (Plato, 12:953e).

The Ancient Greek myth, The Odyssey, follows the adventures of Odysseus. Several instances of Greek society's value for hospitality are present in the myth. For example, during their journey Odysseus and his companions become shipwrecked on an island inhabited by Cyclopes. While looking for food and shelter, Odysseus attempts to convince a Cyclops, Polyphemus, for accommodation. Odysseus argues, "Mighty one, revere the gods. We are your suppliants. Zeus is the protector of suppliants and guest 
friends, the god of guests, who accompanies respectful guests" (Homer, 9:269-271).

Polyphemus, however, argues that the Cyclops does not respect Zeus and will not host travelers, for hatred of Zeus.

Rome. Like the Ancient Greeks revered Zeus as the god of hospitality, in Ancient Roman culture, Jupiter was respected as the god that supervised the law of hospitality (O'Gorman, 2007). The violation of the widely accepted value of hospitality was seen as both criminal and sacrilegious in Rome, just as it was in Greece.

Ovid, an Ancient Roman poet, used the value of hospitality in several of the myths he wrote. For example, in Metamorphoses, in the book titled "Impious Acts and Exemplary Lives," the myth of Baucis and Philemon serves as a lesson for hospitality in Ancient Rome. In the story, two gods, Jupiter and Mercury, disguise themselves as humans and arrive in a deprived, fairly impious town looking for shelter. After being turned down by many residents for a place to sleep, Baucis and Philemon, an elderly couple, welcome the strangers into their home. They treat the guests well, cooking a meal and bathing the strangers. Because of their hospitality, the strangers reveal they are gods in disguise and reward the couple for their pious ways. The gods flood the surrounding homes, punishing the other residents for their reluctance to host a stranger, and transform the home of Baucis and Philemon into a temple. The couple is permitted to live in the temple, and is granted the privilege of both passing away at the same time, so they would never live alone (Ovid, 2004).

Bible. In the Bible, many stories involve the hosting of strangers in one's home. Malina (1985) discusses the strict customs that take place between a host and a stranger by considering the themes in host-guest relationships in many Biblical stories. The first 
step in hospitality process often involves the host testing the stranger, or determining if the stranger is a threat to the community. In some cases, letters of recommendation excuse a stranger from having to complete this test. The second step is the establishment of the roles of the host and the guest. The guest is expected to honor the host's authority and accept offers, especially for food, made by the host. The host must protect guests and show concern for the guest's wants and needs. The third step involves the guest leaving the host's home, either as a friend or an enemy. If the experience was positive the guest often announces her or his praises of the host.

With the multiple, straightforward references to hospitality in the Bible, it is clear that acts of hospitality were valued in a similar way as Ancient Greek and Roman culture valued hospitality. In the Book of Leviticus, God speaks to Moses, explaining laws the people of Israel must follow. Among the many rules, expectations are also set for how the people of Israel must treat guests: "When a foreigner resides among you in your land, do not mistreat them. The foreigner residing among you must be treated as your nativeborn.” (Leviticus 19: 33-34, New International Version).

In the book of Job, Satan tests Job by condemning him to great misfortune to determine Job's faith in God. Job, uncertain about why he is being punished, reflects on his innocence, mentioning his practice of welcoming traveling strangers into his home as a reason why he should not be subject to punishment (Job 31:32, New International Version). Job's reliance on hospitality in his argument for his innocence shows the value placed on welcoming guests in Biblical times.

Early England. Ancient history and mythology tend to focus on the welcoming of a traveling stranger to one's home, while some history of Early English hospitality 
tends to focus on the hosting of economically deprived vagrants. Several kings in early English history created laws banning people from wandering, laws for the creation of border control, and laws banning the presence of strangers in towns (Ribton-Turner, 1972). The wealthy or well-known traveler was much more likely to achieve accommodation in private households than was the poor traveler (Heal, 1990). Outsiders claiming to be traveling salespeople or healers were subject to vagrancy laws and were generally not welcome in private homes, marginalized by hosts' fear of these groups. Despite the disapproval for vagabondage, the Anglo-Saxon monarchs were known for their hospitality of people of all economic statuses, especially around major holidays (Ribton-Turner, 1972).

Travelers in Early Modern England (1400-1700) were often presented with a standard choice of where to lodge while away; the choice usually consisted of inns, monasteries, or strangers' homes along the way. After analyzing several travel diaries from Early Modern England, Heal (1990) found that travelers wishing to lodge in private homes often carried with them letters of recommendation from well-known religious and political figures and other acquaintances. Along their journey, travelers would collect letters from hosts they stayed with along the way to present to future hosts. Aside from letters of recommendation, John Taylor, an early travel writer and author of Penniless Pilgrimage, attempted to travel around Northeastern Europe without paying for any accommodation. Heal (1990) found that Taylor was often able to arrange for accommodation by merely explaining his story. Because people were intrigued, they would agree to host the stranger in their homes. 
Heal (1990) argues that the value society placed on hospitality in Early Modern England was more similar to ancient times than it is to modern times. In other words, the great value placed on hospitality in myths and in religion translated into English values. For example, hospitality was considered, "a matter of public concern” (Heal, 1990, p. 2), and in cases when travelers were having difficulty finding accommodation, the local clergymen would take on the task of arranging for lodging for the traveler in a private home. In comparison to ancient times and Early Modern England, Heal (1990) argues the modern view of hospitality is one of a, "façade of entertainment" ( p. 1), which seeks to offer hospitality with the understanding that the host will be rewarded in return, such as with business lunches.

\section{Theoretical Framework}

Considering everything from travelers in ancient times being welcomed into a home to honor an important god to using the Internet to find a host in another country, the relationship between a host and a guest is an interesting interpersonal connection. Not only do hosts and guests have to make judgments often from initial interactions, but allowing strangers into one's home is risky. The following section looks to existing theory to consider the relationship between a host and a guest.

Trust. Hosts welcoming strangers into their homes have the potential to encounter much risk. With expectations for people throughout history to act as proper hosts, a great deal of trust is placed on the traveling strangers, often with little or no way of knowing more about the person than what is achieved in first impressions. Trustworthiness of another person can be determined extremely rapidly in first impressions, simply by observing facial appearance (Wout \& Sanfey, 2008). Several 
scholars have attempted to conceptualize the term trust, citing an imprecision with the typical use of the word (Barber, 1983; Ganesan \& Hess, 1997). According to Ganesan and Hess (1997), past research about trust does not necessarily differentiate between types of trust. For example, interpersonal trust and organizational trust are often not distinguished from one another. Also, ideas about why people trust one another do not seem to be agreed upon by researchers (Ganesan \& Hess, 1997). In order to look into the role of trust in hospitality, it is imperative to understand how trust is established.

The idea of trust has roots in ancient philosophy, particularly Aristotle's Rhetoric, which is a collection of ideas about crafting and delivering persuasive arguments. A major aspect of an effective argument is the ethos, or the perceived credibility or trust of a speaker. The translation of Aristotle's Rhetoric uses the terms ethos, credibility, and trust interchangeably. Aristotle outlines three "sources of trust" (Aristotle, 1932, p. 9192) that, together, will increase the audience's confidence in the speaker: intelligence, character, and goodwill. Intelligence involves the speaker having a working knowledge of the subject at hand in order to construct a logical argument. Character is the subjective perception of the speaker's morality and likeability. Goodwill is the speaker's focus on the audience's needs. McCroskey and Teven (1999) acknowledge that goodwill is the most understudied aspect of ethos and retested and confirmed the validity of intelligence, character, and goodwill affecting perceptions of credibility. McCroskey and Teven (1999) describe goodwill as the perceived caring, understanding, empathy, and responsiveness of the speaker toward the receiver of the message.

Other researchers have attempted to determine specific dimensions of trust. Ganesan and Hess (1997) propose two qualities that can lead to trusting an individual: 
credibility and benevolence. Although the terms credibility and trust are used interchangeably by Aristotle in Rhetoric, the term credibility, as used by Ganesan and Hess (1997), seems to follow the same definition as Aristotle's idea of character within ethos. Credibility is defined as the, "intention and ability to keep promises and deals with partner characteristics such as task specific competencies, reliability in the delivery of goods and services, and predictability in terms of job related behaviors" (Ganesan \& Hess, 1997, p. 440). Additionally, benevolence, which seems similar to Aristotle's idea of goodwill, is defined as, "based on the qualities, intentions, and characteristics attributed to the focal partner that demonstrate a genuine concern and care for the partner" (Ganesan \& Hess, 1997, p. 440). Ganesan and Hess (1997) looked into trust in sales relationships, and found that interpersonal credibility is more effective in achieving commitment than organizational credibility. Although this study disregarded Aristotle's philosophy of ethos and chose different terms to explain phenomena, the same aspects that create trust were found. Likewise, Barber (1983) proposed three expectations that are fundamental to trust. The first is an expectation for "persistence and fulfillment of the natural and the moral social orders," (Barber, 1983, p. 9), which is similar to Aristotle's idea of character. The second expectation is for "competent role performance" (Barber, 1983, p. 9), or intelligence. The third expectation Barber (1983) proposes is for the expectation that a person will "carry out their fiduciary obligations and responsibilities, that is, their duties in certain situations to place others' interests before their own" (p. 9). This expectation seems similar to Aristotle's idea of the goodwill aspect of trust. Barber (1983) argues that although these three expectations make up trust, differing amounts of each expectation are needed in certain situations. For example, in a family, there is a 
greater need for the first and third expectations, while the need for competence in a task may not be as high.

Yoo (2005) explains the two types of trust: cognitive and behavioral trust. Cognitive trust is a general term to explain what Aristotle calls ethos. In other words, cognitive trust is the perception that the other person has intelligence, character, and goodwill. Further, behavioral trust involves the prediction that a person will act in accordance with the perceived cognitive trust. A trustworthy person in the realm of behavioral trust is somebody who acts with intelligence, character, and goodwill. This is especially true in circumstances where the interactants are particularly vulnerable, because the trust in the person is not only that she or he is perceived to be internally trustworthy, but also that they will behave in a trustworthy manner.

Initial Interactions. The act of hosts welcoming guests into their homes has been practiced since the beginning of recorded history, and possibly earlier, especially with its presence in law, religion, and myth. Although laws requiring people to host travelers are no longer custom, people are still welcoming guests into their homes. In ancient times, a stranger would appear at a door, requesting accommodation (O'Gorman, 2007), and the host was forced to make a decision based on first impressions, whether or not they agree to accommodate the guest. All social interactions involve a certain degree of trust (Barber, 1983) and uncertainty (Yoo, 2005). In fact, Yoo (2005) argues that, "uncertainty reduction is a necessary condition for the development of relational trust" (p. 9). Although a close connection between trust and uncertainty is apparent, very few studies have looked into the relationship. 
Yoo (2005) looked specifically at the role of uncertainty reduction in trust formation. Information-seeking is one way Berger and Calbrese (1975) theorize interactants will attempt to reduce uncertainty. Yoo (2005) looked into whether information received about a task partner was positively or negatively valenced had any effect on the cognitive and behavioral trust for the other person. Participants were asked to play a game called Prisoner's Dilemma, which involved the real possibility for gaining or losing money. Participants were also given information about their partner, which was either positive or negative, as an uncertainty reduction measure. The game allowed the participant to trust the other person with the possibility of stealing or giving the participant money. Findings indicated that positively valenced information presented about the partner affected both cognitive and behavioral trust. In other words, when positive information was presented about the partner, the participant perceived the partner as more trustworthy and was more likely to trust the partner with the money in the game. Because of this, Yoo (2005) makes an argument that uncertainty reduction and trust are related, especially in the case of positive information-seeking behavior.

Because of the relationship between trust and uncertainty reduction and in order to explore the interesting relationship between a host and a guest who is also a stranger, two communication theories will be considered focusing on initial interactions in an interpersonal context: uncertainty reduction theory and predicted outcome value theory.

Uncertainty reduction theory. Uncertainty reduction theory, developed by Berger and Calbrese (1975), theorizes about the role of uncertainty in initial interactions between strangers. This theory seeks to both explain and predict the behavior of interactants in the entry phase of a relationship. Berger and Calbrese (1975) explain in the 
entry phase of a relationship, or in the first interaction, participants in the communication event will often discuss simple demographics, offer similar amounts of disclosure, and will decide toward the end of the interaction whether they would like to move forward to more intimate information and relationship formation.

Also during this initial interaction, participants' main priority is to reduce the uncertainty they are experiencing in this interaction (Berger \& Calbrese, 1975). Uncertainty experienced in an initial interaction is made up of two parts: proactive and retroactive processes (Berger \& Calbrese, 1975). The proactive process is the prediction of the other interactant's behavior and planning for one's own behavior, while the retroactive process involves explanation of the behaviors of both the target and oneself.

Berger and Calbrese (1975) offer seven axioms and 21 theorems about the role uncertainty plays in interaction within their theory of uncertainty reduction. The seven axioms detail the explanation and prediction of uncertainty paired with aspects of communication such as verbal communication, nonverbal affiliative expressiveness, information-seeking behavior, levels of intimacy of content, rate of reciprocity, similarity and liking. The 21 theorems discuss interactions and relationships among the seven axioms of uncertainty reduction.

Later, Berger and Bradac (1982) offered an expansion of uncertainty reduction theory to include conditions for actively trying to reduce uncertainty and strategies to reduce uncertainty experienced in initial interactions. Conditions likely to involve uncertainty reduction behaviors include the other interactant being perceived as having high incentive value, the behavior of the other interactant violating the expectations for a normal interaction, and the likelihood of future interaction. These strategies that Berger 
and Bradac (1982) suggest interactants use to reduce uncertainty in interaction include passive, active, and interactive strategies. A passive strategy involves seeking information from observing the person, without making one's observation known. An active strategy often involves requesting more information about the other interactant from a third party source, such as asking a mutual acquaintance questions about the other person. Another active strategy is to manipulate the environment of the target in order to gain information about the person. Interactive strategies involve gathering information directly from the target, often by asking direct questions and self-disclosing.

Predicted outcome value theory. Predicted outcome value theory is Sunnafrank's (1986) expansion of uncertainty reduction theory. Both theories focus on initial interactions. Sunnafrank (1986) explains that predicted outcome value theory is not completely separate from uncertainty reduction theory, and instead explains that the two theories are complementary. Sunnafrank (1986) argues that uncertainty reduction theory is missing the necessary variable of interactants' desire for future interaction. In order to expand the explanatory and predictive value of the theory, Sunnafrank (1986) proposes considering the relationship between uncertainty reduction and the perceived costs and rewards of the relationship. Sunnafrank (1986) argues that, "Uncertainty reduction would not be the primary concern of individuals, but only a means to achieving the more central goal of maximizing outcomes" (p. 4).

Predicted outcome value theory relies on the idea that interactants will either perceive an interaction to have positive predicted outcome values or negative predicted outcome values. The seven axioms of uncertainty reduction theory are modified around the possible predicted outcome values of interactions. For example, Berger and Calbrese 
(1975) explain in Axiom 3 of uncertainty reduction theory that high uncertainty levels lead to increased information seeking behavior. Sunnafrank (1986) adds to this idea in predicted outcome value theory, predicting that in all initial interactions Berger and Calbrese's (1975) Axiom 3 will remain true, but when the predicted outcome value is positive, reduction of uncertainty will increase the amount of information seeking behavior. However, if the predicted outcome value is negative, reduction of uncertainty will decrease the amount of information seeking behavior. In other words, Sunnafrank (1986) adds a valence to the uncertainty reduction theory, pointing out that in addition to uncertainty reduction, the perception of the relationship plays a role in the prediction of behavior.

Because of the focus on keeping the future of the relationship in mind during initial interactions, Sunnafrank (1986) proposes three possible options for the future of the relationship after the initial interaction: termination, escalation, and maintenance. Uncertainty reduction behaviors allow interactants to make decisions about how to proceed with the relationship. Based on the predicted outcome values, interactants decide if they would like to terminate, or no longer continue the relationship, escalate the relationship to become more intimate, or maintain the relationship at the current intimacy level.

Trust, uncertainty reduction, and prediction of outcomes online. Aristotle's Rhetoric dates back to the approximate timeframe of the $4^{\text {th }}$ century BC. After thousands of years, the elements making up ethos, or trust, are still determined to be relevant (McCroskey \& Teven, 1999). However, this study seeks to look further into trust in the mediated age. As society moves toward mediated communication, how is the 
trustworthiness of others determined? Uncertainty reduction theory and predicted outcome value theory have both been considered in the context of computer mediated communication (e.g., Planalp \& Honeycutt, 1985; Ramirez, 2009; Tidwell \& Walther, 2002). These theories will be used to look into a specific medium for computer mediated communication relying heavily on trust of others: Couchsurfing.

Although uncertainty reduction theory was originally developed to explain and predict initial interactions in a face-to-face context, as technology became a more present factor in interpersonal communication, researchers began looking at how uncertainty reduction theory fits into computer mediated communication (Planalp \& Honeycutt, 1985; Ramirez, 2009; Ramirez, Walther, Burgoon, \& Sunnafrank, 2002). Ramirez et al. (2002) proposed a fourth strategy for reducing uncertainty (in addition to passive, active, and interactive strategies), specific to gathering information online. An extractive strategy of reducing uncertainty about another person involves gathering information about the target online through, for example, search engines and home pages of the individual. This information may be available to the public and can be collected without the target's knowledge or intention. The extractive strategy of reducing uncertainty is unique to computer mediated communication (Ramirez et al. (2002), and may not be applicable to face-to-face communication. However, passive, active and interactive strategies of information-seeking can be used online. Gibbs, Ellison, and Lai (2011) studied online dating participants and the measures they took to reduce uncertainty. Passive, active, interactive, and extractive strategies were used to seek information about potential dating partners, such as using Google to search more about them (extractive) and comparing written profile content to photos (passive). 
Ramirez (2009) explains that uncertainty reduction theory from a face-to-face medium to a computer mediated medium may not translate as expected. He states, "the extent to which participation in computer mediated interaction enhances uncertainty reduction efforts is not as straightforward as expected" (p. 320). Instead, uncertainty reduction theory seems more applicable to computer mediated communication when taking into consideration the predicted outcome value of the relationship, such as with Sunnafrank's (1986) predicted outcome value theory. According to Ramirez et al. (2002), interactants through computer mediated communication participate in informationseeking behavior online, and are often, "even more sensitive to variations in anticipated longevity than are FtF [face-to-face] partners" (p. 4). For this reason, the present study will use both uncertainty reduction and predicted outcome value theories together to better understand trust within the Couchsurfing phenomenon. Trust-building online through communicative aspects of CouchSurfing are best understood through the use of both theories together. Predicted outcome value theory, in combination with uncertainty reduction theory, clarifies the formation of trust more completely than either theory could individually.

Because uncertainty reduction theory and predicted outcome value theory both have to do with initial interactions, it makes sense to use them to look into Couchsurfing. Members are able to use website features to seek out information about someone in order to reduce uncertainty and build trust before committing to allowing a person into their homes. Next, existing literature about Couchsurfing will be discussed. 


\section{Couchsurfing}

Couchsurfing is a hospitality exchange networking website community putting travelers, also known as "surfers," in contact with hosts in areas where they plan on traveling. Other similar hospitality exchange websites exist, but for the purpose of this study, focus will be placed on Couchsurfing. Couchsurfing has revolutionized modern day lodging (Steylaerts \& O'Dubhghaill, 2011), and it includes communication with the potential to move from an online environment to face-to-face. The website has over five million Couchsurfing members representing over 97,000 cities and every country on Earth (Couchsurfing International, 2013a).

Both members and nonmembers acknowledge the risk involved with using the Couchsurfing website (Tran, 2009), but the Couchsurfing organization uses several strategies to minimize these risks and states that, "Couchsurfing members are active participants in the safety of our community" (Couchsurfing International, 2013b, para. 1). Within the web community there is an implicit responsibility for members to contribute to the safety of one another. Members contribute to the safety of the community with the expectation to leave references about members they have met face-to-face (Couchsurfing International, 2013c). Other website features helping to ensure safety of members include members becoming verified through the website or reputable members vouching for

other members they have met. However, Tran (2009) found that members do not put much weight on verification or vouch status of members when making hosting and surfing decisions. With many features available to determine trustworthiness in members, and because of the emphasis on community in Couchsurfing, it is important to keep in mind that "in the context of Couchsurfing, where people meet each other online in order 
to meet face-to-face, how travelers establish trust with strangers, how they encounter strangers and even what they mean by 'stranger', are all open to reinterpretation" (Germann Molz, 2012, p. 86).

Because of the potential risks surrounding the behaviors of Couchsurfers, how do members use the communicative website features to make decisions about whom to meet offline? What makes hosts trust a stranger enough to allow her or him to stay in their homes? Several studies found communicative website features often used in the decision making process are the members' profile photos (Bialski, 2012; Germann Molz, 2012; Liu, 2012; Tran, 2009), references (Germann Molz, 2012; Lauterbach, Truong, Shah, \& Adamic, 2009; Rosen, Lafontaine, \& Hendrickson, 2011; Steylaerts \& O’Dubhghaill, 2011; Tran, 2009), and initial request messages (Bialski, 2011; Liu, 2012; Rosen et al., 2011; Tran, 2009). Another, albeit less studied, feature of the website that has the potential to provide vital information to potential hosts is the textual information found in a profile. Where research is lacking, however, is in determining what members are looking for within the photos, references, request messages, and textual profile information leading them to accept or reject other members.

The ability to look into trust and uncertainty reduction through such an intriguing website as Couchsurfing may lead to a significant contribution to the study of communication. Because the study of trust, uncertainty reduction theory, and predicted outcome value theory all began with face-to-face interactions, applying each of these to the study of a particular computer mediated interaction is worthwhile. Higher levels of trust can reduce the perception of risk of the other person (Ganesan \& Hess, 1997). The internet allows website members to manage their self-presentation in a way that is not 
possible in face-to-face interaction (Tidwell \& Walther, 2002), and encounters using Couchsurfing can be risky. Situations that pose greater amounts of risk often result in interactants using more uncertainty reduction measures (Gibbs et al., 2011). Do people trust others online as they are presenting their own identities? The present study seeks to describe what information is sought out in order to trust others online, through the scope of Couchsurfing.

Before looking into Couchsurfing specifically, it is first important to comprehend what social network and social networking sites are and how research about these websites can be used to better understand Couchsurfing. According to Boyd and Ellison (2008) a distinct difference exists between social network sites and social networking sites. The main purpose of social networking sites is to allow relationship initiation, allowing members to connect with other members who would otherwise be strangers. An example of a typical social networking website is an online dating website. Social network sites, on the other hand, allow members to connect with already existing offline friends online and participate in relational maintenance with those connections. A common example of a social network website is Facebook. Boyd and Ellison (2008) include Couchsurfing in their list of social network sites. More specifically, Boyd and Ellison (2008) included Couchsurfing in a sub-type of social network sites called "passion-centric" (p. 216) or "activity-centered" social network sites.

It seems plausible that Couchsurfing would be considered a social network site because of the potential for members to maintain relationships with existing offline connections through leaving references and vouches, and adding members to one's friends list on the website. An argument could also be made, however, that because 
Couchsurfing allows members to meet strangers they would like to stay with, the website also includes aspects of a social networking site. It is possible that Couchsurfing may be distinctive in that it includes characteristics of both social network sites and social networking sites. Because of this exception in taxonomy of social websites, both social network and social networking literature will be used throughout this review of literature to explore Couchsurfing. First, a background of Couchsurfing will be provided and Research Questions One and Two will be posed. Next, the website features of photos, references, request messages, and textual profile information will be explored as tools for reducing uncertainty and building trust, and Research Questions Three through Ten will be posed.

Trust on Couchsurfing. The typical Couchsurfing interaction begins online and has the potential to move offline. Most often, the traveler is the person requesting to stay with a host (Bialski, 2012). Typically, after a traveler submits a request through the website to a host, the host will make a decision about whether or not to host the surfer. Sometimes, the host and surfer exchange additional messages. Then, if a host decides to accept the surfer into her or his home, the host will welcome the surfer, and give her or him a place to stay, free of charge. The request rarely happens the other way around, with a host requesting a surfer to stay with her or him. Bialski (2012) found that when a host offers a specific surfer a place to stay, without being prompted by the traveler first, it can be interpreted as a sexual advance.

In several studies, members stress that the Couchsurfing community runs on more than the idea of a free place to stay (Bialski, 2012; Germann Molz, 2011; 2012; Skog, 2012). The purpose of Couchsurfing is to exchange culture and gain a better 
understanding of the places one travels to by being guided by a local. Even beyond creating a cultural experience for both surfers and hosts, the Couchsurfing community explains their greater goals are more complex. The community hopes that by spreading this value of global acceptance and trust, they will help to connect and improve the world as a whole (Cova \& White, 2010).

At first mention of a website community like Couchsurfing, where strangers connect online in order to meet face-to-face, often in unfamiliar locations, many people may react negatively to the idea (Bialski, 2012; Skog, 2012). Although a strong sense of community and greater good exists within the web community, dangerous situations have occurred surrounding the use of the website. The most publicized story of Couchsurfing gone wrong involved a young female traveler from Hong Kong, who was raped by her Couchsurfing host in the United Kingdom (Brooke, 2012). Although anecdotes like this exist, the Couchsurfing organization insists that most interactions taking place through the website are overwhelmingly positive (Bialski, 2012; Tran, 2009). Yet, as Lauterbach et al. (2009) state, "there are few situations requiring more trust than letting a stranger sleep in your home, or conversely, staying on someone else's couch” (p. 1).

Risks and motivations. Couchsurfing involves some risk, especially for hosts welcoming travelers into their homes. First impressions of the website community often involve perception of a high degree of risk involved with welcoming a stranger into one's home (Bialski, 2011; Liu, 2012; Skog, 2012). However, most experiences using the website are positive (Skog, 2012).Germann Molz (2012) explains that trust within the Couchsurfing community must be looked at using literature concerning trust issues in hospitality and trust issues within computer mediated relationships. 
The risks involved in hosting Couchsurfers can be physical or financial (Bialski, 2011). The more extreme risks associated with hosting Couchsurfers can involve being robbed or kidnapped (Tan, 2010) or dealing with sexual advances (Skog, 2012). In addition, less threatening risks include having guests that are untidy or unhygienic (Skog, 2012; Steylaerts \& O'Dubhghaill, 2011). Another concern is that guests will misuse property of the host (Germann Molz, 2012; Liu, 2012; Steylaerts \& O’Dubhghaill, 2011). For example, a participant in Steylaerts and O'Dubhghaill's (2011) study complained that a past guest had used his home phone to make international phone calls, and he was not aware of the charges until his phone bill arrived weeks after the guest had left. Another common risk indicated by Couchsurfing members is that the guests might overstay their welcome (Germann Molz, 2012; Steylaerts \& O’Dubhghaill, 2011) or guests obviously using the Couchsurfing service only as free accommodation (Skog, 2012). Liu's (2012) interview participants indicated concern for the risk of the host and guest not connecting well or feeling uncomfortable around one another. However, with all the risks involved with hosting within Couchsurfing, Steylaert and O'Dubhghaill (2011) found that hosts are not discouraged by negative experiences, and instead continue hosting surfers.

Liu (2012) found that members of the Couchsurfing community see the risks involved with the behavior of meeting strangers face-to-face as, "the necessary investment in order to get the benefits" (p. 100). The benefits of Couchsurfing members choosing to host other members is a more complicated issue than the benefits of traveling with the site. For example, travelers using the site for accommodation have the benefit of free lodging, which is reported by Couchsurfers to be a main reason to use the website (Liu, 2012). However, the benefits of hosting are not as clear. Germann Molz (2012) 
found that hosting others in the community is not seen as a chore. Instead, several motivations for hosting can be identified in the existing literature.

The first motive for hosting Couchsurfers is the widely accepted idea of generalized reciprocity within the online community. Lauterbach et al. (2009) and Germann Molz (2012) found that after a member travels with the website and is hosted by another member, there is an obligation for reciprocity. This generalized reciprocity does not necessarily manifest in the original surfer then hosting the original host. Instead, the original surfer has a loose obligation to host another member of the Couchsurfing community in the future. Couchsurfing members often begin their membership as either hosts or surfers, but quickly assume the opposite role (Germann Molz 2012). Lauterbach et al. (2009) found more experienced members, those with ten or more Couchsurfing experiences, had most often served both roles as host and traveler.

Another motivation for members to host travelers is to take part in a cultural exchange. Hosting surfers allows members to experience traveling, without leaving home (Germann Molz, 2012; Skog, 2012). In Bialski’s (2011) study, a Polish Couchsurfing host named Adam said he prefers not to host other Polish citizens because he would not, "get anything out of that" (p. 253). This reveals that, culturally, hosts have something to gain by hosting foreign travelers. Holwick (2011) found that hosting is a way to increase understanding and awareness of other cultures. Other than the awareness of other cultures, the ability to learn from diverse people can be seen as a benefit. A traveling participant in Germann Molz's (2012) study stated, “It's no problem that you spent this time to really show me a city because we exchanged ideas and we talked and we talked 
and who can say who benefited?" (p. 104). This participant seems to believe the rewards of hosting and surfing are equal.

Similar to the motivation of benefiting from a cultural exchange, many studies cited the benefit of experiencing a quickly developing intimate friendship in other members. Some hosts crave intense human interaction that they have difficulty finding in their everyday lives, and use hosting as a way to have strong connections with others (Bialski, 2011). Storytelling is a common activity in Couchsurfing relationships, which is seen as a benefit to hosting in itself (Bialski, 2011). Bialski (2011) found that travelers take on the role of the vagabond, the foreign traveler with stories to tell, and explains the existence of the benefit of emotional fulfillment in hosting others. Because of the intensely intimate relationships developed through the website, a great amount of selfdisclosure occurs. Within this self-disclosure, Bialski (2011) argues that members are able to learn more about themselves through these conversations, leading both hosts and guests to benefit from the emotional discovery taking place.

Another motivation hosts have for taking in travelers is the ability to influence reputation. Hosts admit to welcoming travelers to stay with them for only the benefit of receiving a positive reference on their profile (Bialski, 2012), which then increases their social capital in the community. Another benefit to reputation is the ability for Couchsurfing hosts to show that their home city has value (Bialski, 2011; Steylaerts \& O’Dubhghaill, 2011). A participant in Steylaerts and O'Dubhghaill's (2011) study, Manuel, claimed that he does not open his home in Quito for the benefit of the travelers, but instead for the benefit of his city. He enjoys the opportunity to leave a positive impression of Quito on travelers staying with him. 
In response to the risks and motivations for hosting Couchsurfers, there is a common emphasis put on the "like-mindedness" of members of the Couchsurfing community (Steylaerts \& O’Dubhghaill, 2011, p.262). Germann Molz (2012) found that her participants had a general expectation that all members they would interact with from the Couchsurfing community would be open-minded, curious, and accepting of diversity. In Tan's (2010) interviews with Couchsurfers, every participant brought up the common quality of Couchsurfing participants being open-minded. Participants said it was a personal trait in them drawing them to the Couchsurfing community and a trait they prefer in others they interact with using the website. One participant, an Australian female, acknowledged the risks of Couchsurfing, and emphasized that she not only wants to be physically safe, but also psychologically safe. She claimed that the like-mindedness of members of the community contributed to her feelings of psychological safety when interacting with others using Couchsurfing. In fact, instead of focusing on the risks involved with Couchsurfing, members of the Couchsurfing community tend to embrace strangers and bring them physically and emotionally close (Germann Molz, 2012). They feel that anyone who signed up to participate in a community like Couchsurfing must be a certain kind of person: the kind of person who is not dangerous. Further, Germann Molz (2012) came to the conclusion that even before members have met face-to-face, they are not considered strangers, but instead they are considered "strangers like us" (p. 94). Additionally, Holwick (2011) found that the quickly developing intimacy of Couchsurfing acquaintances is, in part, a result of the like-mindedness of participants. This like-mindedness results in trust in the community being an implicit understanding. 
Couchsurfing trust-building tools. All of the participants in Tan's (2010) study agreed participating in Couchsurfing involves a great deal of trust. When it comes to hosts within the community, specifically, there is a positive correlation between hosting others and trust in the Couchsurfing community (Rosen et al., 2011). Much of the existing literature on Couchsurfing focuses on the establishment and impressions of trust online. As might be expected, female Couchsurfing members are more concerned with their safety and spend more time evaluating potential travelers online before agreeing to host them (Tan, 2010). In order to build trust, a major source for information about a member is their Couchsurfing profile and the initial message sent to a host (Tan, 2010). In addition to physical safety, members are also concerned with establishing trust in the other person's compatibility, in order to gain a true cultural exchange and enjoyment (Bialski, 2011; Tan, 2010).

The Couchsurfing profile allows members to express who they are, and it also allows potential hosts to make judgments about whether or not they would like to interact with the person offline (Bialski, 2011). Tips offered from the Couchsurfing website stress the importance of considering information found on users' profiles before agreeing to meet face-to-face (Couchsurfing International, 2013c). The website suggests, "When you see a profile that looks interesting, take the time to read it carefully, looking for detailed information about them and clear photos of their face" (Couchsurfing International, 2013c).

Using information found on a member's profile, potential hosts attempt to perform an assessment of how risky it would be to host each individual (Bialski, 2011). They use this risk assessment to make a decision about whether to accept or reject the 
member. As noted above, although Couchsurfing offers and encourages users to look to vouching and verification to ensure safety, many members do not consider these features when making hosting decisions (Bialski, 2011). What communicative website features Couchsurfing hosts do use to make decisions about hosting, however, include the photos (Bialski, 2012; Germann Molz, 2012; Liu, 2012; Tran, 2009), references (Germann Molz, 2012; Lauterbach et al., 2009; Rosen et al., 2011; Steylaerts \& O'Dubhghaill, 2011; Tran, 2009), and request messages (Bialski, 2011; Liu, 2012; Rosen et al., 2011; Tran, 2009).

Differences among main features. Through past research about Couchsurfing, three communicative website features continuously identified as important in the decision-making process to meet members offline. In addition to photos, references, and the request message, other textual profile items can also prove information to prospective hosts. Each of these website features offer information different from the other features. Before looking into which feature is used most, it is first important to gain a basic understanding of the four features.

Photos serve as communication between the owner of the profile and the overall Couchsurfing community. The Couchsurfing website allows members to upload several photos onto their profile and include a caption for each photo. The Couchsurfing organization encourages members to take the time to look at photos of others, stating, "It helps a lot to know who you're meeting" (Couchsurfing International, 2013d, para. 3). Because of the emphasis by the Couchsurfing organization on the inclusion of photos on profiles, the Couchsurfing website has rules about what can and cannot be used as a profile photo. Some other social networking sites allow users to use photos of celebrities, cartoon characters, or other graphics as a profile photo, but Couchsurfing does not allow 
use of these types of profile pictures, and Couchsurfing website administrators will delete any photos violating this rule (Bialski, 2012). Historically, travelers would appear at the door of a home and request accommodation, and potential hosts were required to make decisions based on first impressions, and it has been found that people are quick to make judgments about trust based on facial appearance (Wout \& Sanfey, 2008).

References serve as communication between a third party source, usually a person the member has stayed met offline the past, and the overall Couchsurfing community. The references allow members to warn other members of a potentially dangerous Couchsurfing participant or praise a participant after a positive face-to-face meeting. Liu (2012) addresses the concept of "social capital" within the online community, explaining that members with more experience traveling and hosting (i.e., those members with the most references), have more influence within the community (p. 25). Members with a greater amount of social capital are more appealing to other potential interactants through Couchsurfing. The Couchsurfing organization encourages members to pay attention to references left by members that have met the person offline and who have interacted with the member in the same capacity requested of the viewer (i.e. host) (Couchsurfing International, 2013d). Historically, travelers carried letters of recommendation with them on their journeys to help potential hosts make hosting decisions (Heal, 1990). The references feature of the Couchsurfing website is a modern way of gaining third party insight into a potential guest.

Request messages serve as direct communication between the member requesting accommodation and the prospective host. Typically, when a traveler is looking for a host using the Couchsurfing website, she or he will complete a Couch Search of the area in 
which she or he plans on traveling (Liu, 2012). This search displays potential hosts in the city and surrounding areas, and allows travelers to browse profiles to determine from whom they would like to request accommodation. When a potential host is chosen, the member will send the host a request message, a message outlining the dates of accommodation needed and a short message to appeal to the potential host. According to Liu (2012), the request message is often expected to include information about the traveler and the trip.

Aside from photos, references, and request messages, other profile information provided by a Couchsurfing member may have communicative value to reduce uncertainty and increase trust. The Couchsurfing profile allows individual members to include a wide variety of information in their profiles, which is available publically to the Couchsurfing community. For example, members have the opportunity to include general information, such as age, location, sex, occupation and education. Members are able to include languages they speak and include their proficiency for each language. Information about the member's own couch is also displayed, indicating whether or not the member has a couch available for other members and what kind of accommodation can be offered. Other profile sections are titled Personal Description, How I Participate in CS, Couchsurfing Experience, Interests, Philosophy, Music Movies Books, Teach Learn Share, One Amazing Thing I've Seen or Done, Opinion on the Couchsurfing.org Project, Locations Traveled, Groups I Belong To, and Friends. Although no existing studies have indicated that members rely heavily on any of these profile items in particular, the sections of the profile have the potential to provide potential hosts with needed information to trust or distrust a member. 
It is possible to gain information about others to reduce uncertainty online (Planalp \& Honeycutt, 1985; Ramirez et al., 2002; Tidwell \& Walther, 2002), and information-seeking online involves more intimate topics than information-seeking in face-to-face interactions (Tidwell \& Walther, 2002). Overall, Couchsurfing offers members several communicative website tools to make informed decisions about who to meet offline. However, it is apparent that each of these website features is very different from one another, including different senders and intended receivers of information. One factor in determining what strategy to use in information-seeking to reduce uncertainty is the technology related factor (Ramirez et al., 2002). Interactants must determine how effective a particular technology is in acquiring information needed to reduce uncertainty. Research has determined that photos, references, and the request messages are technologies that are effective in provided needed information, and other textual information within a profile can also provide information, but which of the four is most effective in reducing uncertainty to trust the other member? Because each of these features is so different, the present study seeks to discover what information found online is most effective in reducing uncertainty to build trust. Is the source of information important (e.g., a third party source)? Is the intended audience of importance? The following research questions are proposed:

RQ1: What type of information found online serves as extractive information to trust another person?

RQ2: What type of information found online serves as extractive information to distrust another person? 


\section{Photos}

Research questions one and two look into, overall, which feature of the website is of importance when making hosting decisions. Next, each of the website features will be considered to gain an understanding of existing relevant research about each website feature and similar concepts. First, the use of photos to reduce uncertainty and build trust will be considered to gain an understanding about how photos are used, if they are deemed important to members in research questions one and two.

The use of social network and networking sites is increasingly a way to connect with others (Boyd, 2007; Salimkhan, Manago, \& Greenfield, 2010), and a great deal of self-presentation methods take place with the creation and management of an online profile (Schwammlein \& Wodzicki, 2012). The creation of a social network or networking profile often involves offering personal information and photos for other members to view. Goffman (1959) theorized about the self-presentation methods of people in face-to-face interactions. He explained that people put much effort into shaping how they are perceived in order to achieve a desired response, and often even portray an ideal self. According to Goffman (1959), “...when the individual presents himself before others, his performance will tend to incorporate and exemplify the officially accredited values of the society" (p. 35). The use of photos found on profiles of Couchsurfing members is a way to look into self-presentation as outlined by Goffman (1959), but through computer mediated communication. When evaluating others based on their selfpresentation, individuals often look to enduring, unchanging, characteristics to make judgments, such as sex, age, racial indications, and appearance. These lasting characteristics and how they are presented may be apparent in the photos found on 
profiles, which may affect hosts' decision to accept or reject a request upon viewing the photos. This next section outlines existing research about self-presentation methods and evaluation of others using photos posted on Couchsurfing as well as other social network and networking sites.

Self-presentation. Online, first impressions are able to be easily manipulated (Walther, 1992). On social network and networking sites, users make use of photos as a way to tell a story about their previous, current, and potential selves (Salimkhan et al., 2010). According to Haferkamp and Kramer (2010), users of social networking sites tend to be intentional about the information they choose to post online. They found that females tend to be more intentional than males with what they put on their social networking profiles, and females tend to choose photos and information portraying the most honest, yet positive, self possible.

Siibak (2009) found that the photo chosen as a profile picture on a social network site communicates much about the self-presentation goals of the site user. The profile picture displayed on social network sites, such as Facebook, are a way for individuals to present themselves in an implicit way (Zhao, Grasmuck, \& Martin, 2008). In other words, members are able to show, rather than explicitly tell, about themselves. Strano (2008) found that Facebook members tended to choose a profile photo in which they think they appear attractive. Zwier, Aroujo, Boukes, and Willemsen (2011) found users of social network sites choose profile photos portraying them surrounded by friends with hopes to appear highly socially connected to profile viewers.

Siibak (2009) found in a study of Estonian teenagers' use of social network sites that females were especially likely to choose display photos including a significant other, 
that were taken at a special event, or that showed their personality. Both males and females in this study chose display pictures in which they believed they appeared attractive or included beautiful scenery, while also taking into consideration who would be viewing their profile. In addition, Haferkamp, Eimler, Apadakis, and Kruck (2012) found that German social network site members choose photographs differently based on sex. Females tended to choose portrait photographs showing only their face, while males tended to choose a photo showing their whole body. Males were also more likely than females to choose photographs including scenery and other people, and males were more likely to edit photographs included in their profile.

Another self-presentation choice members must make is how many photos to include in their profile. Liu (2012) interviewed 14 Couchsurfing members about their uses and thoughts surrounding Couchsurfing. One participant, Mark, stated that he values simplicity in his profile photos. He only includes two photos on his profile, neither of which shows his face clearly. Another participant, Faith, only has one photo of herself, and she states that she is trying to avoid unwanted romantic advances from males by posting an unattractive photo of herself. This research seems to differ from Haferkamp and Kramer (2010) and Siibak (2009), who found that on other social network and networking sites, users, specifically females, choose photos in which they appear attractive.

Online dating sites and Couchsurfing have similarities because of the typical movement of a relationship from online to offline. Because of this, research about selfpresentation through photos on online dating sites is important to consider while looking into Couchsurfing. Many researchers study deception within online dating profiles (e.g., 
Ellison, Heino, \& Gibbs, 2006; Gibbs, Ellison, \& Heino, 2006; Whitty, 2007). Overall, members of online dating sites tend to take measures to present their ideal self, rather than their true self (Ellison et al., 2006). When expecting to take a relationship from online to offline, online dating website members are more truthful in their profiles (Gibbs et al., 2006). Further, Whitty (2007) determined that in self presentation, online dating participants do not often present a falsified self, but instead present the most attractive aspect of themself on the website. Participants of online dating sites tend to not put much emphasis on the photos provided by members, because the photos are often out of date or of poor quality. Some photos included members having obviously worn a large amount of makeup, which members admit is not a useful guide in learning about another person. Similarly, Hancock and Toma (2009) discovered that the photos used in online dating profiles are inaccurate representations of the person about one-third of the time, and these photos often are out of date, taken by photographers or professionally altered, and show very different physical characteristics from how the person currently appears.

Evaluation of others. In his writing about self-presentation, Goffman (1959) also touches on the evaluation of others' self-presentation attempts. He says that within interaction, people tend to acquire information about others for practical reasons, such as in order to predict what to expect in future interactions. Individuals may judge others by appearance and fit them into expectations they have based on previous interactions with similar people or stereotypes they have of people with certain characteristics (Goffman, 1959, p. 26). Because of the future interactions associated with a request, and the ability for hosts to judge surfers based on their appearance within their profile photos, one must also look at the evaluation hosts perform on surfers upon a request for hospitality. 
Couchsurfing (2013e) offers members tips about how to assess a member's profile. When it comes to photos found on the profile, Couchsurfing advises to look to photos for more information about a surfer: "Maybe all of the photos are taken at night and show big parties. Maybe they're all calm, outdoor scenes," (Couchsurfing International, 2013d, para. 3). Couchsurfing recommends that if the member appears to be similar to the reader, it is probable the two members would get along face-to-face. Axiom six of Berger and Calabrese's (1975) uncertainty reduction theory says that similarity among interactants can reduce uncertainty in the interaction. However, Bialski (2012) found that Couchsurfing members may avoid meeting members offline who seem too similar. It must be determined if similarity as a decisive factor in hosting is as sought after in the Couchsurfing community as it is in other online social situations.

The Couchsurfing page (2013e) also warns about profiles with no photos, stating that it is difficult to get to know another member online without a photo. About 60 percent of the Couchsurfing community has a profile photo displayed, and when members display text information, but not photos, on their profile, other members consider them less trustworthy (Bialski, 2012). Liu (2012) found while interviewing 14 active Couchsurfing members that a profile without a picture displayed causes members to assume that the person is unwilling to be open. All of the participants in Liu's study claimed that they would only consider hosting surfers whose profiles included at least one photo because, "it feels like the person is sincere and real" (Liu, 2012, p. 107). However, having a large amount of photos included on the profile was considered more of an indication of personality, rather than an indication of trustworthiness. It could even be perceived as "showing off in relation to past experience" (Liu, 2012, p. 108). In 
addition, the amount of photos displayed in a profile can add to the member's social capital within the web community, especially if photos portray the member fitting in with typical members of the group, or portraying typical values of Couchsurfers, such as appearing interesting or adventurous (Liu, 2012). DeLaCruz and Claveria (2009) found that a linear relationship exists between the number of photos Couchsurfing members have on their profile and the amount of surfers they have hosted, suggesting that, "visual verification plays a large role in establishing trust and promoting social capital" (p. 16).The Couchsurfing community places value on the use of authentic photos found on a profile, and photos are even seen as a way to reduce the risks involved in Couchsurfing behaviors: "The online photos, the friendship links, the personal statements, etc.- that the other technologies of friendship provide allow users to reduce their fears that the other person will be strange, awkward, or even dangerous” (Bialski, 2012, p. 85). However, what has not yet been determined is what about the online photos eases these fears potential hosts may experience.

On social network and networking sites other than Couchsurfing, individuals tend to evaluate others based on their photos displayed. Wang, Moon, Kwon, Evans, and Stefanone (2009) found Facebook users typically are more prone to initiate friendships with members with attractive profile photos, rather than initiate friendships with members with unattractive photos. In fact, Facebook users were more willing to initiate friendships with people who lacked a photo altogether than with people who had an unattractive photo. On the other hand, Haferkamp and Kramer (2010) found that photos in which a site member appeared attractive were viewed more negatively than photos in which the member appears more average in attractiveness; participants assumed that photos were 
enhanced when they pictured the more attractive individuals. It is possible that in the case of an attractive profile photo, viewers tend to question the authenticity of the member, similar to how member of online dating sites do not put emphasis on photos, assuming they may be fabricated (Whitty, 2007).

Tran (2009) found that, in general, profile photos on Couchsurfing are considered within the decision-making process about whether or not to host a surfer. In Bialski's (2012) ethnography, Adam, a Polish Couchsurfing host, claimed that he would reject someone if the member had, "profile photos which looked 'weird"” (p. 55), or if the person was too bad looking, too good looking, too old, or too young. Adam's perspective about what features of a profile photo lead to a host accepting the request was the only opinion found by Bialski (2012) about preference for what is included in a profile photo. Because Adam's perspective about what he looks for within a photo are included in the ethnography, but not explained, his response raises concern about what exactly Couchsurfing hosts look for within photos to accept or reject a request.

Summary. Goffman's (1959) perspective on self-presentation suggests individuals often portray an ideal self to others, especially an ideal self within a specific community. In an international online community like Couchsurfing, it would be interesting to determine if members attempt to present themselves in photos positively and showing them adhering to the Couchsurfing vision.

Viewing photos on a profile is one way for members to partake in informationseeking behavior in order to reduce uncertainty, which aligns with the third axiom of uncertainty reduction theory (Berger \& Calbrese, 1975). The action of viewing the photos found on a member's profile is an example of extractive information seeking (Ramirez et 
al., 2002). Davis, Lippman, Morris, and Tougas (2012) link the amount of photos found on a Facebook profile to the amount of self-disclosure offered, and Palmieri, Prestano, Gandley, Overton, and Zhang (2012) found that increased self-disclosure on Facebook decreases levels of uncertainty.

Considering predicted outcome value theory, it is proposed by Sunnafrank (1986) that when uncertainty is reduced through information-seeking behavior, "Decreased uncertainty, when associated with positive outcome values, produced increased information-seeking behavior" (p. 20). The increase in information-seeking behavior with a positive outcome value is due to the desire for an interactant to continue the relationship. The opposite is true for a perceived negative outcome value, suggesting the desire of the interactant to maintain or discontinue the relationship. In the context of Couchsurfing, escalating the relationship would indicate agreeing to meet offline, while maintaining or terminating the relationship would indicate the refusal to meet offline. What information can be found in a photo to decrease uncertainty enough to make this decision? Because uncertainty reduction can lead to greater trust (Yoo, 2005), it is important to determine what about viewing photos reduces uncertainty.

Existing research on Couchsurfing shows that members of the site use photos found on members' profiles as a communicative feature to make decisions about initiating and agreeing to interaction. However, existing research fails to explain what about the photos found on profiles communicate information that leads a host to accept or reject a Couchsurfing request. Bialski's (2012) interaction with Adam gives some insight into what one individual member tries to avoid in a guest, but these preferences are not explained, nor are they likely to be universally held by all Couchsurfing hosts. Adam says 
he does not want to accept anyone who is too attractive or too unattractive. What clues do hosts look for within photos of surfers to make their decisions? These concerns lead to the present study's next two research questions:

RQ3: What communicative aspects of a photograph are used to increase trust in the subject of the photo?

RQ4: What communicative aspects of a photograph are used to decrease trust in the subject of the photo?

\section{User References}

In addition to photos, the references found within profiles can be used to determine the trustworthiness of Couchsurfing members. References are used in several contexts in order to gain information about people or products from third party sources. From employment references, to online product references, to references found on Couchsurfing profiles, inputs from others who have had firsthand experience with the participants are valued.

For many years, employment references, either in the form of letters of recommendation, or the providing of contact information for references, have been widely used for potential hiring employers to gain a better understanding of prospective employees. According to Shulz, Mahabir, Song, and Verheyden (2012), 79\% of plastic surgery residency programs used letters of recommendation to make admission decisions. Several studies found that praise inflation is a problem with letters of recommendation and employment references (Bruland, 2009; Nicklin \& Roch, 2009, Stedman, Hatch, \& Schoenfeld, 2009). In addition, Nicklin and Roch (2009) found that participants often indicated that they would include constructive criticism in letters of recommendation they 
write, but rarely observe constructive criticism in letters they receive. This could suggest that referents believe they are providing criticism within their letters, but readers rarely identify the criticism included. Although potential employers are skeptical of information provided by references, they are more likely to take into consideration information provided if the referent is known on a personal level (Nicklin \& Roch, 2009), or is a wellknown expert in the field (Nicklin \& Roch, 2009; Shulz et al., 2012). Bruland (2009) also found in letters of recommendation to an English Ph.D. program, applicants who were accepted had significantly longer letters than those applicants being rejected, and included more specific details and examples regarding the applicant. If the length and detail of a letter of recommendation to an academic program is correlated to acceptance, it needs to be determined if this finding translates to Couchsurfing references online.

Apart from employment references, the use of references is widely used online in the form of user generated content. Research about user generated content often focuses on online reviews of products and services. Van Der Heide, Johnson, and Vang (2013) found that on eBay, a website that facilitates the auctioning of products, the reputation system in place has an effect on sales. Sellers with higher reputation ratings sold products at higher prices and received more bids for the product than members with lower reputation ratings. Munar (2011) focuses on user generated content within the travel industry, and claims this content can be used by consumers as a security measure when making travel decisions: "TCC [tourist created content] shows how tourists are active contributors to a new version of a surveillance society where the big brother is thousands of web empowered tourism consumers" (Munar, 2011, p. 302). 
Tripadvisor.com is a website providing user generated content to travelers specifically about destinations and services. Couchsurfing and TripAdvisor are comparable in their website features, including forums, email, newsletters, pictures, videos, and interactive maps (Dipplereiter, Grun, Pottler, Seidel, Berger, Dittenback, \& Pesenhofer, 2008). Another feature both websites include is the ability to leave references. Vasquez (2012) studied complaints as narratives of negative experiences on TripAdvisor. Vasquez (2012) found complaints were often paired with recommendations for other travelers, who are often complete strangers, to consider, and they also included positive remarks along with the complaint. Users of the website generating recommendations often acknowledged that they were competing for attention from other reviewers, and used specific strategies to stand out, such as drawing readers into their story and taking steps to gain attention of their audience.

Ayeh, Au, and Law (2013) found in user generated content on TripAdvisor, website users reading the content created by other users considered the source credibility of TripAdvisor reviews. Of particular importance is the trustworthiness of the author, which was determined to be more important than the expertise of the author when website viewers were determining their intention to consider the review. Also, Ayeh et al. (2013) found that website viewers were likely to trust user generated content from sources they perceived to be similar to them, which shows a trust in homophily.

The Couchsurfing community encourages members to write references about others they have stayed with or hosted (Couchsurfing International, 2013c), and Germann Molz (2011) and Lauterbach et al. (2009) both found that leaving references is an implied norm within the Couchsurfing community. The reference system used in the 
Couchsurfing community operates with the understanding that references about past behavior help to predict future behavior (Bialski, 2012). When observing a profile, both references that the others write about the member and references the member writes about others are visible to observers. Members are able to manipulate all information within their profile, except the references others leave about them. Members do not have the ability to delete a reference written about them (Bialski, 2011). Because of this, studies have found that Couchsurfing members rely heavily on references from others to gain information about members (Tran, 2009; Liu, 2012). All of Tran's (2009) interview participants admitted that they used references to make decisions about hosting a member, and Liu (2012) and Tan (2010) found that references were determined to be the most important indication of trustworthiness of members. One of Tan's (2010) participants explained that he trusts references most because members have the ability to falsify information within their profiles, but references, coming from a third party, are deemed more truthful.

Reviews left on members' profiles by references they have interacted with include the ability to rate the interaction as positive, neutral, or negative. Like the narrative uses of reviews on TripAdvisor, Couchsurfing also encourages elaboration on reviews, offering members to write about their experiences with members in addition to rating the experience as positive, neutral, or negative (Vasquez, 2012). Bialski (2011) found members emphasize the importance of looking beyond whether a reference is positive, neutral, or negative and look to the details within the open-ended comments box. Skog (2012) writes about the subjectivity of Couchsurfing references, and Liu (2012) explains that because of the subjective nature of references, what one member considers a negative 
experience could be what another member expects. This happens in particular with cultural differences or miscommunication occurring between host and guest.

Lauterbach et al. (2009) identify two benefits of using references within a Couchsurfing profile to make decisions about whom to host or surf. The first benefit is that members are able to gain information about the person from a third party source. The second benefit is knowing the heavy reliance on references within the site, members are motivated to behave in a positive way in order to achieve a positive reference, thus building and maintaining their reputation within the Couchsurfing community. Members with more references within the Couchsurfing community are more likely to have a better reputation within the online community, and more likely to be chosen as a host or surfer by other members (Rosen et al., 2011), because of their high social capital. The more references users have on their profile, the more well-traveled they are assumed to be. The greater the social capital of a member, the more prestigious position they have within the community, the more requests they receive, and the greater their ability is to be accepted by others for accommodation while traveling. Because increased social capital leads to more acceptance by hosts, the more a member is able to Couchsurf and the more interesting experiences they are able to share, leading to acceptance of them as a guest, thus perpetuating their reputation within the community through social capital.

Negative references. Because Couchsurfing members do not have the ability to create or edit references about them, references are often seen as a more reliable indicator of the character of the member than content created directly by the member. However, like the use of employment references (Nicklin \& Roch, 2009; Shulz, et al., 2012; Stedman et al., 2009), many members involved do not put full trust in references. The 
participants in Tran's (2009) interviews showed concern with how reliable references really can be in making decisions about who to meet offline. While the participants stressed the significance of being honest while leaving references, they have recognized praise inflation within Couchsurfing references, similar to studies on employment references. In fact, Bialski (2012) explains that at the time of her study, $99.8 \%$ of Couchsurfing experiences were rated as positive.

Overall, within the Couchsurfing community, references are generally very positive, and a stigma may exist against people with negative references on their profile. Participants in Tran's (2009) study explained that upon indicating on the Couchsurfing website that they would like to leave a negative reference about another member, the website takes steps to ask members if they have tried to work out issues with the member individually before placing a negative reference on her or his profile. The website informs members about the gravity of leaving negative references about another member on their profile. Upon reading this statement displayed when leaving a negative reference, members may be discouraged from leaving a negative reference, even when they may truly feel negatively toward their interaction with the member.

A participant in Steylaerts and O'Dubhghaill's (2011) study, Jade, indicated surprise at how few negative references exist, and believes people are apprehensive about leaving negative references because they worry others well leave negative references in return. Tran (2009) and Steylaerts and O’Dubhghaill (2011) found members may fear retaliation for leaving a negative reference. Because negative references are taken seriously within the Couchsurfing community, members might be more likely to not 
leave a reference at all, or leave a neutral or positive reference, instead of a negative reference, even when the interaction was negative (Liu, 2012).

Also, the unlikelihood of a host and surfer meeting again after a negative experience leaves no personal gain for leaving a negative reference (Liu, 2012). To these participants, sometimes avoiding harm to one's personal reputation is more important than warning the community of a potentially unfavorable interaction. Liu (2012) also found that members often feel their input does not matter in certain situations. For example, if a member has many positive references, leaving a negative reference may seem like an isolated incident and other members reading the reference in the future might not give it full consideration. An example of this is one of Liu's participants who, while hosting a traveler, came to the conclusion that the member had stolen a 600 dollar travel voucher from her home. However, she did not want to be the first person to leave a negative reference about the member because she feared acting negatively in a community so focused on the positive.

Another circumstance when members tend to shy away from leaving negative references is when they are leaving a reference about a host. Members feel a certain obligation, especially to those members that have hosted them, to leave a positive reference in return for their hospitality, even if the experience was negative (Germann Molz, 2012). An example of this is Therese, a Canadian participant in Germann Molz's (2012) study, who stayed with a male host who continually made sexual comments to her throughout her stay. She initially left a positive reference about him, despite her discomfort with the situation. However, upon further reflection she revised her reference because she did not want to put other females at risk. 
Summary. Like viewing photos on a profile, viewing the references left about a member of a website is an example of the uncertainty reduction measure of informationseeking behavior (Berger \& Calbrese, 1975). Reading references found online can be considered an extractive uncertainty reduction strategy (Ramirez et al., 2002). However, gaining information about a person through a third party could also be considered an active strategy for reducing uncertainty (Berger $\&$ Bradac, 1982). This poses an interesting condition because, unlike extractive strategies, active strategies for uncertainty reduction have not been studied in an online environment, especially with the publicly viewable, asynchronous nature of leaving references on another's profile. It will be interesting to determine how references from third parties in an online setting reduce uncertainty. Like with photos, predicted outcome value theory would say that a reduction in uncertainty leads to two possible conditions, based on the predicted outcome value: escalate the relationship, or maintain or terminate the relationship. It is important to determine what about references from a third party contribute to reductions in uncertainty, as uncertainty reduction can lead to greater trust (Yoo, 2005).

Unlike research about photos found within a profile, some research does exist about what members look for within references to make hosting decisions on Couchsurfing. Because of the "like-mindedness" of the community, several studies have found that members look for certain aspects of "like-mindedness" within the members they are considering hosting. Tan (2010) found members looking for "open-mindedness" to determine if the members are open to interacting with people of different cultures. Similarly, participants in Liu's (2012) study indicated, “a member's attractiveness is generally determined by the community's collective value of diversity, mobility, and 
openness" (p. 74). Liu also found that members may look to whether the profile is an accurate representation of the member by comparing information with comments within references.

Even though some research has explored what members look for within references, a greater understanding can be achieved. For example, are members willing to take a chance on participants with some negative references? Within the comments left by past interactants, what are hosts hoping to learn about the traveler? Do they want an indication of her or his personality? Do they want a description of what activities the host and surfer have done in the past? Do they want to know about the cleanliness or personal hygiene of the traveler? All of this is yet to be determined. Because of these unanswered questions the following research questions seek to address these issues:

RQ5: What communicative aspects of online references increase trust in the subject of the references?

RQ6: What communicative aspects of online references decrease trust in the subject of the references?

\section{Request Messages}

The request message is the first direct communication between the member requesting accommodation and the prospective host. Because the request message is a way for travelers to persuade hosts to provide accommodation, the request message can be considered through the scope of compliance-gaining and facework literature.

Compliance-gaining. The act of requesting the services of another is a situation in which compliance-gaining strategies may be used. According to Kellerman and Cole (1994), previous literature identified 64 strategies to gain compliance from another 
person. Miller, Boster, Roloff, and Seibold (1977) found that in different contexts, different compliance-gaining strategies are more likely to be used. In the case of Couchsurfing and making a hosting request, the nature of the relationship is interpersonal and the request is fairly short term. Miller et al. (1977) found the compliance gaining strategies most likely to be used in an interpersonal, short term request are altruism, positive altercasting, and liking. The altruism compliance-gaining strategy involves requesting a personal favor. Positive altercasting involves the person requesting the favor to point out that a person with good qualities would comply with the request. The liking strategy involves getting the person in the right frame of mind to comply with the request, or in other words, to "butter them up" to agree to the request.

Much research has been done about compliance-gaining for the non-profit sector, both in donations and in volunteer time (e.g. Burger, Reed, DeCesare, Rauner, \& Rozolis, 1999; Reingen, 1978; Simmel \& Berger, 2000). Burger et al. (1999) found the opposite of commonly held ideas about compliance-gaining. This study requested college students volunteer to help at an elementary school carnival, originally asking for two days of service, but quickly stating that the participants would only be needed for one day. This study used the strategy called the "that's-not-all technique," which is commonly referred to as "door in the face" technique (Cialdini, Vincent, Lewis, Catalan, Wheeler, \& Darby, 1975). The "that's-not-all" technique actually gained fewer volunteers than the control group, which involved direct requests. Reingen (1978), however, found that while looking for donations for a nonprofit organization, indirect requests using several compliance-gaining strategies were more effective than making a direct request for donations. Donations were given especially with a strategy involving a small request first, 
such as filling out a survey, and then asking to donate even a small amount of money. Similarly, Simmel and Berger (2000) found in telefundraising for a university, certain strategies reduced the chances of a call recipient agreeing to donate to the university. The strategies leading to this outcome included starting the conversation by asking the call recipient how they are and asking a recipient who declines to donate to the university why they declined. Within market research, Reingen and Kerman (1977) found that call recipients are more likely to agree to participate in the market research survey if the initial request is small, with only five questions. When the researchers requested that the participant take a 35-question survey, they were less likely to agree, even when a monetary incentive was involved. This is an example of "foot in the door" technique (Freedman \& Fraser, 1966).

Beyond the specific strategies of compliance gaining, research is also done about how a request is framed, and how it appeals to the recipient. Studies have found that recipients of requests respond effectively to appeals to reason and open explanation about the request (Golish, 1999; Sullivan, Albrecht, \& Taylor, 1990). Golish (1999) found that undergraduate students would most likely attempt to gain compliance of their graduate instructors by appealing honestly and sincerely to the instructor., Sullivan et al. (1990) found that the most common type of compliance gaining strategy was to appeal to reasoning in organizational compliance-gaining between management and subordinates.

Additionally, some other studies found compliance-gaining appeals are often not focused on reason, and, instead, focused on emotion. Boster, Mitchell, Lapinski, Cooper, Orrego, and Reinke (1999) studied compliance gaining in cases when the receiver of a request is feeling the emotion of guilt. When a request receiver feels guilt, it is most 
effective to use a "positive self-feeling" strategy, while if the receiver is not feeling guilt, it is most effective to make a direct request. In the case of persuading peers to drink alcohol, Wagner and Punyanunt-Carter (2009) found that the most commonly used, and perceived most effective, compliance gaining strategies was the use of "negative selffeeling" in the targets. This strategy focuses on the negative feelings that target would experience if she or he did not drink alcohol.

Facework. Goffman's (1959) dramaturgical approach to interaction introduced the concept of face and facework. According to Goffman (1967) face is "the positive social value a person effectively claims for himself by the line others assume he has taken during a particular contact" (p. 5). During interactions, participants have concerns about maintaining or restoring their own face and the face of the person with which they are interacting, an idea Goffman calls facework. According to Brown and Levinson (1987), participants in a social interaction have two main desires when it comes to maintaining face, or preventing loss of face. The first desire is to maintain one's autonomy, or one's negative face. For example, if someone is asking a favor of another person and wants to maintain the other's negative face, one might phrase the favor, "I don't mean to bother you, but I don't suppose you would lend me some change for coffee." This wording of the favor addresses the other person's independence and ability to decline, if she or he desires, resulting in a smaller likelihood of loss of face. The second desire in facework is to gain social connections and be valued by others, also called one's positive face. In the same scenario, an example that would maintain another's positive face would be, "That latte you have looks extraordinary! Pal, you wouldn't be so kind to lend some change for one of my own, would you?" By addressing the other as a "pal," complementing the 
person's character, and using exaggeration, this statement maintains the receiver's positive face. Politeness theory (Brown \& Levinson, 1987) includes the assumption that within interaction, threats to both positive and negative face can occur. Thus, participants use politeness in order to avoid or minimize these threats. The nature of a host request, involving a traveler requesting a host allow her or him into their home, is a negative face threatening act. Because of this, other research about face threatening acts will be considered, and face theory must be kept in mind when considering what hosts look for within request messages.

Several studies looked at facework and politeness theory within online communication. Although computer mediated communication is often thought to lack a nonverbal communication aspect, several nonverbal aspects within computer mediated communication can communicate a message, such as message response time and the presence or absence of typos and misspelled words (Radford, Radford, Connaway, \& DeAngelis, 2011). Because both typed messages and nonverbal cues are present in computer mediated communication, participants work to maintain their face through their interaction both verbally and nonverbally. Radford et al. (2011), for example, found that librarians and students would correct typing mistakes in order to maintain the image they want portrayed to the other interactant. When tutors were asked to treat students with direct messages, Brummernhenrich and Jucks (2013) found that the tutors were likely to use direct language, but also include more politeness strategies within their messages. It is possible that the tutors perceived the direct messages as face threatening, so they lessened the threat to face by including politeness strategies within their messages. 
When it comes to making a request, the positive and negative face of both interactants can be threatened. For example, when a bystander requests that a smoker refrain from smoking in a public place, and when a smoker asks permission of bystanders to smoke in a public place, Curry (2008) found that making a request for certain behavior puts one's positive face desires above one's negative face desires. Because many participants agreed to the requests of others in a public place, Curry (2008) came to the conclusion that people who agree to requests are more concerned with being seen positively by others, rather than maintaining their independence within the interaction. Because Couchsurfing request messages are a direct request completed through computer mediated communication, it is essential to see what types of facework may lead a host to accept a traveler.

Request messages on Couchsurfing. When a traveler is considering hosts within their destination city, members often send requests to several potential hosts (Bialski, 2011). Because of this, members resort to developing a generic message they can easily copy and paste into several request messages to efficiently request accommodation from multiple potential hosts at once. However, several studies have found that potential hosts respond extremely negatively to requests having been obviously sent to a mass audience (e.g. Liu, 2012; Rosen et al., 2011). These hosts much prefer a message sent specifically to the individual, rather than a large group, stroking a host's positive face by showing their value. Liu (2012) also found that over half of her participants indicated a dislike for last minute requests, and preferred time to prepare for a guest to stay at their home.

In fact, especially in popular tourist destination cities, or for hosts who have had negative experiences in the past, some hosts take special precautions to make sure the 
requests they are accepting have taken the time to get to know them on their Couchsurfing profile (Liu, 2012). Members who have had negative experiences with guests often develop extremely meticulous profiles, including clear expectations for travelers they accommodate. Hosts look for evidence within request messages that the member had thoroughly read through the hosts' profile before submitting a request. Some hosts even require request messages to include a hidden word found within the profile, such as one of Liu's (2012) participants who require request messages to include information about the traveler and for the traveler to write something about Hawaii, a requirement he outlines in his profile. This allows hosts to screen out members who have sent mass requests, and to only consider those surfers who have taken the time to read their profiles.

However, some hosts are much less particular about who they accept upon receiving requests. Rosen et al. (2011) found that Couchsurfing members looking to gain more references to help their reputation within the community are more likely to respond to requests obviously sent to a large group looking for a host. Because their reputation is already established, long-term members with greater reputation within the web community are less likely to accept this type of request. They have less of a need for more positive references.

Summary. The first axiom of Berger and Calbrese's (1975) uncertainty reduction theory explains increases in verbal communication decreases the uncertainty felt among interactants. Although a request message is computer mediated, it can still be considered a verbal message. The third axiom of uncertainty reduction explains that experiencing uncertainty leads to information-seeking behaviors, and the fourth axiom indicates that 
uncertainty is decreased with intimate information. Tidwell and Walther (2002) found that in computer mediated communication, interactants provide more intimate disclosures early in a relationship in order to compensate for the limitations, such as lack of nonverbal communication, within the context of online communication. According to the first, third, and fourth axioms of uncertainty reduction theory and Tidwell and Walther's (2002) findings, if a request message is long and includes a large amount of intimate information, uncertainty will be reduced. However, when the predicted outcome value is taken into consideration, Sunnafrank (1986) would offer different predictions. Again, information seeking leading to a positive predicted outcome value will intensify the relationship, while a negative predicted outcome will do the opposite. Because the original request message is asynchronous in nature, it would be considered the first step in the process of interactive information-seeking to reduce uncertainty (Berger \& Bradac, 1982). However, the nature of the initial request message may not translate as expected between face-to-face and asynchronous online communication. Walther (1992) explains that when constructing a message online, people have more opportunity to focus only on the verbal message sent, and not on the other aspects of interaction, allowing them to present preferable cues about themselves. The ability for online interactants to take more time to construct messages that show a more desired self could affect the ability to reduce uncertainty with interactive information seeking strategies. Trust in another person can be achieved with a reduction in uncertainty (Yoo, 2005), so it should be determined what about a request message contributes to a reduction in uncertainty.

Although Couchsurfing research exists about requests sent to mass audiences, and differences in response rates between well-established and new members, little research 
exists regarding what exactly potential hosts are looking for within a request message. What do they want the message to be about? According to Liu (2012), potential hosts look for request messages making the traveler seem sincere and interesting. Also, Liu (2012) found, although travelers admit their primary motivation for using Couchsurfing is the monetary benefit of staying with a host, they portray their motivations differently in the request message. Travelers tend to appeal to their needs for cultural and emotional experiences within a request, rather than practical benefits. Do potential hosts look for an indication of cultural and emotional needs, since those needs were found to be motivators for hosts to take in travelers? Because so many questions exist about how a request message can communicate information to reduce uncertainty to increase or decrease trust, two research questions are generated regarding this topic:

RQ7: What communicative aspects of request messages increase trust in the sender of the message?

RQ8: What communicative aspects of request messages decrease trust in the sender of the message?

\section{Textual Profile Information}

In addition to photos, references, and the request message, potential hosts have the ability to gain information about a member through other textual information found on the profile. Several profile headings are provided as prompts for members to use text to explain more about themselves. It is possible textual profile information can provide hosts with the information needed to trust or distrust a member. Bialski (2012) explains that the way Couchsurfing members present themselves online is imperative in the development of a surfer-host relationship, because the profile is a source of information 
for the host to gain a sense of familiarity with the traveler online. Dan, a founder of Couchsurfing and a participant in Bialski's (2012) study, emphasized the ability for members to self-disclose within their profiles in order for pairs to assess similarity, or homophily, leading to greater trust.

Self presentation and evaluation of others. Just as how Goffman's (1959) work on self-presentation and evaluation of others is applicable to looking into the use of photos used in an online profile, a great deal of self-presentation goes into choosing what to write in the many sections of a Couchsurfing profile. Prentice, Miller, and Lightdale (1994) distinguish between common-identity and common-bond in-person groups. Common-bond communities are communities with the purpose of facilitating interpersonal relationships, while common-identity communities are more focused on the common topics or tasks of a particular community. Schwammlein and Wodzicki (2012) studied how members present themselves through online profile information within these common-bond and common-identity groups, when the groups are found online. They found that upon creation of an online profile, the members of common-bond web communities presented themselves as individuals, while the members of commonidentity online communities presented themselves, focusing on commonalities within the community. In both groups, members maintained their online profiles in order to uphold their self-presentation

The online profile is a tool often used to acquire additional information about an individual (Courtois, All, \& Vanwynsberghe, 2012; Lampe, Ellison \& Steinfield, 2006). Because online profiles often provide varying types of information, different informationseeking strategies are used to learn more about members from their profiles. Courtois et 
al. (2012) found adolescents often turn to social network profiles for information about offline friends, and acquire information both interactively and passively. For example, a person may inconspicuously view a member's profile to acquire information, or the member may interact with the target directly online to acquire information. When a reduction in uncertainty occurred through profile information-seeking, members were more willing to self-disclose.

After viewing social network site profile, the perceptions people form about others tend to be fairly accurate. Kluemper and Rosen (2009) had judges look at participants' Facebook profiles and evaluate them for intelligence, the Big Five personality traits, and global performance in an occupational setting. Subjects were also tested using the scales and their GPA was collected. Ratings of personality, intelligence, and global performance were consistent among raters and were also consistent with the self-reports provided by subjects of the study. Similarly, Kluemper, Rosen, and Mossholder (2012) found similar results. Participants studied Facebook profiles and rated subjects on job performance, hire-ability, and academic performance, which was consistent in inter rater reliability and with self-ratings of subjects.

Haferkamp and Kramer (2010) found members of social networking sites use the same elements of a profile in self-presentation as they do when evaluating others. They also found many of their participants felt confident in their ability to evaluate others based on profile information, and participants indicated they would be comfortable meeting the person face-to-face after viewing their profile. Within the context of Couchsurfing, "the process of self-presentation online is an important aspect in relational development offline" (Bialski, 2012, p. 13). The online profile serves as a way to 
communicate about oneself and increase the knowledge of one's profile viewers (Bialski, 2012).

Summary. The ability to gain information about a member based on her or his profile items is an example of the uncertainty reduction measure of information-seeking behavior (Berger \& Calbrese, 1975). Because online profiles, in general, allow members to present themselves in a certain way, and allow other members to evaluate based on the profile, other Couchsurfing profile items also need to be considered for the present study. The items available on a Couchsurfing profile allow others to use Ramirez et al. (2002) passive and extractive uncertainty reduction measures. The information provided in these categories is created directly by the user, with a public audience within the Couchsurfing community.

The Couchsurfing organization (2013d) provides tips for members about how to use written text within a profile. The website suggests potential hosts to read the text used by members as an opportunity for them to describe themselves. It is recommended to look for indications of personality and individual perspectives within a profile. The website also suggests using the information provided by the member to find commonalities to build a relationship. All of these recommendations can be achieved through passive or extractive information-seeking strategies by taking time to look at the profile. Sunnafrank (1986) explains that within predicted outcome value theory, not only is uncertainty reduced, but judgments are made about whether or not the interactant desires to escalate the relationship. The perspectives, personality, and amount of similarity found in a CouchSurfing profile can reduce uncertainty about a member, but 
can also give the potential host valuable insight to contribute to the desire to escalate the relationship or maintain or deescalate it.

Overall, it needs to be understood what about profile information leads hosts to trust or distrust another member enough to accept or reject her or him. Are potential hosts looking to languages spoken? Are they interested most in members' personal philosophies? Because other profile information may have an effect on a potential host's ability to trust a member, the following research questions are proposed.

RQ9: What textual profile items increase trust in the creator of an online profile? RQ10: What textual profile items decrease trust in the creator of an online profile?

This chapter reviewed existing literature about trust, uncertainty reduction theory, predicted outcome value theory, Couchsurfing, and other similar computer mediated communication. Ten research questions were posed in order to consider what online communication can lead to trust, especially in the medium of Couchsurfing. The following chapter will outline the methods used to attempt to answer these research questions. 


\section{CHAPTER II}

\section{METHODS}

Previous research about Couchsurfing has suggested that references, request messages, and photographs are website features members rely on when making hosting decisions. The present study looks further into these three features, as well as the other textual profile information to determine how trust is achieved through the communicative aspects of these features. This chapter explains the methods for conducting the current

study. First, a description of the sample and how participants were recruited is explained. Next, procedures for the study, measurements used, and how data were analyzed are described.

The present study seeks to determine how uncertainty is reduced to trust others in a relationship having the potential to move from online to face-to-face. Although the present study is looking to uncertainty reduction to lead to either trusting or distrusting another individual, participants of the study were asked about how essential items were to either trusting or distrusting another member. Items served as an operationalization of potential information that could be found from information-seeking strategies to reduce uncertainty. In other words, the conceptual model of the present study looks to the connection between uncertainty reduction and trust, while the operational model uses items as potential information that could be obtained in order to trust or distrust enough to accept or reject a request. 
The present study is descriptive in nature, seeking to further explore and explain the fairly new phenomena of trust online and Couchsurfing. According to Bhattercherjee (2012) three types of scientific research exist: exploratory, descriptive, and explanatory. Exploratory research often takes place in new areas of research and seeks to gain a better understanding of a phenomenon, such as the magnitude of the phenomenon. Descriptive studies take place when focus is placed on the what, where, and when of a phenomenon. This type of study closely follows the scientific method. Last, explanatory scientific research looks beyond the what, where, and when to explain the why and how of a phenomenon. It looks into the causes and outcomes of the variables within a phenomenon, seeking to predict using the scientific method. Performing a descriptive study about uncertainty reduction and trust building online through the use of Couchsurfing, although not predictive, has merit. Bhattercherjee (2012) explains, "Most academic or doctoral research belongs to the explanatory category, though some amount of exploratory and/or descriptive research may also be needed during initial phases of academic research" (p.6).

Although uncertainty reduction theory has explanatory and predictive value, this study focuses on the ability to use the theory to explain trust building using Couchsurfing. In the case of applying trust and uncertainty reduction theory to an online environment, especially through such an intriguing medium as Couchsurfing, which has very little research done about it, it is necessary to be able to fully describe the phenomenon before researchers are able to predict. For that reason, the present study focuses on describing the phenomenon of trust and uncertainty reduction through the communicative functions of the online medium of Couchsurfing. 


\section{Sample}

A total of 231 members participated in the study. Incomplete surveys and surveys from non-US citizens were discarded, leaving a sample of 216 participants, made up of $65 \%$ males, $34 \%$ females, and one participant did not indicate sex. The mean age of participants was 35.43 years old, with a range in ages from 20 to 70 years old. Sixteen percent of participants indicated they were married and seven percent had children living in the home. All participants had hosted through Couchsurfing in the past, with participants having hosted an average of 34.5 guests, and 22 international guests. Many members also participated in the community as guests, with participants indicating an average of 8.19 times having been a guest through Couchsurfing, and 4.7 times internationally. Interestingly, the average amount of months spent living outside the United States was 40.99 months.

Participants were recruited through the Couchsurfing website using several methods to contact hosts. The main method for recruitment involved the city newsfeeds offering discussions for members of the site affiliated with a city. An invitation to participate was posted on the message boards for the four cities in the United States with the largest populations of Couchsurfing members, including Los Angeles, San Francisco, Denver, and New York (Couchsurfing International, 2013e). These message boards appear to a member from that particular city whenever they log into the website, making the opportunity visible to any member from those cities logging into the website. This strategy was effective in inviting 91,205 Couchsurfing members (Couchsurfing International, 2013e) to participate. 
Two other methods were also used to ensure all United States Couchsurfing hosts had the opportunity to participate. First, a request for participants was posted on a variety of public message boards for Couchsurfing hosts worldwide, including additional location-based message boards and discussion groups about certain topics, such as student Couchsurfing members or advice for hosts. This message board serves as a way for hosts to share stories and pose questions to other hosts. Second, in addition to connecting with the Couchsurfing website, the researcher posted a request for participants on the Reddit Couchsurfing discussion page.

Current Couchsurfing literature is often is written from the European perspective (Bialski, 2011; Cova \& White, 2010; Holwick, 2011; Skog, 2012; Steylaerts \& O’Dubhghaill, 2011; Tran, 2009), and research is lacking in the perspective of Couchsurfers in the United States, especially since the United States is the country with the largest number of Couchsurfing members in the world (Couchsurfing International, 2013c). In order to contribute to gaining a worldwide perspective on the Couchsurfing phenomenon, the present study was limited to only Couchsurfing hosts citizens of the United States. Aside from a lack of research about the United States perspective, another reason for this study to only look into the United States perspective on Couchsurfing was because the potential existed for many confounding variables to affect the validity of the study, especially in such a large, worldwide community. Translating survey items accurately into the native language of Couchsurfing members from around the world was unmanageable. Other confounding variables could be cultural impacts on Couchsurfing practices, such as the unique standards Moroccan Couchsurfing hosts are held to within their culture, with hosts often being criticized because of their behaviors allowing 
strangers into their homes (Buchberger, 2011). Because of the large potential for confounding variables affecting the study, the scope of this particular study was narrowed to only Couchsurfing hosts who were United States citizens. In order to accomplish this goal a clause was included in the informed consent explaining that the research is concerned with the United States Couchsurfing hosts' perspectives. A question was also included within demographic items in the questionnaire about whether or not the participant is a United States citizen. In 15 cases, participants completed the questionnaire but also indicated that she or he was not a United States citizen, and the submission was disregarded.

\section{Procedures}

Because most of the existing literature about Couchsurfing has been accomplished qualitatively, and often with a small sample size, much of the existing literature is not generalizable to the Couchsurfing community as a whole. Although with such a new phenomenon as Couchsurfing it makes practical sense to gain in-depth insight from members within the community, it also may be beneficial to gain more generalizable, quantitative data about use of the website with a larger sample of Couchsurfing members. For example, Tan (2010) observed and interviewed 15 Couchsurfing members about their use of the Couchsurfing profile to build trust and concluded that Couchsurfing members look to profiles in idiosyncratic ways, with no apparent pattern. However, with such a small sample size it is possible no patterns emerged, leading Tan (2010) to believe members look at profiles idiosyncratically, while patterns may become apparent with a larger sample using quantitative means of collecting data. Because of this lack of 
generalizable data, a quantitative approach to this study was taken to determine the decision making of Couchsurfing hosts through use of a questionnaire.

Upon showing interest in participating in the study by clicking on the Select Survey link, participants were brought to an informed consent page. Within the informed consent page members first identified as United States citizens and as an adult of at least 18 years of age. The informed consent also included information about the anonymous nature of online surveys and that participation was voluntary. If a participant agreed to participate she or he moved onto the questionnaire, which asked questions about the decision-making process of hosts using the Couchsurfing website. At the end, a total of eleven demographic and background information questions were asked, including age, marital status, U.S. citizenship, biological sex, and Couchsurfing experience. All procedures were approved by the Institutional Review Board (IRB).

\section{Measurements}

To study the uncertainty reduction and trust building behaviors of members using the Couchsurfing website, a survey was constructed specifically for the present study using several sources of information. First, many items on the survey are based on previous research about Couchsurfing and the use of social network and networking sites in general. Next, some items were added to cover aspects of uncertainty reduction theory and predicted outcome value theory. For example, items within the section testing how Couchsurfing members use photos to reduce uncertainty were developed to test the sixth axiom of uncertainty reduction theory, proposing that similarity between interactants reduces uncertainty (Berger \& Calbrese, 1975). An item included in the survey to test this idea is, "The person in the photo appears to be the same ethnicity as me." To address 
politeness theory and maintaining positive and negative face, two items were added to the Likert-type items about the request message. To maintain the host's negative face, the item, "The message is not demanding and includes phrases such as 'no pressure' or 'it's okay if you are unable to host me'," was included, appealing to the host's autonomy. To maintain the host's positive face, the item, "The message makes me feel good about helping by including phrases like, 'It would be so kind of you to host me'," was included, appealing to the host's need for acceptance and inclusion.

In addition to including items developed by the researcher having to do with Couchsurfing and social network and networking research and aspects of uncertainty reduction and predicted outcome value theories, insight from others was collected to improve the survey. A post was published on the Couchsurfing website's forum for hosts, posing a general question about how hosts use the website in order to make decisions about who to accept and who to reject. The post was effective in receiving 17 responses from active hosts, all with approximately a paragraph of insight about the topic. Some respondents shared entire lists of criteria, while others shared specific stories, and many posts served to interact with previous responses, either questioning or agreeing with previous ideas. Insight from the 17 responses on the Couchsurfing forum for hosts was used in finalizing items on the survey for the present study.

Lastly, the survey items were tested using the think aloud protocol developed by Ericsson and Simon (1980). The think aloud protocol asks participants to verbalize their thought processes during a task. To test the usability of the questionnaire for the present study, two volunteers were used to verbalize their thoughts as they completed the survey. One volunteer was experienced in research methods, survey design, and has done 
research about Couchsurfing in the past. The other volunteer was an experienced Couchsurfing member. Each of the participants completed the survey while verbalizing their thought processes, which made unclear items and problematic wording apparent. Observations from the think aloud protocol were used to finalize directions and items within the survey.

Considering uncertainty reduction in trust building through the use of Couchsurfing, the survey was presented differently to participants based on previous answers. The first question intended to determine which of the four major communicative website features (i.e. photos, references, request message, or other textual profile information) provide the essential information needed to reduce uncertainty and trust another to be willing to accept a member. Participants rank-ordered the four features. Based on participants' answer to the first question, they were presented corresponding questions having to do with the feature they chose as the most essential in gaining information about a member. For example, if a participant ranked the request message as the most essential feature of the site to make decisions, they were prompted to answer Likert-type questions about the aspects of the request message providing information to reduce uncertainty and promote trust, such as presence or absence of misspelled words and whether or not the message appears to be copy and pasted to a mass audience. Participants responded to each item using a Likert-type response with a response of one indicating the item is trivial in providing information needed and a five indicating the item is essential in providing necessary information to encourage trust. All items are operational manifestations of information-seeking behaviors possible on Couchsurfing. 


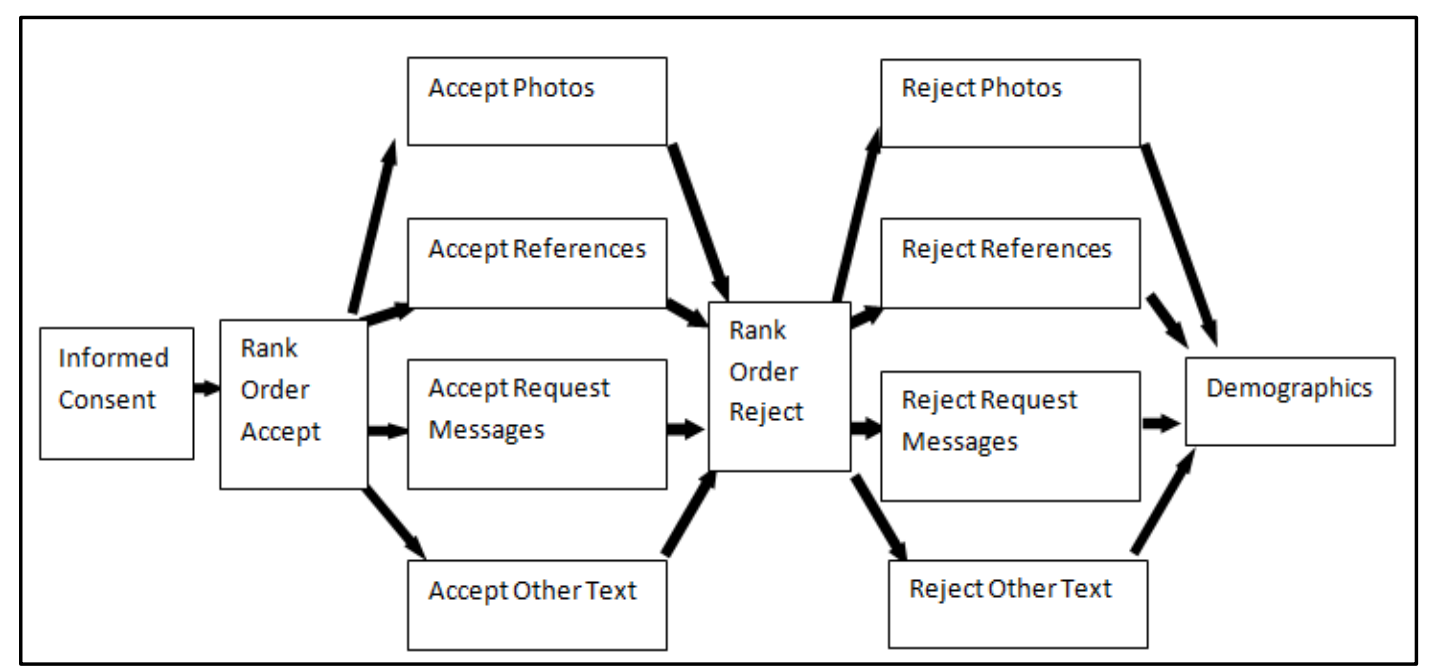

Figure 1: Online Questionnaire Participant Process

After rank ordering the four features in how essential they are to acceptance, and completing the subsequent follow-up questions about that particular feature, participants completed the same survey, but this section asked about what information is essential to distrust and reject a request. The section allowing participants to rank order the four communicative features was presented again, but this time with directions to choose which features provides the necessary information to reject a member. Based on their answer to the rank-order question, participants were brought to a set of questions regarding the feature that was indicated as most essential in providing needed information. Participants, again, completed a Likert-type response to each of the items regarding their use of the item in gaining necessary information for rejection of a request. The final section of the survey inquired about demographic information and Couchsurfing experience. Figure 1 shows a visual representation of the participant process for the online questionnaire. 
Each item on the survey included a corresponding textbox, allowing participants to elaborate on or explain their response to each of the items. Participants also had the opportunity to choose the option "other" within each condition if they thought of an aspect of a feature of the website providing them with information needed, not already included in the survey.

\section{Analysis}

To analyze data, several statistics were run to answer research questions. Chisquare goodness of fit tests were used to compare frequencies of website features having been marked by participants as the most relied upon feature for accepting or rejecting requests. Researchers ran chi-square goodness of fit tests to help answer research questions one and two.

Paired samples $t$-tests were performed to compare means to determine essentiality of items, to contribute to answering all ten research questions. Where significant differences in means appeared, delineation points in data were determined, allowing items to be grouped into levels of essentiality. Additional paired samples $t$-tests were run to confirm the grouping of items was significant throughout.

Because significance can be achieved fairly easily with paired samples $t$-tests, and because some research questions for the present study acquired only a small sample size, coefficient of determination $\left(r^{2}\right)$ was found to determine the effect size (Reinard, 2008). Larger effect sizes explained that the significant differences in means found using paired samples $t$-tests were, indeed, meaningful.

Overall, through several participant recruitment methods, participants completed an online questionnaire. The questionnaire allowed participants to experience an 
individualized questionnaire, depending on their answers to questions throughout. Data was analyzed through several methods. The following chapter explains the results of the online questionnaire. 


\section{CHAPTER III}

\section{RESULTS}

The previous chapter explained details about the sample, recruitment methods, procedures, measurements, and data analysis procedures. The online questionnaire circulated through the Couchsurfing community was effective in receiving 216 usable responses. Data were analyzed using chi-square goodness of fit tests and paired samples $t$-tests, and coefficient of determination was used to calculate effect sizes to confirm that significant results were meaningful. Both quantitative and qualitative data were collected and analyzed. The current chapter, now, looks to the quantitative and qualitative results to research questions. Quantitative results will be explained before qualitative results are, then, considered.

\section{Quantitative Results}

\section{Research Questions 1 and 2}

Research question one was developed to determine what information found online is most likely to be used to reduce uncertainty about a person seeking a host. Participants were asked to rank order the four communicative features of an online Couchsurfing interaction to the extent they rely on each of the features for information when making a hosting decision. Upon observing the initial frequency distributions of items ranked as most important to the decision-making process, 93 participants ranked the request first, 23 participants ranked the photos first, 84 participants ranked references first and 31 
participants ranked other textual profile information first. A chi-square goodness of fit test was calculated comparing the frequencies of each website feature being ranked as the most used feature. Significant deviation from chance was found in the chi-square goodness of fit test $\left(\chi^{2}(3)=66.03, p<0.001\right)$, meaning that frequencies are distributed differently from chance. This can be seen in the high frequencies for the request message and references and relatively lower frequencies for other textual profile information and photos.

To expand on the chi-square goodness of fit test, means of rank-ordered responses were also considered. Because participants provided information with rank-ordered responses, with one being most important and 4 being least important, the means of the four items were ordered from smallest to largest. The smallest mean, then is the most essential feature, and the highest mean is the least essential website feature. Preliminary observations showed the item with the highest mean, or the feature that is least important in the decision-making processes of hosts, is the photo, with a mean score of $2.91(\mathrm{sd}=$ 1.0. $n=216)$. The item identified as the most important to trust another individual is the request message $($ mean $=1.97, \mathrm{sd}=1.03, n=216)$, and the item identified as the next most important is the references found on the profile (mean $=2.05, \mathrm{sd}=1.05, n=216$ ). The features ranked as the two least important were the other textual profile information $($ mean $=2.81, \mathrm{sd}=1.04, \mathrm{n}=216)$ and the photos $($ mean $=2.91, \mathrm{sd}=1.00, \mathrm{n}=216)$.

Paired samples $t$-tests were calculated to compare the mean rank-ordered responses for all four website features. No significant difference was found between the request message and the references feature $(t=-0.83, p=0.41)$, the top two rated means. However, between the references and other profile information (mean $=2.81, \mathrm{sd}=1.04, n$ 
$=216)$ communicative website features, a significant difference in means was found $(t=-$ 6.872, $p<0.001$ ), with a coefficient of determination showing the difference accounting for $18 \%$ of the variance. To also determine if a significant difference exists between the request message and the other profile information, a paired samples $t$-test was performed on the two items, and a significant difference was evident between the first and third rated website features $(t=-7.49, p<0.001)$, with an effect size of $21 \%$ of the variance. A significant difference did not exist between the third and fourth rated items, other profile information and photos $(t=-1.02, p=0.311)$.

To answer research question two, participants' responses to another rank order question were used. These items covered what website features provide the needed information to reject a request from a member. Initial observations of frequency distributions of items ranked as most important to the decision-making process found 73 participants ranked the request messages as first, 14 participants ranked the photos as first, 64 participants ranked references as first and 21 participants ranked other textual profile information as first. A chi-square goodness of fit test was calculated comparing the frequencies of each website feature being ranked as the most used feature when rejecting a request. Significant deviation from chance was found in the chi-square goodness of fit test $\left(\chi^{2}(3)=62.01, p<0.001\right)$, meaning that frequencies are distributed differently from chance. This can be seen in the high frequencies for the request message and references and rather low frequencies for other textual profile information and photos.

Like with research question one, means of rank-ordered responses were also considered for this research question. Similar results were found. Unlike research 
question one, references $($ mean $=1.94, \mathrm{sd}=0.94, n=161)$ are relied on more heavily than request messages $($ mean $=1.99, \mathrm{sd}=1.10, n=161)$; however the difference is not of statistical significance $(t=-0.33, p=.739)$. Of significance, however, is the difference between the request message and other profile information $(n=154)$, which showed a mean of 2.61 and standard deviation of $0.94(t=-5.36, p<.001)$, with an effect size of 16 percent. In using paired samples $t$-test, comparing the references mean to the other profile elements mean, a statistically significant difference was found $(t=-5.76, p<.001)$, with a medium effect size explaining 18 percent of the variance. The difference between the means of other profile information and the photographs (mean $=3.11, \mathrm{sd}=0.99, n=161)$ was also of statistical significance $(t=-5.12, p<0.001)$, with 15 percent of the variance accounted for by this difference. Overall, this creates three distinct groups of essential information when rejecting a request on Couchsurfing, created by statistically significant differences in mean causing delineation points in the data. Of highest essentiality are both the references and request message website features. The second most essential information comes from other textual profiles information. Last, the least essential information comes from photographs on the profile.

Through the use of two statistical tests, chi-square goodness of fit tests and paired samples $t$ - tests, similar profiles emerged. These tests determined that for both accepting and rejecting request messages, Couchsurfing members tend to rely most heavily on the original request message and the references found on the profile.

\section{Research Questions 3 and 4}

Research questions three and four had to do with the communicative aspects of photos providing information needed to trust or distrust a member. When it came to 
accepting, or trusting a member, participants provided Likert-type answers about the essentiality of each of the 16 items for trusting a member, and Table 1 displays means for items. Upon initial observation, it is apparent that the presence of at least one photo on a member's profile is the most essential communicative aspect influencing decisions to accept a request $($ mean $=1.37, \mathrm{sd}=1.17, n=27)$. The items with the two lowest means both had to do with the member's similarity or difference in ethnicity to the subject of the photo, with different ethnicity $($ mean $=1.59, \mathrm{sd}=1.18, n=27)$ being only a slightly higher mean than the same ethnicity (mean $=1.50, \mathrm{sd}=1.07, n=28)$.

As seen in Table 2, several paired samples $t$-tests were calculated to compare the means of each of the items, in order from highest to lowest mean. A significant difference $(t=2.185, p=0.038)$ between the fifth and sixth highest ranked items was apparent, with $16 \%$ of the variance explained by this difference, while a significant difference between any other of the top five highest ranked items was not apparent. Upon looking further into the significance of the separation among the top five highest ranked items with the item "Photo showed evidence of previous travel", significant differences were found in all means, with effect sizes ranging from 16 percent to 48 percent of the variance explained, creating a delineation point between the fifth and sixth highest ranked means, shown in Table 2a. This delineation point creates a grouping of the most significantly essential items to trust members, including the presence of at least one photo, no photos provided, the photo shows the member's face clearly, the photo shows aspects of personality, and the multiple photos are provided.

When participants indicated they would reject based on information found from viewing a photo, the 16 items were also used to determine what information affects trust 
in another member, and means are shown in Table 3. Although the frequency of participants responding that photographs were the most important factor in rejecting requests was 14, participant dropout resulted in only nine participants responding to items about rejecting based on photographs. Rejecting requests based on photographs had a lack of substantial findings, with an extremely small sampl. Although statistical significance was achieved in differences in means, results should be accepted with caution. The item measuring when no photos are presented on a profile had a much higher mean $($ mean $=4.67, \mathrm{sd}=0.50, n=9)$ than even the second highest rated item, scoring almost a full point above that item, "presence of at least one photo on profile" (mean $=3.78, \mathrm{sd}=0.97, n=9)$. Preliminary observations showed that many of the items tested reported means under the mid-point of the Likert-type scale, under the score of three. Of the 16 items, only four showed means of three or higher.

Paired samples $t$-tests were performed on the means of all items in descending order, as seen in Table 4. The highest-ranked item, a profile containing no photos, showed a mean response of 4.67 , resulting in a statistically significant difference from the next highest rated item of the profile containing one photo with a mean of $3.78(t=2.53$, $p=0.035)$. The effect size for this relationship was high at 44 percent. No other pairs within using photos to reject requests were determined to be of significant difference.

\section{Research Questions 5 and 6}

Research questions five and six were developed to determine the information found in references influencing trust and leading to acceptance or rejection. As seen in Table 5, of the eleven items studied within the use of references for acceptance of 
requests, the highest rated item was the presence of references from past hosts, while the lowest rated item was that references discuss activities the respondent dislikes.

Of the rank-ordered means of items, significantly different pairs were found on several occasions, as seen in Table 6. First, when accepting a member based on references, the item with the highest mean of $4.23(\mathrm{sd}=1.03, n=53)$ was references written by past hosts, clearly approached statistical significance in mean difference from the next highest mean $(t=2.0, p=0.051)$. However, although approaching statistical significance, this finding was not considered a clear delineation point in the data of essentiality of reference information.

The first pair reaching significance occurred between the seventh and eighth highest means, items measuring the essentiality of the presence of one or more negative references and references discussing activities the respondent also likes. No statistical significance was found in the differences among the top seven pairs. Statistical significance was found between the seventh and eighth highest means $(t=2.59, p=$ $0.01)$, with means of $3.48(\mathrm{sd}=1.31, n=52)$ and $2.89(\mathrm{sd}=1.37, n=53)$, respectively. The effect size for the relationship proved to be moderate in strength $\left(r^{2}=0.12\right)$. To further consider the significance of the relationship between the seventh and eighth highest means, the first through seventh ranked means were also compared to the eight highest mean, which is shown in Table 6a. All pairs were statistically significant, showing significance levels of between $p<.001$ to $p=0.01$. Effect sizes for these pairs ranged from the medium effect size of $r^{2}=0.12$ to a large effect explaining that references come from past hosts, approaches significance to be the most essential item for members to accept a request, although it has a small effect size. Other than the first item 
approaching significant difference in essentiality, another group of important items emerged, including the top rated means compared to the eighth highest ranked items, creating a delineation point and a grouping of important items.

A third significant pairing occurred between the ninth and tenth highest rated means, items measuring if references discuss whether members fit in with the community (mean $=2.87, \mathrm{sd}=1.43, n=53)$ or if references are coming from members met at Couchsurfing community events ( mean $=2.32, \mathrm{sd}=1.01, n=53$ ). Table $6 \mathrm{~b}$ displays a significant difference was found in comparing the means of these two items with paired samples $t$-test $(t=2.70, p=0.01)$, with a medium effect size of $r^{2}=0.12$. Overall, this shows that the most essential group includes references coming from past hosts, positive references, discussion of personality, confirmation of profile information, written by a past guest, discussion of cleanliness, and even information found in negative references. The last group of information was found to be the least essential, including references coming from members met at local events and references discussion activities the participant dislikes.

Research question six also considered the role of references, but focused on the use of references when rejecting a request. Means for items ranged from 2.16 to 4.33 , with the highest ranked item indicating that the references were written by past hosts, and the lowest ranked item was that the references discussed activities the member likes, seen in Table 7. Paired samples $t$-tests were completed on each of the pairs, with means in descending order, displayed in Table 8. The first significant difference in means $(t=2.78$, $p=0.01$ ) occurred in comparing the seventh and eighth items, having to do with the presence of all positive references ( mean $=3.20, \mathrm{sd}=1.44, n=51$ ) and evidence that the 
member fits in well with the community (mean $=2.60, \mathrm{sd}=1.39, n=50)$. The effect size for this relationship was 14 percent of the variance. To confirm that this delineation point is significant for all items with higher means, the top seven items were compared to the eighth item using paired samples $t$-tests, and Table 8a illustrates confirmation of the delineation point. All items showed a significant difference in means, ranging from $p<$ 0.001 to $p=0.01$, with effect sizes ranging from moderate at $r^{2}=0.14$ to very high at $r^{2}=$ 0.57. These significance levels confirm the delineation point between the seventh and eighth highest rated means, grouping seven items into a group of most essential information, including that references comes from a past host, the presence of negative references, references are written from a past guest, references discuss the cleanliness of the member, references discuss the member's personality, references are consistent with other profile information, and that all references were rated as positive. The items found to be of trivial essentiality included that the references discuss how the member fits in with the Couchsurfing community, come from member met at local events, discuss activities the participant dislikes, and the activities a member likes.

\section{Research Questions 7 and 8}

Research questions seven and eight used 15 items to determine what information found in a request message leads to acceptance or rejection, with means displayed in Table 9. Upon preliminary observation, when accepting a request based on the request message, four of the fifteen items were rated as 3.0 or higher, showing that more items suggested were not even considered somewhat essential by most participants.

Of all means, paired samples $t$-tests were performed to determine significant differences in means, found in Table 10. A significant difference in means $(t=3.09, p=$ 
0.003 ) with an effect size of $r^{2}=0.12$ was found using a paired samples $t$-test between the fourth and fifth items with the highest means of $4.01(\mathrm{sd}=0.97, n=141)$ and $3.72(\mathrm{sd}$ $=1.21, n=142$ ), respectively. To confirm the delineation point in data, all other higher means were compared to the fifth ranked item, "The message gave me time to prepare for the guest." All paired samples $t$-tests showed a significant difference $(p<0.001, p=$ 0.001, $p=0.001, p=0.003$ ) in means among each of the highest means and the fifth ranked mean $(t=4.96,3.70,3.42$, and 3.09), shown in Table 10a. Effect sizes for this data ranged from $r^{2}=0.12$ to $r^{2}=0.25$. This creates a delineation point in data about how request messages are used when accepting a request. The items of most essentiality to accepting a request include that the message is personalized, focuses on more than obtaining a free place to stay, mentions the host's profile information, and discusses why the particular host is desired.

Research question eight looked to determine what communicative aspects of a request message are most informative when rejecting a request, and means for items are illustrated on Table 11. Interestingly, upon initial observation, it appeared that most items were rated near the midpoint of data, with means ranging from 2.12 to 3.85 , a small range compared to other sets of data in this study. When denying a request and means to items are ordered in ascending order, no significant difference was found in any of the items' means after performing paired samples $t$-tests, displayed on Table 12. These observations signify that when rejecting a request based on the request message, no one type of information or group of information was of more essentiality than others. In fact, it appears that all items were generally of moderate essentiality, with no significant difference among communicative aspects of the message. 


\section{Research Questions 9 and 10}

The last set of research questions used paired samples $t$-tests and coefficient of determination to consider differences in means of eight items providing other textual information found in a profile leading to acceptance or rejection. Table 13 displays means for each item. When accepting members' requests, preliminary observation showed a large range in means, ranging from 1.81 to 3.94 , but with only two means above 3.0. Table 14 shows after arranging means in order from highest to lowest, results indicated that the highest-ranked item, the personal description found on the profile, which showed a mean score of $3.94(\mathrm{sd}=0.92, n=34)$, was statistically significantly different from the second highest mean score of $3.38(\mathrm{sd}=1.41, n=34)$ for the General Information section of a profile $(t=2.41, p=0.022)$, with an effect size of $r^{2}=0.11$.

A second significant difference $(t=2.05, p=.049)$, explored in Table 14a occurred between the two smallest means, the community connections elements of the profile $($ mean $=2.32, \mathrm{sd}=1.09, \mathrm{n}=34)$ and the locations traveled $($ mean $=1.81, \mathrm{sd}=$ $0.86, n=32$ ). The effect size for this pair was $r^{2}=0.12$. These observations show an essentiality of information found in the personal description on a profile and trivial essentiality about locations the member has traveled. All other items make up a group of items moderately essential for information seeking about a member when accepting a request. These profile elements include general information, philosophical information, Couchsurfing participation, interests, Teach Learn Share, and connections in the Couchsurfing community. 
To consider research question ten, when denying a request, other textual profile elements were put in mean order for analysis, shown in Table 15. Preliminary observations showed a range in means from 1.83 to 3.79 , with only two means above 3.0. Paired samples $t$-tests showed no significant difference among any of the eight items analyzed. This indicates that, even with a fairly wide range of means for different items (Table 16), no item was significantly more or less essential than other items to distrust another member enough to deny a request based on textual profile information.

\section{Qualitative Results}

In addition to what was provided by quantitative data, participants were also given the opportunity to qualitatively explain their responses to survey items in text boxes throughout the questionnaire. Because this questionnaire was developed for the purpose of this study and had not been previously tested, participants were given the opportunity to add insight or clarify responses throughout. It is possible that Couchsurfing members could individually identify more aspects of profile features that provide needed information to reduce uncertainty that the researcher had not previously considered. It is also possible that Couchsurfing hosts were able to more fully explain their answers to questionnaire items with more insight. Therefore, in order to grasp the process of trust-building by Couchsurfing hosts in a way that quantitative data could not, text boxes were provided after each survey item to allow participants to explain or elaborate. These open-ended responses provide further insight into the study to allow for greater understanding of uncertainty reduction through information-seeking in order to build trust on the Couchsurfing website. 
All qualitative responses were unitized according to predetermined rules, including that units would be mutually exclusive and each instance, or phrase, was counted as a unit, even within the same text entry. All units were considered and placed in relevant categories that emerged based on reviewing all qualitative responses. Within each research question, several themes became apparent that were developed based on reoccurring, overarching occurrences in units.

\section{Research Questions 1 and 2}

When given the opportunity to elaborate on rank-order responses to answer research questions one and two, participants provided valuable insight about why certain website features were determined to be of most use when deciding to trust or distrust another member.

Consistent with previous quantitative analysis, qualitative data confirmed that the references and request message were of importance when making hosting decisions. Participants who chose references as one of their most used sources of information commented that references are trusted because they come from a third party source. The fact that members have no control over references on their profile and cannot remove or edit references left about them led members to trust based on references. It was also mentioned that, although members can delete their profile at any time and start with a new profile if they have developed a bad reputation on the website, the presence of positive references takes time and experience to obtain. One participant stated, "References are harder to fake. Everything else on the list can be fabricated easily, but to fabricate a reference would take several additional steps.” 
Also of interest is a theme that emerged when participants were given the opportunity to elaborate on the rank-order question about accepting and rejecting requests. Several participants emphasized the ability to ascertain whether or not the potential guest has an understanding of the Couchsurfing philosophy or spirit. Whether through references, the request message, photos, or textual profile information, this idea came up several times. One participant, who indicated that the request message was of most importance in accepting, elaborated, "If a person sends a very good message that includes information from your profile and explains their personality, they are very likely to be a good surfer who understands the spirit of CS." Another participant ranked references as most used to accept a request and commented, "The more references they have, the more likely they're active and understand the community." Participants commented that with whichever feature they tend to rely on, they are often looking for someone who wants more than just a free place to stay, and instead wants a true cultural exchange.

Although some comments surrounded the idea of trust and safety on the site, many participants did not focus on this. Instead, participants commented that they are open to taking a chance and hosting people, for example, without references. One participant even commented that he accepts almost every request he receives. Instead of focusing on safety, many participants explained that they use the website features to determine whether or not hosting the person would be a pleasant experience. One participant put it well when she stated, "Personally, I'm apt to trust most people off of the site enough to let them into my home. What I'm really screening for is whether I think 
I'll *enjoy* having somebody in my home. I've never had Couchsurfers steal, or break my trust. I have, however, met plenty of Couchsurfers who were fantastically irritating."

\section{Research Questions 3 and 4}

Although very few participants chose the use of photographs as the most relied upon website feature, the comments provided by participants were useful in understanding the use of photos.

When accepting, quantitative data suggested that several items were of most essentiality to trust another member. The highest ranked item, that the profile had the presence of at least one photo, also was covered in several comments by participants. One participant commented, "If the person has not posted a photo I'm pretty unlikely to accept," while another wrote, "I would never accept the request of someone without a picture." Some participants emphasized that having a complete profile, including at least one photo, showed respect for the Couchsurfing community and processes. Other participants, however, focused on the presence of a photo for practical reasons, such as being able to identify a guest at the predetermined public meeting place, or comparing textual information to what is visible in a photo. Similarly, participants discussed the importance of having a clear photo of the potential guest's face. One participant offered, "Seeing the face engenders trust. It makes me feel that it is less likely to be a fake photo."

When rejecting based on communicative aspects of photographs, quantitative data suggested that the single most essential element for rejecting is if no photo is displayed on the profile. This was also a strong theme in qualitative responses. The presence of a photo seemed to be more about building trust in safety of the member, rather than understanding how pleasant of a hosting experience it would be. One participant 
commented about no photo being present, "Get real. I could be hosting the Most Wanted murderer in the South East."

The photo showing evidence of personality was also a highly rated item of essentiality in accepting requests based on photos. When including additional qualitative information about personality, participants included several personality factors they look for when accepting a request. A major theme in personality was evidence of happiness or a positive attitude. Another personality trait that was mentioned several times was that the person appears to be open-minded or adventurous. Several comments included phrases such as, "open to trying new things," or, "keen to discover." When rejecting someone based on photos, participants often pointed to evidence of excessive partying by, for example, including photos taking place at a bar. On participant explained, "If it's a typical picture that could be used for checking in at a bar on Facebook (Look at me: I am FUN!), I immediately lose interest."

\section{Research Questions 5 and 6}

Qualitative data about references also tends to focus on the ability to judge the safety of hosting a particular member. Members emphasize throughout the reliance on references because they cannot by altered by members, both for safety and for ensuring a pleasant hosting experience. One participant stated:

"Everything other than references is something the person can control him or herself. If he or she is a bad person (thief, rapist, serial murderer... or somewhat less extreme: poor people skills, just looking for a place to crash...) she or he can alter the tone of all the information that is being entered by the person. References 
are generally from people who know the person and usually give honest feedback about her or him, therefore I trust the references a lot more."

When looking to accept or reject a request, a strong emphasis is placed on the valence of the references. Quantitatively, one of the highest ranked items when accepting a request is that the member has all positive references, while when rejecting a request one of the highest rated items was the presence of negative references on the profile. These responses were further explained qualitatively. Neutral and negative references are taken very seriously in the Couchsurfing community. Several comments about the valence of the references explained that if a neutral or negative reference is present it would result in an automatic rejection of a request. Others explained that a neutral or negative reference would not necessarily lead to a rejection, but would be carefully scrutinized to be better understood. Participants often explained that they understand that not everyone always gets along, and they would be willing to consider someone with one negative reference. However, if more than one negative reference is present, it often leads to rejection. One participant explained:

"If someone has one negative review, it might be a difference in personalities, but if there is more than one or two, it might be an indicator of a generally disagreeable character... it is obvious it is beyond disharmonious personal chemistry."

When receiving a request from a Couchsurfing member with a negative reference, participants explained they would seek a better understanding for the disagreement. Participants claimed they would be willing to look past certain negative references, such a failure to respond to an online request in the past. Some participants also explained they 
would be inclined to view the profile of the person leaving the negative reference to determine his or her credibility in the community, or even ask the member directly about the incident.

An emerging theme having to do with the valence of references considered the rarity and severity of negative references. Several participants explained that it is uncommon to find members with negative references, and that when a negative reference is left, it often is a result of an extremely negative experience, rather than a mildly unpleasant experience. One participant explained:

"Most CSers who send requests seem to have only positive reviews as people tend to be nice. If there is even one negative review, I think seriously as to why because it seems to be an unspoken rule that you'd only leave a negative review if it was a truly bad experience."

Although sometimes excusable after further investigation, participants explained that negative references are a cause for concern. One participant explained that the presence of negative references is, "so rare it's a huuuuuge red flag."

Like with photos, desirable and undesirable personality traits were also discussed as important to accepting and rejecting requests from Couchsurfing members. Personality traits detected in photos were similar to personality traits detected in references for accepting requests. A positive attitude and a sense of adventure or outgoing demeanor were referenced several times by participants. Different from photos, however, is the ability to ascertain other positive personality traits such as respect and appreciation or gratefulness toward past hosts. Several participants referenced these personality traits that may become obvious only to hosts, rather than general personality portrayed in a public 
setting. As for personality traits that lead to rejection of a request, selfishness and intolerance for others was mentioned several times by participants.

\section{Research Questions 7 and 8}

Quantitative results showed the request message sent was relied upon heavily both when accepting and when rejecting a request. Qualitative responses clarified and elaborated on quantitative data discussing essential communicative aspects of request messages.

Of major quantitative significance and highly discussed in text boxes provided was the essentiality of request messages being personalized and perceived as being sent to only one potential host. Participants commented that it is essential for a prospective guest to address the requested host by name. Another reoccurring comment suggested that participants prefer potential guests include information about why they chose to request lodging from that particular host. Participants continually explained their desire for requests that express interest in the particular host in order to have a personal connection. One participant offered insightful explanation when she stated, "I have to feel like the person read my profile and is sending me a request because they have an interest in meeting me, not just to get a free place to crash. I have to feel that I'm someone they would want to meet even if I didn't have a couch to offer."

When it comes to personalized messages, participants explain special precautions they take in order to ensure requesting guests are taking an interest in them. Many participants pointed to a particular secret word found in their profiles that must be reported or hidden question in profiles that must be answered in the request message. When requesting guests include this information, hosts know that their profiles were read 
thoroughly. On the other hand, if the secret word or answer is not included in the request message, the host might be alerted that the potential guest did not take the time to carefully consider a host, and may have even copy and pasted a request message to several hosts. One participant explained the idea behind referencing a particular word in the request message when explained, "Like many other CSers do to ensure that surfers are reading the entire profile and truly thinking about whether it would be a good fit, I ask surfers to reference a particular word in their request." Another participant explained an interesting question asked in the profile, "In my profile I write that I enjoy cooking, and would love to learn new recipes from surfers - I ask them to detail some good things they would be willing to teach me during their stay."

\section{Research Question 9 and 10}

The final category, having to do with other textual information provided in the profile, showed a small amount of emphasis placed on that information during hosts' decision-making processes in quantitative results.

One item, the vouched and verification status of members, was reported by several people as being of essentiality when making decisions based on other profile information. This item was not considered as part of quantitative data, but several participants commented that they rely on whether members have been vouched for or verified. One participant explained, "Location verified Couchsurfing members whom have had their profile identity checked are usually guaranteed couch space with us." Some participants explained that being vouched for or verified by the organization are not essential, but when requests are received by these members they are given preference. 
Although the personal description was rated as the most essential part of the profile when gaining information to accept a request, participants did not go into much detail about what they look for within the personal description. Although some provided some examples of desirable traits, such as hardworking, having similar interests as the prospective host, and willing to both host and travel using Couchsurfing, no major themes emerged. The only reoccurring comment about textual profile elements was that members look to the thoroughness of the information. Participants indicated that they appreciate when a Couchsurfing member has taken the time to fill out all parts of the profile. One participant explained their expectation for profile information, "The biggest factor for me is the time they have put into their profile and the quality of the answers given." Another participant explained his reasoning for expecting members to spend time filling out their profiles when he stated, "time investment is the most important thing to me, since I'll be investing time in them."

Overall, both quantitative and qualitative data provided interesting results. Quantitative data was able to explain which website features are relied upon most heavily when making hosting decisions and which communicative items within each feature are most essential to trust another member. Qualitative findings clarified and added to quantitative results. The next chapter will discuss the implications of these findings, as well as the limitations to the current study and future directions for similar research. 


\section{CHAPTER IV \\ DISCUSSION}

The previous chapter outlined the quantitative and qualitative results of the present study. The current chapter will discuss those findings. First, a synthesis of findings is presented. Next, implications, limitations, and future directions are discussed before finally concluding.

\section{Synthesis of Findings}

\section{Website Features}

Research questions one and two asked what information found online contributes to either trusting or distrusting another individual. In order to contribute to answering these questions, Couchsurfing hosts were asked to rank order the communicative website features by their reliance on the information provided in each feature. Both chi-square goodness of fit tests and paired samples $t$-tests showed a definite reliance on information found in members' request messages and references, while a lack of reliance placed on information found in photos and other textual profile information.

Because each of the website features provide different information presented to different audiences, the nature of each of the features might point to some more general understandings about trust online. Request messages, specifically, experienced a much higher frequency count of rankings of most important than other website features. These request messages are sent directly from a prospective guest to a prospective host and are 
not visible to the public. The messages are also sent with the direct purpose of obtaining compliance from another member. This provides an opportunity for prospective guests to present themselves one-on-one and allows prospective hosts to make judgments about the person based on this direct message. Similarly, references found on a profile provide interesting insight about the member because the information comes from a third party source. This information could be critical in determining trust because it does not rely on direct self-presentation online, but rather includes insight from an uninvolved member of the community.

Conversely, photos and other textual profile information are created by the member and are put on display for the entire web community. Both of these items experienced low frequencies of being chosen as the most informative website when making hosting decisions both to accept and reject members' requests. This is a significant finding because it provides insight into what information is not trusted as much online. It seems that self-presentation attempts intended for a large audience, such as photos and text found in a profile, are not relied on heavily when determining trust of another individual. The nature of photos and textual profile information differentiate these features from the two features most relied on when making hosting decisions because they are displayed for the entire CouchSurfing community. Qualitative responses solidify the idea that self-presentation to the entire Couchsurfing community is not relied on heavily by hosts when making decisions. Hosts prefer to look to information coming directly to them from the prospective guest or to information provided by a third party source. 


\section{Photos}

In quantitative findings, when accepting requests based on photos, five aspects of photos were rated as most essential. These five items included the profile having the presence of at least one photo, no photos present on the profile, the photo showing the member's face clearly, the photo showing an aspect of the member's personality, and multiple photos found on the website. When rejecting a request from a member based on photos, the most significant item was when no photo was present on the profile, although findings should be accepted with caution because of the small sample. Qualitative data explained that photos are often used as a safety precaution to be able to check the identity of prospective guests, and many members commented that they would be unwilling to host a member without a photo at all. Overall, it seems that when Couchsurfing hosts are looking to photos to make hosting decisions they are more focused on the presence, absence and number of photos, rather than what is included or portrayed in the photo. Information one could ascertain from a photo, such as biological sex, ethnicity, and attractiveness were not highly rated. In qualitative responses they were also disregarded.

\section{References}

When it comes to making hosting decisions based on references, a significant finding was that the valence of reference seemed to have great essentiality in information-seeking. Not only were items that discussed the valence of references rated as essential in quantitative responses for both accepting and rejecting requests, but were also explained often in qualitative responses. Participants explained that negative references are somewhat rare in the Couchsurfing community, so when a negative reference is present on a profile it is cause for immediate consideration. Some 
participants explained they would be unlikely to host someone with a negative reference, while others said they would consider hosting a guest with one negative reference, but rarely more. In this case, members tend to participate in some more extractive information-seeking behaviors in order to reduce their uncertainty about the other member.

In both accepting and rejecting requests based on references, a high essentiality was placed on references from past hosts, rather than references coming from past guests or other members met at local events. It could be that members encountering the potential guest in situations where they are the guest or another attendee at a get-together would not evaluate the member based on the same criteria another host would be inclined to. Hosts are looking for a third party opinion about the person, but most essentially, the opinion from a third party source that would have the same relationship with the member as the potential host. Also, when potential hosts are looking to references for information about personality they are looking for information about how respectful and appreciative the member is. This is information that would likely come from a past host, rather than a past guest or event attendee.

\section{Request Message}

Participants expressed great reliance on the request message when making decisions, showing a high frequency count of participants who rated it as their most used website feature, and a high mean overall compared to other website features. Within the request message, several significant findings were uncovered. First, when accepting a request based on the request message, hosts are looking for the message to be personalized to them. This is shown in the aspects of the message that were rated as most 
essential, including that the message was personalized, focused on more than a free place to stay, mentioned information found in the potential host's profile, and discusses why that particular host was requested. All of these items show that the member had taken the time to read and carefully consider the person as a host before writing the request message. In qualitative data, it was discovered that hosts often look for potential guests to mention specific profile information, and some even have requirements that guests mention certain secret words or answer a particular question in their request message to prove they took the time to read the profile.

Although not significantly different from other aspects of the request message, the item with the highest mean when asking participants what about messages is essential for a rejection was that the message seemed to focus on acquiring a free place for lodging. The opposite was true, of significance, in hosts who use messages for accepting requests, showing a large essentiality for an understanding that the exchange would not only be about a free place to stay. This was also mentioned in qualitative responses throughout the questionnaire. Participants explained that lodging for free is not within the spirit or understanding of the community. Instead, members emphasized the ability to learn from one another and participate in cultural exchange.

\section{Other Textual Profile Elements}

Although it received a fairly small frequency of ratings for most used website feature when making decisions, and consequently received a low mean overall, some significant findings were uncovered about other textual profile information. Quantitative data suggested that the most essential aspect of profile information is the personal 
description, although qualitative data revealed that what mattered most about profile information was that each section is complete and thorough.

Also, several participants explained the importance of members having their identities verified through the Couchsurfing organization and having been vouched for. Although these items were determined to be trivial in past research (Tran, 2009; Bialski, 2011), comments from participants in this study show that some members do place reliance on vouched and verified statuses. Both Tran (2009) and Bialski (2011) collected data about Couchsurfing members' use of the website qualitatively. The larger sample size considered in the present study might has uncovered that members do, indeed, look to vouch and verification status of members when making hosting decisions, a finding that was not possible with looking to a small sample qualitatively.

\section{Implications}

Although the present study looks specifically into how Couchsurfing members determine whether or not to trust another member based on website features and information, the findings in this study have implications for a much broader understanding of trust to contribute to the field of communication in general. Trust, a concept studied since ancient philosophers looked into persuasive techniques, is facing a revolution when it comes to understanding the ability to trust others in a mediated context. Through considering uncertainty reduction strategies, such as informationseeking, while keeping the predicted outcome in mind, such as accepting or rejecting a Couchsurfing request, it is possible for researchers to look further into the concept of trust online. Through general and specific findings about the use of Couchsurfing to build trust, several implications for these findings were determined. 
The present study considered trust online within one domain, Couchsurfing. However, findings form the present study could likely have implications for many other websites or domains online, far beyond the scope of Couchsurfing. Other social network and networking sites, for example, might benefit from these findings about how to achieve trust online. Businesses with a large online presence may find these results of particular interest to learn how to nurture a trusting relationship with clients online. Websites themselves are methods of self-presentation for a company or individual. The findings within the present study have implications for any individual or business looking to present itself in a way that encourages the formation of trust in an online environment.

Goffman (1959) theorized about self-presentation within a communicative lens. Whenever a person presents himself or herself in a particular way, the action is communicative in itself. In the case of online self-presentation, the present study looked to several forms, such as request messages, photos, and other textual profile information. A major finding in the present study is what Couchsurfing website features are relied on most heavily when making hosting decisions. Results indicated that references and the request message provided important information needed to either trust or distrust a member enough to accept or reject a request. The two features that involved a members' self-presentation to the entire online community, photos featured on the profile and other textual profile information, have been found to not be relied on heavily by Couchsurfing members. The present study suggests that it is possible that messages constructed for a large audience are not taken seriously in an online environment like Couchsurfing, and, instead, trust is built more on one-on-one online communication and insight from third party sources. This information could translate to online trust beyond Couchsurfing. For 
example, when choosing where to purchase an item online it is possible that similar methods are used to determine trust in the seller. It is possible that the seller's website is not a heavily relied upon source of information because the seller created it for a large audience. However, if the potential buyer contacts the seller individually or seeks third party opinion, such as reviews online from past customers, trust may be more easily achieved.

Much research about computer mediated communication, especially through the use of social network and social networking sites, focuses on Goffman's (1959) idea of self presentation and the evaluation of others' self-presentation attempts. Although Goffman's (1959) work focused on face-to-face interactions, many researchers use the concepts to consider computer-mediated contexts. The findings from this study, however, might suggest self-presentation and evaluation of self-presentation attempts are not critical in the ability to trust others online only when they are intended for a large overall audience. Although these concepts might have other purposes online, such as reputation management or maintenance of friendships on social network sites, the initiation of relationships, especially in contexts that involve risk and trust-building, looking to general messages sent to a large audience may be the wrong direction for research. Instead, one-on-one communication and insight from third-party sources may be a better direction for research in relationship initiation online. Self-presentation methods are used in request messages, but they are an example of direct communication between a potential guest and a potential host. Website features not of importance to members involve self-presentation to a general audience. 
Next, within references on Couchsurfing, an interesting finding was that potential hosts find references from other past hosts more essential in accepting or rejecting a request than they place essentiality on references from others in the community. This suggests that when building trust online, members of online communities are looking for third-party information from others who know the person in the same capacity through which they might interact with that person. For example, when choosing a professor based on instructor review webpages, students may put more reliance on reviews from students who have taken the same course with the instructor, rather than having taken a different course with the same instructor. Similarly, they might look for students who have taken the particular instructor at the same university, rather than at a previous place of employment.

Photos on a Couchsurfing profile are considered as a precaution that they confirm identity to warrant safety. Members seem to be satisfied with the presence of photos at all, rather than the communicative aspects within photos. The absence of a photo was, for many participants, the major factor in determining rejecting of a request. This issue of trust can also translate to other online environments that involve the ability to include photographs.

Another implication for a major finding in the request messages is that when determining acceptance or rejection of a request, an emphasis is placed on the message communicating that the host was chosen after consideration, showing that the message and request was personalized. Members expect potential guests to mention information found in a requested host's profile and explain why that particular member was chosen over other hosts in the area. Some members even request that a secret word or answer to a 
question be included to confirm that members took the time to carefully read that prospective host's profile. Although this requirement might not exist for the purpose of determining risk or safety of another individual, participants indicated that it helped to ensure a pleasant hosting experience. Personalized messages, however achieved, may be more effective in other online trust-building contexts. Would this idea translate to online dating websites, for example? If a member of a dating website mentions information found in the profile, rather than a generic message, are potential dates more willing to meet in person? Implications for findings about trust-building on Couchsurfing exist for a variety of online interactions.

\section{Limitations}

Although the present study contributed significant findings to research about Couchsurfing, trust-building online and the field of communication in general, some limitations to this study exist.

\section{Small Sample Size}

The first method of participant recruitment, posting invitations to participate in places-oriented discussion forums, had the potential of inviting 91,205 Couchsurfing members (Couchsurfing International, 2013e). In addition to the places-oriented discussion forums, an invitation was also posted in other relevant Couchsurfing discussion forums and on the Reddit Couchsurfing discussion board. Although it was predicted that these methods may have a low response rate, it was assumed that having such a large sample pool would result in an appropriately sized sample of between 300 and 400 participants, ideally having at least 100 responses for each of the features (i.e., photos, references, request messages, and other profile information). However, the 
response rate was much lower than predicted, at 216 usable participant questionnaires total. More specifically problematic, in the condition for rejecting a request based on photos, the number of participants who chose that condition and answered the items was only nine people. Although statistical significance was able to be achieved with this low sample size, the findings may not be generalizable to the entire population of Couchsurfing members relying on photos to reject requests. A larger sample size may have provided different information.

In fact, in addition to a low response rate, the postings within discussion groups inviting Couchsurfing members to participate in the questionnaire were not well received. The community seemed generally uninterested in participating and sometimes even offended that a researcher would recruit participants on Couchsurfing discussion forums. The Couchsurfing organization removed two posts after they were flagged by members as being off-topic. Members commented on other posts, disapproving of the invitation to participate. Some members used contact information provided in the informed consent page to contact the researcher directly with concerns. Most concerns had to do with members believing the link to the online questionnaire was spam, while other concerns were focused on disapproval with posting an invitation to participate on Couchsurfing discussion forums. Hirsch, Thompson, and Every (2014) used the Couchsurfing website to recruit interview participants for a study about use of the Indian rail system. Although Hirsch et al. (2014) were able to recruit the desired amount of participants, they explain that one of the limitations to using the Couchsurfing website for participant recruitment is the website's overuse for research. 
Prentice, Miller, and Lightdale (1994) introduced two types of groups. Commonbond groups focus on interpersonal relationships within the group, while commonidentity groups focus on the overall goals of the entire group above goals of any individual. Schwammlein and Wodzicki (2012) determined that self-presentation in online profiles is often based on whether the community is a common-bond or commonidentity group affiliation. Individuals belonging to common-identity groups presented themselves online in a manner that focused on upholding the goals of the group. Because Boyd and Ellison (2008) categorized Couchsurfing as a passion-centric or activitycentered social network site, and Cova and White (2010) explained that the overall goal of the Couchsurfing community is to connect and improve the world as a whole, Couchsurfing seems to fit within the definition for a common-identity group. Type of group affiliation may help determine why invitations to participate in research were not well received in the online community.

Utz and Sassenberg (2002) studied the differences between common-bond and common-identity groups in the distribution of positive and negative outcomes, such as the distribution of lottery earnings versus distribution of a debt among a group of people. Findings indicated that in common-identity groups, the primary concern in distribution of positive and negative outcomes was for the group, rather than for any one individual. In common-identity groups, members were more willing to split both positive and negative outcomes equally among members. This was especially true in common-identity groups with strong attachment to the group as a whole. When taking these findings into consideration with the difficulties encountered when recruiting online participants within the website, it may be possible that invitations to participate were not well received in 
discussion forums because the post of an invitation indicated a goal of the individual researcher, rather than the goal of the group as a whole. In a common-identity group like Couchsurfing, members may have been offended that someone was using the discussion forum for seemingly personal gain, over gain for the entire group.

Other researchers have identified problems with participant recruitment in online communities. Mendelson (2007) used online discussion forums for patients with Lupus to recruit participants for a study. Like recruitment for the present study, Mendelson (2007) also experienced rejection of recruitment posts on discussion forums for Lupus patients. Three of the seven proposed recruitment posts were rejected by group moderators, who often explained in their reasoning that recruitment of research participants on the website was an, "intrusion on the site" (Mendelson, 2007, p. 319). Mendelson (2007) explained that group moderators may merely be attempting to maintain the intended use of discussion boards, but also predicted that group moderators might also be rejecting research recruitment invitations in order to give discussion board participants the impression that they are being protected from outsiders.

Like Mendelson (2007), Hudson and Bruckman (2004) found great opposition to research in online communities. Hudson and Bruckman (2004) studied responses of online chat room participants upon being asked to participate in research, with recruitment messages with varying degrees of courtesy. When research presence was explicitly stated to the chat room, research participants were removed from the site 63.3 percent of the time. Group moderators sometimes provided a short message explaining why the person was removed from the chat room. Of the times the researcher was banned, 17 percent of the messages accused the researcher of spam or advertising within 
the group. Another 13 percent cited discomforting with being studied. When Hudson and Bruckman (2004) allowed chat room participants the option of participating in the study, only four of 766 chat room members opted to participate. In most cases when the researcher was not immediately removed from a chat room, the researcher was ignored in conversation.

The responses to Hudson and Buckman's (2004) recruitment for research participation were similar to the responses received in the present study. One Couchsurfing member contacted the researcher and explained that, although nothing was being sold for economic profit, recruitment of participants could be considered spam because it provides some kind of profit for the researcher. When no direct concerns were posted by members in response to the invitation for participation, it seemed that the post was ignored, and often resulted in an extremely low participation rate.

\section{Focus of Population}

For several reasons discussed in the methods section, the present study focused solely on the perspective of Couchsurfing hosts in the United States. While focusing on this specific population allowed for avoidance of certain confounding variables, it also eliminated the ability for this study to be generalizable to all Couchsurfing members, since Couchsurfing is a worldwide phenomenon. However, although the present study may not provide generalizable information about Couchsurfers around the world, the information it provides about uncertainty reduction and trust online is valuable itself.

For future researchers looking specifically into Couchsurfing, it would be beneficial to have a generalizable understanding of how the entire community works, rather than focusing on a smaller population within that community. This method would 
also allow researchers to look into differences among countries, continents and cultures in decision-making practices of hosts. To do this well, however, would require the ability to circulate an online questionnaire worldwide and recruit participants from every country. Certain confounding variables to a study like this would need to be addressed. One of these variables is the native language of participants. Online questionnaires would need to be translated correctly into other languages in order to avoid differing responses based on the inability for individual participants to understand the language. Also, customs in other countries could introduce cultural confounding variables that have the potential to affect validity of results. Future researchers looking to study Couchsurfing should consider researching a worldwide population, but must first consider how these confounding variables could be avoided.

\section{Measurement}

Another limitation to the present study was a technical problem resulting from participant misunderstanding that became apparent during the data analysis stage. Within the online questionnaire, two questions were included to determine what feature of the website is most important to gain information about another member. Directions for these two questionnaire items asked participants to rank order their choices on a scale of one to four, with one being the most important item. The intention was for participants to use a unique number for each of the four items presented. Select Survey did not give the option to require participants to use each of the four numbers or to restrict members from reusing numbers. Directions presented to participants read, "Please rank-order the importance of the following four items when accepting a request from a CouchSurfing member (1=most important, $4=$ least important)," and a secondary direction was provided 
directly above where participants respond, reading, "Rank the items below from 1 to 4 with 1 being the most important and 4 being the least important." Directions for how participants were supposed to answer the question should have been more clearly stated.

Upon viewing data, it became apparent that some participants did not always provide a unique number for each item, and would sometimes repeat numbers. This happened on 12 occasions. For example, a participant may have marked his or her most important profile element as a one, while marking the three others as twos. Mistakes like this did not affect participants' movement through the questionnaire or the results to the chi-square goodness of fit test, but these data most likely had an effect on the paired samples $t$-tests, comparing overall means of the rank-ordered items. Not all data to support research questions one and two involved participants marking a unique ranking for each item.

On 20 occasions, participants identified more than one item as most important, or ranked as their first choice of website features. For example, a participant may have identified both references and messages as the most important, indicating a ranking of one for both features. In these cases, participant movement through the questionnaire was affected. Participants marking more than one item as their most important website features were directed to one of the items identified as the most important. Responses like this also had an effect on the outcome of the chi-square goodness of fit tests, because it affected the frequencies of first ranked items, and it potentially also had an effect on the paired samples $t$-tests, comparing means of each item.

On 16 occasions, participants did not identify any item ranked first, or as number one, in the rank order section. For example, a participant may have ranked all items as 
twos, failing to mark any item as the most important. In these cases, participants were presented all of the questionnaire pages about the different website features when navigating through the questionnaire. These participants' responses were not included in the chi-square goodness of fit tests, because no items were marked as most important. These responses, however, most likely had an effect on the paired samples $t$-tests performed to differentiate the means for each item. If participants were forced to enter a unique number for each item, results may have been altered.

Although directions for the rank-ordered items were unclear, possibly affecting statistical results, the responses were not discarded. These responses, although not following the intended format, still provide insight into the larger sample's views about the website features. This is a limitation to the study because failure to provide clear directions resulted in skewed results. However, the results were still of value to the present study, so even responses that did not follow rank-order directions were kept and analyzed.

\section{Directions for Future Research}

Studying the ability to reduce uncertainty and develop trust online is a fairly new phenomenon. Couchsurfing, also, is a modern concept that involves a relationship that has the potential to move from an online environment to an offline environment. The present study focused on describing how information seeking online allowed for a decrease in uncertainty in order to build trust in others. Some findings in the present study call for more focused research in specific areas to gain a better understanding of the causes and implications of the findings. Also, other concepts that were out of scope of the 
present study are outlined in the following section as future directions for this type of research.

\section{Sample}

As discussed, the sample size for the present study was smaller than desired and may not have been representative of all United States hosts' experiences because invitations to participate were posted in cities with the largest amount of Couchsurfing members. However, because of the struggles encountered during the present study to attract members to participate in the research, future researchers in the Couchsurfing community will most likely encounter the same obstacles. Future researchers looking into the Couchsurfing community should spend a large amount of time and consideration strategizing participant recruitment methods.

It would be beneficial for future researchers in the Couchsurfing community to create a working relationship with the Couchsurfing organization. Although for the present study, the Couchsurfing organization refused offers to be involved, including the organization in research participant recruitment may be beneficial. For example, if the Couchsurfing organization could provide researchers with contact information for a random sample of United States citizen Couchsurfing members, researchers may have better response rate. Using this method, all United States members would have an equal chance of being invited to participate, rather than only being aware of the opportunity if it is posted in their cities' discussion boards. Also, sending individual messages may have a larger response rate than posting a generic message to all members of a certain discussion board. This could counteract the low response rate by Couchsurfing members found in the present study. 
Beyond Couchsurfing, also, the concepts in this study could be translated into a variety of online situations that involve the ability to trust or distrust others online. In online dating communities, for example, trust in another person is vital to meet offline. In other online communities, such as websites like Craigslist.org where people can post items or services for sale, how do people trust others enough to arrange to meet to exchange goods? When going to the internet when renting properties, arranging job interviews, choosing babysitters, purchasing products, deciding which professor to choose for a course, or searching for advice online, it should be determined how trust is achieved. This study was able to gain an understanding of trust in the particular online environment of Couchsurfing. It is essential to gain a broader understanding of trust in other online communities.

\section{Predictive}

Although most academic research is explanatory, or predictive (Bhattercherjee, 2012), it was necessary for this study to first gain a descriptive understanding of the phenomenon of trust-building on the Couchsurfing website. Because of this, a future direction for this type of research would be to use the descriptive findings of the present study to develop a predictive study. A predictive study would allow for greater insight into, not only what is happening within the phenomenon, but also why and exactly how it is happening (Bhattercherjee, 2012). Uncertainty reduction theory is both an explanatory or predictive theory (Berger \& Calbrese, 1975). This study focused on the ability to explain the phenomenon of reducing uncertainty to trust others online, but future research has the opportunity to look into the predictive power of uncertainty reduction theory. 
A suggested research design for this type of study would be an experimental design involving a collection of mock Couchsurfing profiles with certain elements of the photos, references, request messages, and other profile information varying among profiles presented to participants. To avoid confounding variables within the study, only one element of the original profile would be changed at a time for each manipulated profile presented to participants. An uncertainty reduction or interpersonal trust scale could be used to rate the Couchsurfing members based on the varying profile elements. Based on the descriptive results of the present study, researchers in the future will have the ability to predict the decision of Couchsurfing hosts based on the amount of information presented to reduce uncertainty and build trust in other members online.

\section{Demographic Differences}

Although the present study collected information about particular demographics, it was beyond the scope of this study to look into the effects of demographic factors on methods used to trust others through viewing online information. Do females place reliance on different website features than men? Do females look more into safety when trust-building than men? Are males more likely to be willing to host someone of a different sex? Does age play a role in how trust is achieved online? When a Couchsurfing host has a spouse or children in the home are methods used for trusting or distrusting another individual on the Couchsurfing website affected? Does hosting experience affect the decision-making process? Does travel experience affect the decision-making process? Do people who have lived abroad go about building trust on Couchsurfing differently from those who have never lived outside the United States? All of these questions should be considered in future research. Not only would the answers to 
these questions provide valuable information about trust-building on Couchsurfing, but they would also add to knowledge of how trust is achieved for different demographics online in general.

\section{Social Capital}

In the present study, although some survey items focus on what can be gained from hosting, the study does not directly explore the nature of social capital within uncertainty reduction and trust in a Couchsurfing host-guest relationship. Social capital is defined by Putnam (2000) as, "features of social organization such as networks, norms, and social trust that facilitate coordination and cooperation for mutual benefit" (p. 67). This idea suggests that group membership contributes to social trust, but Putnam (2000) found that Americans' group membership is declining, and where membership exists most often is in organizations that promote individual goals. Putnam (2000) also found that Americans are less trusting than they were in the 1960s.

While Putnam (2000) focused on social capital offline, Aubrey and Rill (2013) studied social capital in online environments. They found that in the context of Facebook, members often used the website to gain social capital. Benefits to members included a large number of weak connections and the opportunity to build or maintain close relationships offering emotional support. Because benefits are apparent for both online and offline group membership and relationships, future research could look into the existence of reliance on social capital in the Couchsurfing community and its implications for hosting decisions.

Future research should look explicitly into how social capital, specifically types and amounts of benefits, lead to uncertainty reduction and trust. What is gained from a 
Couchsurfing interaction could contribute to the decision-making processes of hosts as much as trust contributes to the decision. Future research should determine explicitly how social capital is integrated into the Couchsurfing community.

\section{Conclusion}

Trust, a classic communication concept, needs to be considered in the context of an online environment. Through uncertainty reduction and predicted outcome value theories, trust can be researched in an online environment, especially through looking at information-seeking strategies. Couchsurfing, a fairly risky online medium through which trust is formed to meet others offline, is an interesting source of examining trustbuilding online. Although the Couchsurfing concept only covers a specific instance of trust-building online, hopefully this study will be a starting point for future research about the ability and necessity of understanding how trust is built, maintained, and depreciated in an online environment. 


\section{REFERENCES}

Aristotle. (1932). The Rhetoric of Aristotle. (L. Cooper, Trans.). Englewood Cliffs, NJ: Prentice Hall, Inc.

Aubrey, J. S., \& Rill, L. (2013). Investigating relations between Facebook use and social capital among college undergraduates. Communication Quarterly, 61, 479-496. doi: 10.1080/01463373.2013.801869

Ayeh, J. K., Au, N., \& Law, R. (2013). Do we believe in TripAdvisor? Examining credibility perceptions and online travelers' attitude toward using user-generated content. Journal of Travel Research, 52, 437-452. doi: $10.1177 / 0047287512475217$

Barber, B. (1983). The logic and limits of trust. New Brunswick, NJ: Rutgers University Press.

Berger, C. R., \& Calabrese, R. J. (1975). Some explorations in initial interaction and beyond: Toward a developmental theory of interpersonal communication. Human Communication Research, 1, 99-112. doi: 10.1111/j.1468-2958.1975.tb00258

Berger, C. R., \& Bradac, J. J. (1982). Language and social knowledge: Uncertainty in interpersonal relations. London, UK: Edward Arnold, Ltd.

Bhattercherjee, A. (2012). Social science research: Principles, methods and practices. Tampa Bay, FL: USF Tampa Bay Open Access Textbooks Collection.

Bialski, P. (2011). Technologies of hospitality: How planned encounters develop between strangers. Hospitality \& Society, 1, 245-260. doi: 10.1386/hosp.1.3.245_1

Bialski, P. (2012). Becoming intimately mobile. In J. Wasilewski (Ed.) Warsaw studies in culture and society (Vol. 2). Retrieved from

http://intimatetourism.files.wordpress.com/ 2012/07/paula-bialskibecomingintimatelymobile-ebook.pdf

Boster, F. J., Mitchell, M. M., Lapinski, M. K., Cooper, H., Orrego, V. O., Reinke, R. (1999). The impact of guilt and type of compliance-gaining message on compliance. Communication Monographs, 66, 168- 177. doi: $10.1080 / 03637759909376470$

Boyd, D. M. (2007). Social network sites: Definition, history, and scholarship. Journal of Computer-Mediated Communication, 13, 210-230. doi: 10.1111/j.10836101.2007.00393.x

Boyd, D. M., \& Ellison, N. B. (2008). Social network sites: Definition, history, and scholarship. Journal of Computer-Mediated Communication, 13, 210-230. doi: 10.1111/j.1083-6101.2007.00393.x

Brooke, C. (2012, October 12). Chinese tourist 'raped' after being offered free bed for the night from man on 'Couchsurfing' website. Daily Mail Online. Retrieved from http://www.dailymail.co.uk/news/article-1205794/Rape-horror-tourist-usedCouchsurfing-website-aimed-travellers.html 
Brown, P., \& Levinson, S. (1987). Politeness: Some universals in language usage. Cambridge, UK: Cambridge University Press.

Bruland, H. H. (2009). Rhetorical cues and cultural clues: An analysis of the recommendation letter in English studies. Rhetoric Review, 28, 406-424. doi: 10.1080/07350190903185064

Brummernhenrich, B., \& Jucks, R. (2013). Managing face threats and instructions in online tutoring. Journal of Educational Psychology, 105, 341-350. doi: $10.1037 / \mathrm{a} 0031928$

Buchberger, S. (2011). Hospitality, secrecy and gossip in Morocco: Hosting Couchsurfers against great odds. Hospitality \& Society, 1, 299-315. doi: 10.1386/hosp.1.3.299_1

Burger, J. M., Reed, M., DeCesare, K., Rauner, S., Rozolis, J. (1999). The effects of initial request size on compliance: More about the that's-not-all technique. Basic and Applied Psychology, 21, 243-249. doi: 10.1207/15324839951036407

Cialdini, R. B., Vincent, J. E., Lewis, S. K., Catalan, J., Wheeler, D., \& Darby, B. L. (1975). Reciprocal concessions procedure for inducing compliance: The door-inthe-face technique. Journal of Personality and Social Psychology, 31, 206-215. doi: $10.1037 / \mathrm{h} 0076284$

Couchsurfing International, (2013a). About Couchsurfing. Retrieved from https://www.Couchsurfing.org/about/

Couchsurfing International, (2013b). Safety. Retrieved from https://www.Couchsurfing.org/safety

Couchsurfing International, (2013c). Safety tips. Retrieved from http://www.Couchsurfing.org/safety/tips

Couchsurfing International, (2013d). How to read a profile. Retrieved from http://www.Couchsurfing.org/read_profile_tips.html

Couchsurfing International, (2013e). Statistics. Retrieved from http://www.Couchsurfing.org/statistics

Courtois, C., All, A., \& Vanwynsberghe, H. (2012). Social network profiles as information sources for adolescents' offline relations. Cyberpsychology, Behavior, and Social Networking, 15(6). 290-295. doi: 10.1089/cyber.2011.0557

Cova, B., \& White, T. (2010). Counter-brand and alter-brand communities: The impact of Web 2.0 on tribal marketing approaches. Journal of Marketing Management, 26, 256-270. doi: 10.1080/02672570903566276

Curry, C. (2008). Perceptions of direct requests: Politeness theory and smoking behavior. Paper presented at the annual meeting of the National Communication Association. San Diego, CA.

Davis. D. C., Lippman, M. B., Morris, T. W., \& Tougas, J. A. (2012). Face-off: Different ways identity is privileged through Facebook. In C. Cunningham (Eds.). Social networking and impression management: Self-presentation in the digital age (pp. 61-83). Lanham, MD: Rowman \& Littlefield Publishing Group.

DeLaCruz, B. P., \& Claveria, M. (2009). ICS 691: Trust and social capital on Couchsurfing and OkCupid. Retrieved from http://www.bjpeterdelacruz.com/files/ics691finalpaper.pdf

Dipplereiter, B., Grun, C., Pottler, M., Seidel, I., Berger, H., Dittenback, M., \& Pesenhofer, A. (2008). Online tourism communities on the path to Web 2.0: An 
evaluation. Information Technology and Tourism, 10, 329-353. doi: $10.3727 / 109830508788403132$

Ellison, N., Heino, R., \& Gibbs, J. (2006). Managing impressions online: Selfpresentation processes in the online dating environment. Journal of ComputerMediated Communication, 11, 415-441. doi: 10.1111/j.1083-6101.2006.00020.x

Ericsson, K. A., \& Simon, H. A. (1980). Verbal reports as data. Psychological Review, 87(3), 215-251. doi: 10.1037/0033-295X.87.3.215

Freedman, J. L., \& Fraser, S. C. (1966). Compliance without pressure: The foot-in-thedoor technique. Journal of Personality and Social Psychology, 4, 195-202. doi: $10.1037 / \mathrm{h} 0023552$

Ganesan, S., \& Hess, R. (1997). Dimensions and levels of trust: Implications for commitment to a relationships. Marketing Letters, 8, 439-448. doi: 10.1023/A:1007955514781

Germann Molz, J. (2011). Couchsurfing and network hospitality: 'It's not just about the furniture'. Hospitality \& Society, 1, 215-225. doi: 10.1386/hosp.1.3.215_2

Germann Molz, J. (2012). Hospitality: The mobile conviviality of Couchsurfing. In J. Germann Molz (Ed.) Travel connections: Tourism, technology, and togetherness in a mobile world (pp. 83-110). London, UK: Routledge.

Gibbs, J. L., Ellison, N. B., \& Heino, R. D. (2006). Self presentation in online personals: The role of anticipated future interaction, self-disclosure, and perceived success in internet dating. Communication Research, 33, 152-177. doi: 10.1177/0093650205286368

Gibbs, J. L., Ellison, N. B., \& Lai, C. H. (2011). First comes love, then comes Google: An investigation of uncertainty reduction strategies and self-disclosure in online dating. Communication Research, 38, 70-100. doi: 10.1177/0093650210377091

Goffman, E. (1959). The presentation of self in everyday life. New York, NY: Anchor Books.

Goffman, E. (1967). Interaction ritual: Essays on face-to-face behavior. New York, NY: Anchor Books.

Golish, T. D. (1999) Students' use of compliance gaining strategies with graduate teaching assistants: Examining the other end of the power spectrum. Communication Quarterly, 47, 12-32. doi: 10.1080/014633379909370121

Haferkamp, N., Eimler, S., Papadakis, A. M., Kruck, J. V. (2012) Men are from Mars, women are from Venus? Examining gender differences in self-presentation on social networking sites. Cyberpsychology, Behavior, and Social Networking, 15, 91-98. doi: 10.1089/cyber.2011.0151

Haferkamp, N., \& Kramer, N.C. (2010). Creating a digital self: Impression management and impression formation on social networking sites. In Drotner, K. \& Schroder, K. C. (Eds.). Digital content creation: Creativity, competence, critique, (129146). New York, NY: Peter Lang.

Hancock, J. T., \& Toma, C. L. (2009). Putting your best face forward: The accuracy of online dating photographs. Journal of Communication, 59, 367-386. doi: 10.1111/j.1460-2466.2009.01420.x

Heal, F. (1990). Hospitality in early modern England. Oxford, UK: Clarendon Press. 
Hirsch, L., Thompson, K., \& Every, D. (2014). From computer to computer: Considerations for the use of social networking sites for participant recruitment. The Qualitative Report, 19(2) 1-13.

Holwick, K. (2011). Sleeping with strangers: Redefining experiences in a Couchsurfing world. Saarbrucken, Germany: Lambert Academic Publishing.

Homer. (1974). The odyssey. (A. Cook, Trans.). New York, NY: W. W. Norton \& Company.

Hudson, J. M., \& Bruckman, A. (2004). "Go away": Participant objections to being studied and the ethics of chatroom research. The Information Society, 20, 127139. doi: 10.1080/01972240490423030

Kellerman, K., \& Cole, T. (1994). Classifying compliance gaining messages: Taxonomic disorder and strategic confusion. Communication Theory, 4, 3-60. doi: 10.1111/j.1468-2885.1994.tb00081.x

Kluemper, D. H., \& Rosen, P. A. (2009). Future employment selection methods: Evaluating social networking web sites. Journal of Managerial Psychology, 24, 567-580. doi: 10.1108/02683940910974134

Kluemper, D. H., Rosen, P. A., \& Mossholder, K. W. (2012). Social networking websites, personality ratings, and the organizational context: More than meets the eye? Journal of Applied Social Psychology, 42, 1143-1172. doi: 10.1111/j.15591816.2011.00881.X

Lauterbach, D., Truong, H., Shah, T., \& Adamic, L. (2009). Surfing a web of trust: Reputation and reciprocity on Couchsurfing.com. Computational Science and Engineering , 4, 346-353. doi: 10.1.1.184.6359

Liu, J. (2012). The intimate stranger on your couch: An analysis of motivation, presentation and trust through Couchsurfing. Retrieved from, http://uu.divaportal.org/smash/get/ diva2:560145/FULLTEXT01.pdf

Malina, B. J. (1971). Hospitality. In Harper's Bible dictionary. (pp. 408-409). San Francisco, CA: Harper \& Row.

McCroskey, J. C., \& Teven, J. J. (1999). Goodwill: A reexamination of the construct and its measurement. Communication Monographs, 66, 90-103. doi: $10.1080 / 03637759909376464$

Mendelson, C. (2007). Recruiting participants for research from online communities. Computers, Informatics, Nursing, 25(6) 317-323. doi: 10.1098/01.NCN.0000299653.13777.51

Miller, G., Boster, F., Roloff, M., \& Seibold, D. (1977). Compliance-gaining message strategies: A typology and some findings concerning effects of situational differences. Communication Monographs, 44, 37-51. doi: $10.1080 / 03637757709390113$

Munar, A. M. (2011). Tourist-created content: Rethinking destination branding. International Journal of Culture, Tourism and Hospitality Research, 5, 291-305. doi: 10.1108/17506181111156989

Nicklin, J. M., \& Roch, S. G. (2009). Letters of recommendation: Controversy and consensus from expert perspectives. International Journal of Selection and Assessment, 17, 76-91. doi: 10.1111/j.1468-2389.2009.00453 
O'Gorman, K. D. (2007). Dimensions of hospitality: Exploring ancient and classical origins. In C. Lashley, P. Lynch, \& A. Morrison (Eds.), Hospitality: A social lens (pp. 17-32).Oxford, UK: Elsevier.

Ovid. (2004). Metamorphosis. (C. Martin, Trans.). New York, NY: W. W. Norton \& Company.

Palmieri, C., Prestano, K., Gandley, R., Overton, E., \&Zhang, Q. (2012). The Facebook phenomenon: Online self-disclosure and uncertainty reduction. China Media Research, 8(1), 48-53.

Planalp, S., \& Honeycutt, J. M. (1985). Events that increase uncertainty in personal relationships. Human Communication Research, 11, 593-604. doi: 10.1111/j.1468-2958.1985.tb00062.x

Plato. (1980). The laws of Plato. ( T. L. Pangle, Trans.). New York, NY: Basic Books, Inc.

Prentice, D. A., Miller, D. T., \& Lightdale, J. R. (1994). Asymmetries in attachments to groups and to their members: Distinguishing between common-identity and common-bond groups. Personality and Social Psychology Bulletin, 20, 484-493. doi: 10.1177/0146167294205005

Putnam, R. D. (1995). Bowling alone: America's declining social capital. Journal of Democracy, 6(1), 65-78. doi: 10.1353/jod.1995.0002

Ramirez, A. (2009). Information seeking role on computer-mediated interaction. Western Journal of Communication, 73, 300-325. doi: 10.1080/1057031903082040

Ramirez, A., Walther, J. B., Burgoon, J. K., \& Sunnafrank, M. (2002). Informationseeking strategies, uncertainty, and computer-mediated communication. Human Communication Research, 28, 213-228. doi: 10.1111/j.1468-2958.2002.tb00804.x

Radford, M. L., Radford, G. P., Connaway, L. S., \& DeAngelis, J. A. (2011). On virtual face-work: An ethnography of communication approach to a life chat reference interaction. Library Quarterly, 81, 431-453. doi: 0024-2519/2011/8104-0004

Reinard, J. C. (2008). Introduction to communication research $\left(4^{\text {th }} \mathrm{ed}\right.$.). New York, NY: McGraw-Hill.

Reingen, P. H., \& Kernan, J. B. (1977). Compliance with an interview request: Foot-inthe-door, self-perception interpretation. Journal of Marketing Research, 14, 365369. doi: $10.2307 / 3150775$

Reingen, P. H. (1978). On inducing compliance with requests. Journal of Consumer Research, 5, 96-102. doi: 10.1086/208720

Ribton-Turner, C. J. (1972). A history of vagrants and vagrancy and beggars and begging. Montclair, NJ: Patterson Smith.

Rosen, D., Lafontaine, P. R., Hendrickson, B. (2011). Couchsurfing: Belonging and trust in a globally cooperative online social network. New Media \& Society, 13, 981998. doi: $10.1177 / 1461444810390341$

Salimkhan, G., Manago, A., \& Greenfield, P. (2010). The construction of the virtual self on MySpace. Cyberpsychology: Journal of Psychosocial Research on Cyberspace, 4. Retrieved from, http://www.cyberpsychology.eu/view.php?cisloclanku=2010050203

Schwammlein, E., \& Wodzicki, K. (2012). What to tell about me? Self-presentation in online communities. Journal of Computer-Mediated Communication, 17, 387407. doi: 10.1111/j.1083-6101.2012.01582.x 
Shulz, K., Mahabir, C., Song, J., Verheyden, C. N. (2012). Evaluation of the current perspectives on letters of recommendation for residency applicants among plastic surgery program directors. Plastic Surgery International, 1-5. doi: $10.1155 / 1012 / 728981$

Siibak, A. (2009). Constructing the self through the photo selection: Visual impression management on social networking websites, Cyberpsychology: Journal of Psychosocial Research on Cyberspace, 3, 1-9.

Simmel, L. L., Berger, P. D. (2000). The art of the ask: Maximizing verbal compliance in telefundraising. Journal of Interactive Marketing, 14, 12-40. doi: 10.1002/15206653

Skog, C. (2012). Couchsurfing: A choice for travelers. Retrieved from http://publications. theseus.fi/ bitstream/handle/10024/39018/Skog_Christina.pdf?sequence=1

Stedman, J. M., Hatch, J. P., \& Schoenfeld, L. S. (2009). Letters of recommendation for the predoctoral internship in medical schools and other settings: Do they enhance decision making in the selection process? Journal of Clinical Psychology in Medical Settings, 16, 339-345. doi: 10.1007/s10880-009-9170-y

Steylaerts, V., \& O'Dubhghaill, S. (2011). Couchsurfing and authenticity: Notes towards an understanding of an emerging phenomenon. Hospitality and Society, 1, 261278. doi: 10.1286/hosp.1.3.261_1

Sullivan, J. J., Albrecht, T. L., Taylor, S. (1990). Process, organization, relational, and personal determinants of managerial compliance-gaining communication strategies. Journal of Business Communication, 27, 331-355. doi: $10.1177 / 002194369002700402$

Strano, M. (2008). User descriptions and interpretations of self-presentation through Facebook profile images. Cyberpsychology: Journal of Psychosocial Research on Cyberspace, 2(2), 1-12.

Sunnafrank, M. (1986). Predicted outcome value during initial interactions: A reformulation of uncertainty reduction theory. Human Communication Research, 13, 3-33. doi: 10.1111/j.1468-1958.1986.tb00094.x

Tan, J. E. (2010). The leap of faith from online to offline: An exploratory study of Couchsurfing.org. In Acquisti, A., Smith, S.W., \& Sadeghi, A.R. (Eds.). (2010). Proceedings from Trust and Trustworthy Computing Third International Conference. Berlin, Germany: Springer.

Tidwell, L. C., \& Walther, J. B. (2002). Computer-mediated communication effects on disclosure, impressions, and interpersonal evaluations: Getting to know one another a bit at a time. Human Communication Research, 28, 317-348. doi: $10.1093 / \mathrm{hcr} / 28.3 .317$

Tran, L. D. (2009). Trust in an online hospitality network: An interpretive study on The Couchsurfing Project. Retrieved from https://oda.hio.no/jspui/handle/10642/877

Utz, S., \& Sassenberg, K. (2002). Distributive justice in common-bond and commonidentity groups. Group Processes \& Intergroup Relations, 5(2) 151-162. doi: 10.1177/1368430202005002542

Van Der Heide, B., Johnson, B. K., \& Vang, M. H. (2013). The effects of product photographs and reputation systems on consumer behavior and product cost on eBay. Computers in Human Behavior, 29, 570-576. doi: 10.1016lj.chb.2012.11.002 
Vasquez, C. (2011). Complaints online: The case of TripAdvisor. Journal of Pragmatics, 6, 1707-1718. doi: 10.1016/j.pragma.2010.11.007

Wagner, T. R., Punyanunt-Carter, N. (2009). Come on... have another drink: College students' perceptions of compliance-gaining strategies used for drinking alcohol. Human Communication, 12, 477-483.

Walther, J. B. (1992). Interpersonal effects in computer-mediated interaction: A relational perspective. Communication Research, 19, 52-90. doi: 10.1177/009365092019001003

Wang, S. S., Moon, S., Kwon, K. H., Evans, C. A., \& Stefanone, M. A. (2009). Face off: Implications of visual cues on initiating friendship on Facebook. Computers in Human Behavior, 26, 226-234. doi: 10.1016/j.chb.2009.10.001

Whitty, M. T. (2007). Manipulation of self in cyberspace. In B. H. Spitzberg \& W. R. Cupach (Ed.) The dark side of interpersonal communication ( $2^{\text {nd }}$ ed.). Mahwah, NJ: Routledge.

Wout, M., \& Sanfey, A. G. (2008). Friend or foe: The effect of implicit trustworthiness judgments in social decision-making. Cognition, 108, 796-803. doi: 10.1016/j.cognition.2008.07.002

Yoo, J. (2005). Why should I trust you: The path from information valence to uncertainty reduction, cognitive trust, and behavioral trust. Paper presented at the annual meeting of the International Communication Association. New York, NY.

Zhao, S., Grasmuck, S., \& Martin, J. (2008). Identity construction on Facebook: Digital empowerment in anchored relationships. Computers in Human Behavior, 24, 1816-1836. doi: 10.1016/j.chb.2008.02.012

Zwier, S., Araujo, T., Boukes, M., \& Willemsen, L. (2011). Boundaries to the articulation of possible selves through social networking sites: The case of Facebook profilers' social connectedness. Cyberpsychology, Behavior \& Social Networking, 14, 571-576. doi: 10.1089/cyber.2010.0612 
APPENDIX A

TABLES 
Table 1

Accept Photo Mean Order

\begin{tabular}{ll} 
Item & Mean \\
\hline Presence of One Photo & 4.30 \\
No photo & 3.82 \\
Photo Shows Face & 3.62 \\
Photo Shows Personality & 3.21 \\
Presence of Multiple Photos & 3.19 \\
Photo Shows Travel & 2.61 \\
Photo Attractive & 2.59 \\
Photos of Activities I like & 2.36 \\
Photos of Activities I Dislike & 2.08 \\
Different Biological Sex & 1.97 \\
Photo With Friends & 1.93 \\
Photos Unattractive & 1.86 \\
Same Biological Sex & 1.82 \\
Photo Alone & 1.64 \\
Different Ethnicity & 1.59 \\
Same Ethnicity & 1.50 \\
\hline
\end{tabular}


Table 2

Accept Photo Paired Samples $t$-Test

\begin{tabular}{|c|c|c|c|c|}
\hline Pair & & $\begin{array}{c}\text { Paired } \\
\text { Differences } \\
\text { Means }\end{array}$ & $\mathrm{t}$ & $\mathrm{df}$ \\
\hline 1 & Presence of One Photo - No photo & 0.48 & 1.386 & 26 \\
\hline 2 & No photo - Photo Shows Face & 0.14 & 0.379 & 27 \\
\hline 3 & Photo Shows Face - Photo Shows Personality & 0.41 & 1.619 & 28 \\
\hline 4 & $\begin{array}{l}\text { Photo Shows Personality - Presence of Multiple } \\
\text { Photos }\end{array}$ & 0 & 0 & 26 \\
\hline 5 & $\begin{array}{l}\text { Presence of Multiple Photos - Photo Shows } \\
\text { Travel }\end{array}$ & 0.63 & $2.185^{*}$ & 26 \\
\hline 6 & Photo Shows Travel - Photo Attractive & 0.11 & 0.372 & 27 \\
\hline 7 & Photo Attractive - Photos of Activities I like & 0.14 & 0.51 & 27 \\
\hline 8 & $\begin{array}{l}\text { Photos of Activities I like - Photos of Activities I } \\
\text { Dislike }\end{array}$ & 0.31 & 0.969 & 25 \\
\hline 9 & $\begin{array}{l}\text { Photos of Activities I Dislike - Different } \\
\text { Biological Sex }\end{array}$ & 0.27 & 0.979 & 25 \\
\hline 10 & Different Biological Sex - Photo With Friends & -0.07 & -0.263 & 27 \\
\hline 11 & Photo With Friends - Photos Unattractive & 0.07 & 0.338 & 27 \\
\hline 12 & Photos Unattractive - Same Biological Sex & 0.04 & 0.124 & 27 \\
\hline 13 & Same Biological Sex - Photo Alone & 0.22 & 0.744 & 26 \\
\hline 14 & Photo Alone - Different Ethnicity & 0.04 & 0.135 & 25 \\
\hline 15 & Different Ethnicity - Same Ethnicity & 0.07 & 0.44 & 26 \\
\hline
\end{tabular}

$* \mathrm{p}<.05, * * \mathrm{p}<.01 * * * \mathrm{p}<.001$ 
Table 2a

Accept Photos Paired Samples t-Test (Confirming Delineation Point)

Paired

Differences $\quad t \quad d f$

Means

\begin{tabular}{llrrr}
\hline 1 & Presence of One Photo - Photo Shows Travel & 1.67 & $4.94 * * *$ & 26 \\
2 & No photo - Photo Shows Travel & 1.21 & $3.33 * *$ & 27 \\
3 & $\quad$ Photo Shows Face - Photo Shows Travel & 1.07 & $4.09 * * *$ & 27 \\
4 & $\quad$ Photo Shows Personality - Photo Shows Travel & 0.61 & $2.68 *$ & 27 \\
5 & $\quad$ Presence of Multiple Photos - Photo Shows Travel & 0.63 & $2.19 *$ & 26 \\
\hline$* \mathrm{p}<.05, * * \mathrm{p}<.01 * * * \mathrm{p}<.001$ & & &
\end{tabular}

Table 3

Reject Photo Mean Order

\begin{tabular}{ll} 
Item & Mean \\
\hline Reject No Photo & 4.67 \\
Reject One Photo & 3.78 \\
Reject Photos Activities I Dislike & 3.44 \\
Reject Multiple Photos & 3.11 \\
Reject Photo Shows Personality & 2.67 \\
Reject Shows Face Clearly & 2.67 \\
Reject Unattractive & 2.44 \\
Reject Attractive & 2.22 \\
Reject Photos Activities I Like & 2.11 \\
Reject Different Sex & 1.89 \\
Reject Photo Alone & 1.89 \\
Reject Photo Shows Travel & 1.67 \\
Reject Photo With Friends & 1.67 \\
Reject Same Sex & 1.56 \\
Reject Same Ethnicity & 1.44 \\
Reject Different Ethnicity & 1.00 \\
\hline
\end{tabular}


Table 4

Reject Photo Paired Samples t-Test

Pair

Paired

Differences $t \quad d f$

Means

\begin{tabular}{lllll}
\hline 1 & R No Photo - R One Photo & 0.89 & $2.53 *$ & 8 \\
2 & R One Photo - R Photos Activities I Dislike & 0.33 & 0.76 & 8 \\
3 & R Photos Activities I Dislike - R Multiple Photos & 0.33 & 1.00 & 8 \\
4 & R Multiple Photos - R Photo Shows Personality & 0.44 & 0.88 & 8 \\
5 & R Photo Shows Personality - R Face Clearly & 0.00 & 0.00 & 8 \\
6 & R Face Clearly - R Unattractive & 0.22 & 0.30 & 8 \\
7 & R Unattractive - R Attractive & 0.22 & 0.35 & 8 \\
8 & R Attractive - R Photos Activities I Like & 0.11 & 0.43 & 8 \\
9 & R Photos Activities I Like - R Different Sex & 0.22 & 0.56 & 8 \\
10 & R Different Sex - R Photo Alone & 0.00 & 0.00 & 8 \\
11 & R Photo Alone - R Photo Shows Travel & 0.22 & 1.00 & 8 \\
12 & R Photo Shows Travel - R Photo With Friends & 0.00 & 0.00 & 8 \\
13 & R Photo With Friends - R Same Sex & 0.11 & 0.32 & 8 \\
14 & R Same Sex - R Same Ethnicity & 0.11 & 0.22 & 8 \\
15 & R Same Ethnicity - R Different Ethnicity & 0.44 & 1.32 & 8 \\
\hline
\end{tabular}

$* p<.05, * * p<.01 * * * p<.001$ 
Table 5

Accept References Mean Order

\begin{tabular}{ll} 
Item & Mean \\
\hline Reference from Host & 4.23 \\
All Positive References & 3.89 \\
Discuss Personality & 3.72 \\
Reference Consistent With Other Info & 3.62 \\
Reference from Surfer & 3.62 \\
Cleanliness of Surfer & 3.60 \\
Presence of One of More Negative & \\
Reference & 3.48 \\
Activities I Like & 2.89 \\
Fits in With Community & 2.87 \\
Reference From Get-Togethers & 2.32 \\
Activities I Dislike & 2.27 \\
\hline
\end{tabular}


Table 6

Accept References Paired Samples t-Test

\begin{tabular}{|c|c|c|c|c|}
\hline Pair & & $\begin{array}{l}\text { Paired } \\
\text { Differences }\end{array}$ & $\mathrm{t}$ & df \\
\hline 1 & Reference from Host - All Positive References & 0.34 & 2.00 & 52 \\
\hline 2 & All Positive References - Discuss Personality & 0.17 & 0.93 & 52 \\
\hline 3 & Discuss Personality - Ref Consistent with Other Info & 0.09 & 0.52 & 52 \\
\hline 4 & Ref Consistent with Other Info - Reference from Surfer & 0.00 & 0.00 & 51 \\
\hline 5 & Reference from Surfer - Cleanliness of Surfer & 0.00 & 0.00 & 51 \\
\hline 6 & $\begin{array}{l}\text { Cleanliness of Surfer - Presence of one or more Neg } \\
\text { Reference }\end{array}$ & 0.12 & 0.56 & 51 \\
\hline 7 & $\begin{array}{l}\text { Presence of one or more Neg Reference - Activities I } \\
\text { like }\end{array}$ & 0.60 & $2.59 *$ & 51 \\
\hline 8 & Activities I like - Fits in With Community & 0.02 & 0.10 & 52 \\
\hline 9 & $\begin{array}{l}\text { Fits in With Community - Reference from Get } \\
\text { Togethers }\end{array}$ & 0.55 & $2.70^{*}$ & 52 \\
\hline 10 & Reference from Get Togethers - Activities I dislike & 0.04 & 0.20 & 51 \\
\hline
\end{tabular}

$* \mathrm{p}<.05, * * \mathrm{p}<.01 * * * \mathrm{p}<.001$ 
Table $6 a$

Accept References Paired Samples t-Test (Confirming Delineation Point 1)

\begin{tabular}{|c|c|c|c|c|}
\hline Pair & & $\begin{array}{c}\text { Paired } \\
\text { Differences } \\
\text { Means }\end{array}$ & $\mathrm{t}$ & $\mathrm{df}$ \\
\hline 1 & Reference from Host - Activities I like & 1.34 & $6.71 * * *$ & 52 \\
\hline 2 & All Positive References - Activities I like & 1.00 & $5.25 * * *$ & 52 \\
\hline 3 & Discuss Personality - Activities I like & 0.83 & $5.23 * * *$ & 52 \\
\hline 4 & $\begin{array}{l}\text { Ref Consistent with Other Info - Activities I } \\
\text { like }\end{array}$ & 0.74 & $3.49 * *$ & 52 \\
\hline 5 & Reference from Surfer - Activities I like & 0.71 & $3.31 * *$ & 51 \\
\hline 6 & Cleanliness of Surfer - Activities I like & 0.72 & $3.27 * *$ & 52 \\
\hline 7 & $\begin{array}{l}\text { Presence of one or more Neg Reference - } \\
\text { Activities I like }\end{array}$ & 0.60 & $2.59 *$ & 51 \\
\hline
\end{tabular}

Table $6 \mathrm{~b}$

Accept References Paired Samples t-Test (Confirming Delineation Point 2)

\begin{tabular}{lllll} 
Pair & \multicolumn{1}{c}{$\begin{array}{c}\text { Paired } \\
\text { Differences } \\
\text { Means }\end{array}$} & t & df \\
\hline $1 \quad \begin{array}{l}\text { Activities I like - Reference from Get - } \\
\text { Togethers }\end{array}$ & 0.57 & $2.93 *$ & 52 \\
$2 \quad \begin{array}{l}\text { Fits in With Community - Reference from Get- } \\
\text { Togethers }\end{array}$ & 0.55 & $2.70 *$ & 52 \\
\hline$* \mathrm{p}<.05, * * \mathrm{p}<.01 * * * \mathrm{p}<.001$ & & &
\end{tabular}


Table 7

Reject References Mean Order

\begin{tabular}{ll} 
Item & Mean \\
\hline Reject Reference From Host & 4.33 \\
Reject Presence of Negative References & 4.08 \\
Reject Reference From Surfer & 3.86 \\
Reject Cleanliness & 3.67 \\
Reject References Discuss Personality & 3.39 \\
Reject References Consistent with Profile & 3.35 \\
Reject All Positive References & 3.20 \\
Reject Fits in with Community & 2.60 \\
Reject Reference From Get Together & 2.43 \\
Reject Activities I Dislike & 2.26 \\
Reject Activities I Like & 2.16 \\
\hline
\end{tabular}


Table 8

Reject References Paired Samples t-Test

\begin{tabular}{|c|c|c|c|c|}
\hline Pair & & $\begin{array}{c}\text { Paired } \\
\text { Differences } \\
\text { Means }\end{array}$ & $\mathrm{t}$ & df \\
\hline 1 & $\begin{array}{l}\text { R Ref From Host - R Presence of Neg } \\
\text { References }\end{array}$ & 0.25 & 1.64 & 50 \\
\hline 2 & $\begin{array}{l}\text { R Presence of Neg References - R Ref From } \\
\text { Surfer }\end{array}$ & 0.22 & 1.18 & 50 \\
\hline 3 & R Ref From Surfer - R Cleanliness & 0.20 & 1.03 & 50 \\
\hline 4 & R Cleanliness - R Ref Personality & 0.24 & 1.37 & 48 \\
\hline 5 & $\begin{array}{l}\text { R Ref Personality - R Ref Consistent With } \\
\text { Profile }\end{array}$ & 0.08 & 0.49 & 48 \\
\hline 6 & $\begin{array}{l}\text { R Ref Consistent With Profile - R All Positive } \\
\text { References }\end{array}$ & 0.16 & 0.78 & 50 \\
\hline 7 & $\begin{array}{l}\text { R All Positive References - R Fits In With } \\
\text { Community }\end{array}$ & 0.64 & $2.78 *$ & 49 \\
\hline 8 & $\begin{array}{l}\text { R Fits In With Community - R Ref From Get } \\
\text { Together }\end{array}$ & 0.18 & 0.89 & 49 \\
\hline 9 & $\begin{array}{l}\text { R Ref From Get Together - R Activities I } \\
\text { Dislike }\end{array}$ & 0.16 & 0.72 & 49 \\
\hline 10 & R Activities I Dislike - R Activities I Like & 0.10 & 0.65 & 49 \\
\hline
\end{tabular}


Table 8a

Reject References Paired Samples t-Test (Confirming Delineation Point)

Paired

Pair

Differences $\quad t \quad d f$

Means

\begin{tabular}{lllll}
\hline 1 & $\begin{array}{l}\text { R Ref From Host - R Fits In With } \\
\text { Community }\end{array}$ & 1.72 & $8.04 * * *$ & 49 \\
2 & $\begin{array}{l}\text { R Presence of Neg References - R Fits In } \\
\text { With Community }\end{array}$ & 1.46 & $6.82^{* * *}$ & 49 \\
3 & $\begin{array}{l}\text { R Ref From Surfer - R Fits In With } \\
\text { Community }\end{array}$ & 1.26 & $5.70^{* * *}$ & 49 \\
4 & $\begin{array}{l}\text { R Cleanliness - R Fits In With Community } \\
\text { R Ref Personality - R Fits In With }\end{array}$ & 1.06 & $4.39 * * *$ & 49 \\
5 & $\begin{array}{l}\text { Community } \\
\text { R Ref Consistent With Profile - R Fits In }\end{array}$ & 0.76 & $3.76^{* * *}$ & 48 \\
& $\begin{array}{l}\text { With Community } \\
\text { R All Positive References - R Fits In With }\end{array}$ & 0.74 & $3.32^{* * *}$ & 49 \\
\hline & Community & 0.64 & $2.78^{*}$ & 49 \\
\hline
\end{tabular}

$* \mathrm{p}<.05, * * \mathrm{p}<.01 * * * \mathrm{p}<.001$ 
Table 9

Accept Request Message Mean Order

\begin{tabular}{ll} 
Item & Mean \\
\hline Message Personalized & 4.01 \\
Message Teach Learn Share & 3.72 \\
Message Mentions My Profile & 3.69 \\
Message Discusses Why Me & 3.62 \\
Message Time to Prepare & 2.97 \\
Message Likes Similar & 2.95 \\
Message Free Place & 2.61 \\
Message No Typo & 2.53 \\
Message Negative Face & 2.53 \\
Message Positive Face & 2.52 \\
Message Sent to Multiple & 2.44 \\
Message Likes Dissimilar & 2.37 \\
Message Last Minute & 2.31 \\
Message Teach Me & 2.24 \\
Message Typo & 2.01 \\
\hline
\end{tabular}


Table 10

Accept Request Message Paired Samples t-Test

\begin{tabular}{|c|c|c|c|c|}
\hline Pair & & $\begin{array}{c}\text { Paired } \\
\text { Differences } \\
\text { Means }\end{array}$ & $\mathrm{t}$ & df \\
\hline 1 & $\begin{array}{l}\text { Message Personalized - Message Teach Learn } \\
\text { Share }\end{array}$ & 0.28 & 1.76 & 74 \\
\hline 2 & $\begin{array}{l}\text { Message Teach Learn Share - Message Mentions } \\
\text { My Profile }\end{array}$ & 0.03 & 0.16 & 74 \\
\hline 3 & $\begin{array}{l}\text { Message Mentions My Profile - Message Discusses } \\
\text { Why Me }\end{array}$ & 0.07 & 0.62 & 73 \\
\hline 4 & $\begin{array}{l}\text { Message Discusses Why Me - Message Time to } \\
\text { Prepare }\end{array}$ & 0.62 & $3.09 * *$ & 72 \\
\hline 5 & Message Time to Prepare - Message Likes Similar & 0.05 & 0.30 & 73 \\
\hline 6 & Message Likes Similar - Message Free Place & 0.33 & 1.53 & 71 \\
\hline 7 & Message Free Place - Message No Typo & 0.10 & 0.42 & 70 \\
\hline 8 & Message No Typo - Message Negative Face & 0.00 & 0.00 & 74 \\
\hline 9 & Message Negative Face - Message Positive Face & 0.01 & 0.09 & 74 \\
\hline 10 & Message Positive Face - Message Sent to Multiple & 0.11 & 0.55 & 73 \\
\hline 11 & $\begin{array}{l}\text { Message Sent to Multiple - Message Likes } \\
\text { Dissimilar }\end{array}$ & 0.05 & 0.30 & 74 \\
\hline 12 & Message Likes Dissimilar - Message Last Minute & 0.07 & 0.45 & 74 \\
\hline 13 & Message Last Minute - Message Teach Me & 0.07 & 0.35 & 73 \\
\hline 14 & Message Teach Me - Message Typo & 0.26 & 1.52 & 71 \\
\hline
\end{tabular}


Table 10a

Accept Request Message Paired Samples t-Test (Confirming Delineation Point)

\begin{tabular}{|c|c|c|c|c|}
\hline Pair & & $\begin{array}{c}\text { Paired } \\
\text { Differences } \\
\text { Means }\end{array}$ & $\mathrm{t}$ & df \\
\hline 1 & Message Personalized - Message Time to Prepare & 1.03 & $4.93 * * *$ & 73 \\
\hline 2 & $\begin{array}{l}\text { Message Teach Learn Share - Message Time to } \\
\text { Prepare }\end{array}$ & 0.73 & $3.70 * * *$ & 73 \\
\hline 3 & $\begin{array}{l}\text { Message Mentions My Profile - Message Time to } \\
\text { Prepare }\end{array}$ & 0.73 & $3.42 * *$ & 73 \\
\hline 4 & $\begin{array}{l}\text { Message Discusses Why Me - Message Time to } \\
\text { Prepare }\end{array}$ & 0.62 & $3.09 * *$ & 72 \\
\hline
\end{tabular}

Table 11

Reject Request Message Mean Order

\begin{tabular}{lr} 
Item & Mean \\
\hline Reject Message Free Place & 3.85 \\
Reject Message Sent to Multiple & 3.38 \\
Reject Personalized Message & 3.29 \\
Reject Message Why Me & 3.18 \\
Reject Message Teach Learn Share & 3.07 \\
Reject Message Mentions Profile & 2.92 \\
Reject Message Dissimilar Likes & 2.59 \\
Reject Message Last Minute & 2.42 \\
Reject Message Contains Typos & 2.42 \\
Reject Message Similar Likes & 2.42 \\
Reject Message Time to Prepare & 2.31 \\
Reject Message Positive Face & 2.29 \\
Reject Message Negative Face & 2.13 \\
Reject Message Contains No Typos & 2.08 \\
Reject Message Teach & 2.05 \\
\hline
\end{tabular}


Table 12

Reject Request Message Paired Samples t-Test

\begin{tabular}{|c|c|c|c|c|}
\hline Pair & & $\begin{array}{c}\text { Paired } \\
\text { Differences } \\
\text { Means }\end{array}$ & $\mathrm{t}$ & df \\
\hline 1 & R Message Free Place - R Message Sent To Multiple & 0.39 & 1.60 & 58 \\
\hline 2 & $\begin{array}{l}\text { R Message Sent To Multiple - R Personalized } \\
\text { Message }\end{array}$ & 0.08 & 0.31 & 60 \\
\hline 3 & $\begin{array}{l}\text { R Personalized Message - R Message Answers Why } \\
\mathrm{Me}\end{array}$ & 0.12 & 0.88 & 59 \\
\hline 4 & $\begin{array}{l}\text { R Message Answers Why Me - R Message Teach } \\
\text { Learn Share }\end{array}$ & 0.12 & 0.71 & 58 \\
\hline 5 & $\begin{array}{l}\text { R Message Teach Learn Share - R Message Mentions } \\
\text { Profile }\end{array}$ & 0.15 & 1.01 & 58 \\
\hline 6 & $\begin{array}{l}\text { R Message Mentions Profile - R Message Dissimilar } \\
\text { Likes }\end{array}$ & 0.32 & 1.71 & 58 \\
\hline 7 & $\begin{array}{l}\text { R Message Dissimilar Likes - R Message Was Last } \\
\text { Minute }\end{array}$ & 0.17 & 0.90 & 57 \\
\hline 8 & $\begin{array}{l}\text { R Message Was Last Minute - R Message Contains } \\
\text { Typos }\end{array}$ & -0.02 & -0.10 & 58 \\
\hline 9 & $\begin{array}{l}\text { R Message Contains Typos - R Message Time to } \\
\text { Prepare }\end{array}$ & 0.14 & 0.81 & 58 \\
\hline 10 & R Message Time to Prepare - R Message Positive Face & -0.03 & -0.23 & 57 \\
\hline 11 & R Message Positive Face - R Message Negative Face & 0.15 & 1.35 & 58 \\
\hline 12 & $\begin{array}{l}\text { R Message Negative Face - R Message Contains No } \\
\text { Typos }\end{array}$ & 0.07 & 0.48 & 58 \\
\hline 13 & R Message Contains No Typos - R Message Teach & 0.03 & 0.20 & 58 \\
\hline
\end{tabular}


Table 13

Accept Other Profile Information Mean Order

\begin{tabular}{ll} 
Item & Mean \\
\hline Other Personal Description & 3.94 \\
Other General Info & 3.38 \\
Other Philosophical Information & 2.76 \\
Other CS Participation & 2.65 \\
Other Interests & 2.62 \\
Other Teach Learn Share & 2.53 \\
Other Connections & 2.32 \\
Other Locations & 1.81 \\
\hline
\end{tabular}

Table 14

Accept Other Profile Information Paired Samples t-Test

\begin{tabular}{|c|c|c|c|c|}
\hline Pair & & $\begin{array}{c}\text { Paired } \\
\text { Differences } \\
\text { Means }\end{array}$ & $\mathrm{t}$ & df \\
\hline 1 & Other Personal Description - Other General Info & 0.56 & $2.41 *$ & 33 \\
\hline 2 & $\begin{array}{l}\text { Other General Info - Other Philosophical } \\
\text { Information }\end{array}$ & 0.62 & 2.01 & 33 \\
\hline 3 & $\begin{array}{l}\text { Other Philosophical Information - Other CS } \\
\text { Participation }\end{array}$ & 0.12 & 0.42 & 33 \\
\hline 4 & Other CS Participation - Other Interests & 0.03 & 0.10 & 33 \\
\hline 5 & Other Interests - Other Teach Learn Share & 0.09 & 0.33 & 33 \\
\hline 6 & Other Teach Learn Share - Other Connections & 0.21 & 0.79 & 33 \\
\hline 7 & Other Connections - Other Locations & 0.47 & $2.05 * *$ & 31 \\
\hline
\end{tabular}

$* \mathrm{p}<.05, * * \mathrm{p}<.01 * * * \mathrm{p}<.001$ 
Table 14a

Accept Other Profile Information Paired Samples t-Test (Confirming Delineation Point)

\begin{tabular}{llccc} 
Pair & & $\begin{array}{c}\text { Paired } \\
\text { Differences } \\
\text { Means }\end{array}$ & $\mathrm{t}$ & $\mathrm{df}$ \\
\hline $1 \quad$ & Other Philosophical Information - Other Locations & 0.97 & $4.12 * * *$ & 31 \\
2 & Other CS Participation - Other Locations & 0.81 & $3.23 * *$ & 31 \\
3 & Other Interests - Other Locations & 0.81 & $4.33 * * *$ & 31 \\
4 & Other Teach Learn Share - Other Locations & 0.75 & $2.95 *$ & 31 \\
5 & Other Connections - Other Locations & 0.47 & $2.05 *$ & 31 \\
\hline$* \mathrm{p}<.05, * * \mathrm{p}<.01 * * * \mathrm{p}<.001$ & & &
\end{tabular}

Table 15

Reject Other Profile Information Mean Order

\begin{tabular}{ll} 
Item & Mean \\
\hline Reject Other Personal Descriptions & 3.79 \\
Reject Other General Info & 3.42 \\
Reject Other Philosophical Information & 2.95 \\
Reject Other Interests & 2.63 \\
Reject Other CS Participation & 2.58 \\
Reject Other Teach Learn Share & 2.11 \\
Reject Other Connections & 1.89 \\
Reject Other Locations & 1.83 \\
\hline
\end{tabular}


Table 16

Reject Other Profile Information Paired Samples t-Test

\begin{tabular}{|c|c|c|c|c|}
\hline Pair & & $\begin{array}{c}\text { Paired } \\
\text { Differences } \\
\text { Means }\end{array}$ & $\mathrm{t}$ & $\mathrm{df}$ \\
\hline 1 & R Other Personal Description - R Other General Info & 0.37 & 1.02 & 18 \\
\hline 2 & R Other General Info - R Other Philosophical Info & 0.47 & 1.53 & 18 \\
\hline 3 & R Other Philosophical Info - R Other Interests & 0.32 & 1.19 & 18 \\
\hline 4 & R Other Interests - R Other CS Participation & 0.05 & 0.14 & 18 \\
\hline 5 & $\begin{array}{l}\text { R Other CS Participation - R Other Teach Learn } \\
\text { Share }\end{array}$ & 0.47 & 1.76 & 18 \\
\hline 6 & R Other Teach Learn Share - R Other Connections & 0.21 & 0.78 & 18 \\
\hline 7 & R Other Connections - R Other Locations & 0.06 & 0.22 & 17 \\
\hline
\end{tabular}


APPENDIX B

\section{ONLINE QUESTIONNAIRE}


Thank you for agreeing to participate in this study. The goal of the study is to determine what about a CouchSurfing profile leads a host to trust or distrust a member enough to respectively accept or reject a hosting request. As you complete the questionnaire, you will first be asked about how parts of a request lead to acceptance of that request. Later, you will be asked about how parts of a request lead to rejection of that request. Each question includes a text box allowing you to elaborate on your response, if you desire. However, it is not required that you complete the text box for any item.

Please focus exclusively on how you choose to accept a couch request. Which of these website features provide you with the information you most need to trust a member enough to accept a CouchSurfing member's request? Please rank-order the importance of the following four items when accepting a request from a CouchSurfing member (1=most important, $4=$ least important).

_ Couch Request Message

$\begin{array}{ll}\text { - } & \text { Photos } \\ \text { - } & \text { Otherences information (general information, philosophies, interests, etc.) }\end{array}$

Explain: (text box)

You have indicated that viewing references on a traveler's profile provides you with the most essential information to trust a member. For this next section, please focus exclusively on how you choose to accept a couch request. Which of the following items gives you the essential information leading you to trust a member enough to accept her or his request? Please click the appropriate choice best describing how essential the item is to accepting the request $(1=$ not essential at all, trivial; 5= completely essential for acceptance )

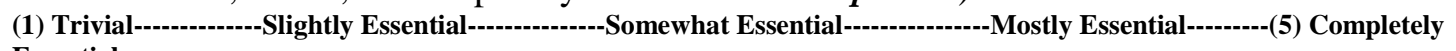

Essential

References are left from hosts with whom the member has stayed

$$
\text { o }
$$

O

o

O

O

Explain: (text box)

References are left from surfers the member has hosted

$$
\text { o }
$$

O

o

$\mathrm{O}$

O

Explain: (text box)

References are left from CouchSurfing members met through get-togethers or community events

$$
\text { o }
$$

$\mathrm{O}$

o

$\mathrm{O}$

O

$$
\text { Explain: (text box) }
$$

All positive references

o o

o

O

O

Explain: (text box)

Presence of one or more negative references

o

o

o

o

O

Explain: (text box)

References are consistent with other profile information (e.g., textual or photographs)

o

o

o

O

o

Explain: (text box)

References discuss activities done between surfers and hosts during stays that I would also be interested in participating. 
References discuss activities done between surfers and hosts during stays that I would not be interested in participating

o $\quad$ o

o

Explain: (text box)

References discuss the member's personality

o

o

o

O

o

Explain. What personality trait is most likely to lead to acceptance of a request? (text box)

References discuss that the member fits in with the CouchSurfing community

$\begin{array}{llll}0 & 0 & 0 & O\end{array}$

O

Explain: (text box)

References discuss the respect or cleanliness of surfer

$\begin{array}{llll}0 & 0 & 0 & 0\end{array}$

O

Explain: (text box)

Other - What else about references helps you make hosting decisions?

(text box)

You have indicated that viewing photos on a traveler's profile is the most important aspect of communication in making a decision about whether or not to host a CouchSurfing member. For this next section, please focus exclusively on how you choose to accept a couch request. Which of the following items gives you the essential information leading you to trust a member enough to accept her or his request? Please click the appropriate choice best describing how essential the item is to accepting the request ( $1=$ not essential at all, trivial; $5=$ completely essential for

\section{acceptance)}

(1) Trivial----------Slightly Essential------------Somewhat Essential--------------Mostly Essential--------(5) Completely

Essential

No photos

O

O

O

O

Explain: (text box)

The presence of at least one photo

o 0 o

O

$\mathrm{O}$

Explain: (text box)

Multiple photos displayed

o $\mathrm{O}$

O

O

o

Explain: (text box)

In the photo, the person is participating in activities I also like

o

o

o

o

o

Explain: (text box)

In the photo, the person is participating in activities I dislike

O

o

$\mathrm{O}$

O

o 


\section{Explain: (text box)}

In the photo, the surfer appears attractive

o $\mathrm{o}$

o

o

o

Explain: (text box)

In the photo, the surfer appears unattractive

o $\mathrm{o}$

o

o

o

Explain: (text box)

The person appears to be the same ethnicity as me

o

o

O

o

$\mathrm{O}$

Explain: (text box)

The person appears to be a different ethnicity from me

o $\mathrm{O}$

o

O

$\mathrm{O}$

Explain: (text box)

The person appears to be the same biological sex as me

o

o

o

O

Explain: (text box)

The person appears to be the opposite biological sex from me

o $\mathrm{O}$

o

o

O

Explain: (text box)

The photo shows an indication of personality

o $\quad 0$

O

O

O

Explain. What personality trait is most likely to lead to acceptance of a request? (text box)

The photo shows evidence of previous travel

o $\mathrm{O}$

O

o

O

Explain: (text box)

The photo shows the member alone

o 0

o

o

O

Explain: (text box)

The photo shows the member with friends

$\mathrm{O} \quad \mathrm{O}$

o

O

o

Explain: (text box)

The photo shows the member's face clearly

$\mathrm{O} \quad \mathrm{O}$

o 0

o

o

Explain: (text box)

Other - What else about photos helps you make hosting decisions?

(text box)

You have indicated that the initial request message from the surfer is the most important aspect of communication in making a decision about whether or not to host a CouchSurfing member. For this next section, please focus exclusively on how you choose to accept a couch request. Which 
of the following items gives you the essential information leading you to trust a member enough to accept her or his request? Please click the appropriate choice best describing how essential the item is to accepting the request ( $1=$ not essential at all, trivial; $5=$ completely essential for acceptance)

(1) Trivial--------------Slightly Essential---------------Somewhat Essential----------------Mostly Essential---------(5) Completely

Essential

The message was obviously personalized and only sent to me
o
o
o
o

o

Explain: (text box)

The message was obviously sent to multiple potential hosts (i.e., copy and pasted message)

o

o

o

o

o

Explain: (text box)

The message is not demanding and includes phrases such as "no pressure" or "it's okay if you are unable to host me"
o
o
o
o

o

Explain: (text box)

The message makes me feel good about helping by including phrases like, "It would be so kind of you to host me"
o
o
o
o

O

Explain: (text box)

Typos or misspelled words are present in the message

o 0

0

o

o

Explain: (text box)

Typos and misspelled words are absent from the message

o $\mathrm{O}$

o

o

Explain: (text box)

The message describes the potential guest's likes and dislikes, which are similar to my likes and dislikes.

O $\quad \mathrm{O}$

0

$\mathrm{O}$

$\mathrm{O}$

Explain: (text box)

The message describes the potential guest's likes and dislikes, which are different from my likes and dislikes

o

O

O

O

$\mathrm{O}$

Explain: (text box)

The message describes what the surfer can teach me

o $\mathrm{O}$

o

o

o

Explain: (text box)

The message mentions information found in my CouchSurfing profile

o

o

o

o

o

Explain: (text box) 
The message discusses why the surfer chose to ask me to host her or him

o $\quad 0 \quad 0 \quad 0$

$\mathrm{o}$

Explain: (text box)

The message seems to focus on acquiring a free place to stay.

$\begin{array}{llll}0 & 0 & 0 & 0\end{array}$

o

Explain: (text box)

The message seems to focus on more than acquiring a free place to stay (e.g., teaching, learning, cultural experiences, etc.)
$\mathrm{o}$
$\mathrm{O}$
o
o

o

Explain: (text box)

This was a last-minute request

o $\mathrm{O}$

o

o

o

Explain: (text box)

This request gave me time to prepare for the visitor

o

o

o

o

Explain: (text box)

Other - What else about the request message helps you make hosting decisions?

(text box)

You have indicated that viewing other information on a traveler's profile provides you with the most essential information to trust a member. For this next section, please focus exclusively on how you choose to accept a couch request. Which of the following items gives you the essential information leading you to trust a member enough to accept her or his request? Please click the appropriate choice best describing how essential the item is to accepting the request $(1=$ not essential at all, trivial; 5= completely essential for acceptance)

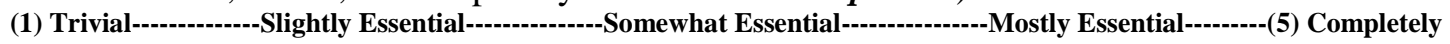

Essential

General Information (e.g., name, age, location, education, sex, languages spoken, etc.)

o

o

o

o

o

Explain: (text box)

Connections (e.g., groups, friends)

o 0

o

o

o

Explain: (text box)

Personal Description

o

O

o

o

o

Explain: (text box)

Interests (e.g., interests, music/movies/books)

o $\mathrm{O}$

0

O

o

Explain: (text box)

Philosophical information (e.g., Philosophy, Types of People I Enjoy, One Amazing Thing I've Seen or Done)

O

O

o

o

O 


\section{Explain: (text box)}

Teach, Learn, Share

o

Explain: (text box)

CouchSurfing participation (e.g., How I Participate in CS, CouchSurfing Experience, Opinion on the CouchSurfing.org project, Couch Information)

o

o

o

o

o

Explain: (text box)

Locations Traveled

o

o

$\mathrm{O}$

O

Explain: (text box)

Other - What else about a profile helps you make hosting decisions? (text box)

Now, let's switch focus from accepting couch requests to rejecting requests. For this next section, please focus exclusively on how you choose to reject a couch request. Which of these website features provide you with the information you most need to distrust a member enough to reject a CouchSurfing member's request? Please rank-order the importance of the four following items when rejecting a CouchSurfing member's request (1=most important, $4=$ least important).

○ Couch Request Message

○ Photos

○ References

○ Other information (e.g., general information, philosophies, interests, etc.)

Explain: (text box)

You have indicated that viewing references on a traveler's profile is the most important aspect of communication in making a decision about whether or not to host a CouchSurfing member. For this next section, please focus exclusively on how you choose to reject a couch request. Which of the following items gives you essential information, affecting your ability to trust a member enough to reject her or his request? Please click the appropriate choice best describing how essential the item is to rejecting the request $(1=$ not essential at all, trivial; $5=$ completely essential for rejection)

(1) Trivial-----------Slightly Essential------------Somewhat Essential-------------Mostly Essential--------(5) Completely

Essential

References are left from hosts with whom the member has stayed

o

$\mathrm{O}$

Explain: (text box)

References are left from surfers the member has hosted

o

O

Explain: (text box)

References are left from CouchSurfing members met through get-togethers or community events

o

O

O

Explain: (text box)

All positive references 
Presence of one or more negative reference

o

o

Explain: (text box)

References are consistent with other profile information (textual or photographs)

o $O$

o

$\mathrm{O}$

Explain: (text box)

References discuss activities done between surfers and hosts during stays that I would also be interested in participating.

o 0

O

O

o

Explain: (text box)

References discuss activities done between surfers and hosts during stays that I would not be interested in participating

o

O

O

$\mathrm{O}$

Explain: (text box)

References discuss the member's personality

o 0

o

o

O

Explain. What personality trait is most likely to lead to rejection of a request? (text box)

References discuss that the member fits in with the CouchSurfing community

o

o $\mathrm{o}$

$\mathrm{O}$

Explain: (text box)

References discuss the respect or cleanliness of surfer

o

o

o

o

$\mathrm{O}$

Explain: (text box)

Other - What else about references helps you make hosting decisions?

(text box)

You have indicated that viewing photos on a traveler's profile is the most important aspect of communication in making a decision about whether or not to host a CouchSurfing member. For this next section, please focus exclusively on how you choose to reject a couch request. Which of the following items gives you essential information, affecting your ability to trust a member enough to reject her or his request? Please click the appropriate choice best describing how essential the item is to rejecting the request $(1=$ not essential at all, trivial; $5=$ completely essential for rejection)

(1) Trivial-----------Slightly Essential------------Somewhat Essential--------------Mostly Essential--------(5) Completely Essential

No photos

O

O

O

O

O

Explain: (text box)

The presence of at least one photo 
Multiple photos displayed

o 0

Explain: (text box)

In the photo, the person is participating in activities I also like

O

Explain: (text box)

In the photo, the person is participating in activities I dislike

o 0

o

o

o

Explain: (text box)

In the photo, the surfer appears attractive

o $\mathrm{O}$

o

O

O

Explain: (text box)

In the photo, the surfer appears unattractive

o 0

o 0

o

O

Explain: (text box)

The person appears to be the same ethnicity as me

o $\mathrm{O}$

o

o

O

Explain: (text box)

The person appears to be a different ethnicity from me

o

O

o

o

O

Explain: (text box)

The person appears to be the same biological sex as me

o

o

o

O

O

Explain: (text box)

The person appears to be the opposite biological sex from me

o

o

o

O

O

Explain: (text box)

The photo shows an indication of personality

o

o

o

o

O

Explain. What personality trait is most likely to lead to rejection of a request? (text box)

The photo shows evidence of previous travel

o

O

O

O

Explain: (text box)

The photo shows the member alone 
The photo shows the member with friends

$\mathrm{O} \quad \mathrm{O}$

O

Explain: (text box)

The photo shows the member's face clearly

$\mathrm{O} \quad \mathrm{O}$

$\mathrm{O}$ o

O
O

o

O

Explain: (text box)

Other - What else about photos helps you make hosting decisions?

(text box)

You have indicated that the initial request message from the surfer is the most important aspect of communication to make a decision about whether or not to host a CouchSurfing member. For this next section, please focus exclusively on how you choose to reject a couch request. Which of the following items gives you essential information, affecting your ability to trust a member enough to reject her or his request? Please click the appropriate choice best describing how essential the item is to rejecting the request $(1=$ not essential at all, trivial; $5=$ completely essential for rejection)

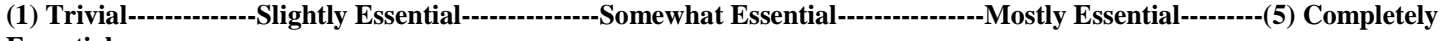
Essential

The message was obviously personalized and only sent to me
o
o
o
o

o

Explain: (text box)

The message was obviously sent to multiple potential hosts (i.e., copy and pasted message)
o
o
o
o

O

Explain: (text box)

The message is not demanding and includes phrases such as "no pressure" or "it's okay if you are unable to host me"

o $\quad$ o

o

O

O

Explain: (text box)

The message makes me feel good about helping by including phrases like, "It would be so kind of you to host me."

O

O

o

o

O

Explain: (text box)

Typos or misspelled words are present in the message

o

o

o

O

o

Explain: (text box)

Typos and misspelled words are absent from the message

o $o$

o

O

O

Explain: (text box)

The message describes the potential guest's likes and dislikes, which are similar to my likes and dislikes. 
The message describes the potential guest's likes and dislikes, which are different from my likes and dislikes
o
O
O
O

$\mathrm{O}$

Explain: (text box)

The message describes what the surfer can teach me
O
o
o
o

o

Explain: (text box)

The message mentions information found in my CouchSurfing profile

$\begin{array}{llll}0 & 0 & 0 & 0\end{array}$

O

Explain: (text box)

The message discusses why the surfer chose to ask me to host her or him

$\begin{array}{llll}\mathrm{O} & \mathrm{O} & \mathrm{O} & \mathrm{O}\end{array}$

O

Explain: (text box)

The message seems to focus on acquiring a free place to stay.

o 0

o

o

O

Explain: (text box)

The message seems to focuses on more than acquiring a free place to stay (e.g., teaching, learning, cultural experiences, etc.)

o $\mathrm{O}$

Explain: (text box)

This was a last-minute request

o o

o

\section{O}

Explain: (text box)

This request gave me time to prepare for the visitor

o

$\mathrm{O}$

o

o

O

Explain: (text box)

Other - What else about the request message helps you make hosting decisions? (text box)

You have indicated that viewing other information on a traveler's profile provides you the most essential information in trusting a member. For this next section, please focus exclusively on how you choose to reject a couch request. Which of the following items gives you essential information, affecting your ability to trust a member enough to reject her or his request? Please click the appropriate choice best describing how essential the item is to rejecting the request $(1=$ not essential at all, trivial; 5= completely essential for rejection)

(1) Trivial-------------Slightly Essential-------------Somewhat Essential--------------Mostly Essential---------(5) Completely Essential

General Information (e.g., name, age, location, education, occupation, sex, etc.)

o 
Explain: (text box)

Languages Spoken

o $\quad 0$

o

o

o

Explain: (text box)

Connections (e.g., groups, friends)

$\begin{array}{llll}0 & 0 & 0 & 0\end{array}$

o

Explain: (text box)

Personal Description

o

o

o

o

o

Explain: (text box)

Interests (e.g., interests, music/movies/books)

o $\mathrm{O}$

o $\quad$ o

o

o

Explain: (text box)

Philosophical information (e.g., Philosophy, Types of People I Enjoy, One Amazing Thing I've Seen or Done)

o $\quad 0$

o

o

o

Explain: (text box)

Teach, Learn, Share

o

O

O

O

Explain: (text box)

CouchSurfing participation (e.g., How I Participate in CS, CouchSurfing Experience, Opinion on the CouchSurfing.org project, Couch Information)

o

o

o

O

O

Explain: (text box)

Locations Traveled

o

O

O

o

O

Explain: (text box)

Other - What else about a profile helps you make hosting decisions? (text box)

Please answer the following demographic and background information questions by clicking into the radial box corresponding to your answer or typing into the provided text box.

What is your age?

Are you married? _yes _ no.

If you have children, are they still living in your home? __ yes _ _ no

Are you a United States citizen? _ yes _ no

What is your sex? _ male _female _other/no response

Have you hosted CouchSurfers in the past? _ yes __ no

If so, how many surfers have you hosted?

How many international surfers have you hosted?

How many times have you been a guest through CouchSurfing?

How many times have you been a guest through CouchSurfing internationally? 
How many months have you spent living outside the United States? (Type 0 if you have never lived outside the United States) 